\title{
Suistalinable

\section{Applications of Sensitized Semiconductors as Heterogeneous Visible-Light Photocatalysts in Organic Synthesis}

\author{
Daniele Franchi* and Zacharias Amara* \\ Cite This: ACS Sustainable Chem. Eng. 2020, 8, 15405-15429 \\ Read Online
}

ABSTRACT: The industrial transition to more-sustainable chemical manufacturing requires the development of a variety of highperformance heterogeneous catalysts. Recently, new classes of heterogeneous and recyclable catalysts that exploit visible-light activation have emerged in the field of organic synthesis. Among these systems, sensitized semiconductors occupy a strategic place as they are able to initiate single electron transfer processes under heterogeneous conditions and using medium-to-low energy light activation. This technology can promote a range of synthetically useful reactions, such as oxidations, reductions, or additions, including $\mathrm{C}-\mathrm{C}$ bond formation, under very mild conditions and with high selectivity. Sensitized semiconductors have been known for decades in solar cell technologies (the so-called "Dye-Sensitized Solar Cells") but

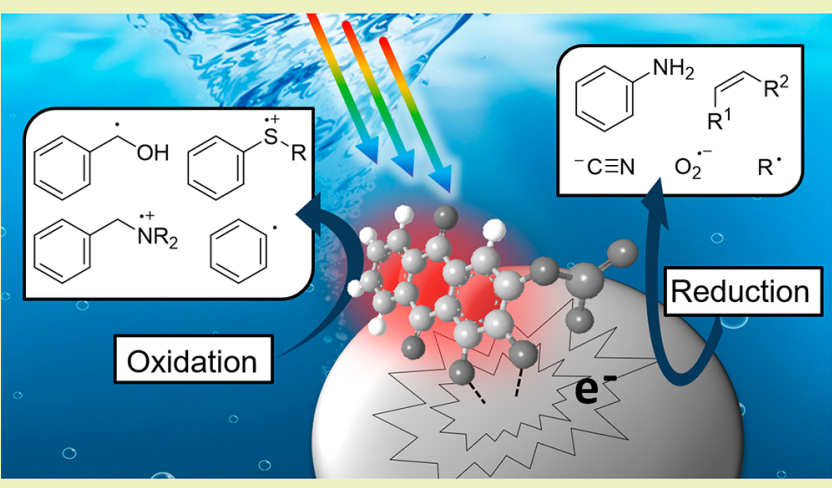
applications in organic synthesis are only very recent. This Review provides a comprehensive overview of the mechanisms, reactivity, and scope of this technology, with a focus on their new and promising synthetic applications.

KEYWORDS: Semiconductors, Organic Dyes, Organometallic Dyes, LMCT Sensitizers, Photocatalysis, Heterogeneous Catalysis, Visible Light, Organic Synthesis, Green Chemistry

\section{INTRODUCTION}

The development of processes that are less energy-demanding is a crucial endeavor for today's chemical industry, which has long relied on highly energetic and wasteful approaches. This global shift to more-sustainable manufacturing explains the rapid expansion of photochemical activation across chemical science, where light is used as the main energy source. Light has very unique assets, because it can be obtained from solar radiations or produced at a low energy cost using light-emitting diodes (LEDs). ${ }^{1}$ Solar light has already demonstrated its strategical role in the production of clean energy and $\mathrm{H}_{2}$ production, ${ }^{2-6}$ the reduction of atmospheric $\mathrm{CO}_{2},{ }^{7-9}$ the degradation of waste, ${ }^{10-12}$ and, more recently, in promoting selective reactivity in organic synthesis. ${ }^{13-15}$ On the other hand, LED irradiation is a powerful technology, since the length and the intensity of the emission source can be accurately modulated to closely match the absorption corresponding to the electronic transitions of the targeted molecule and thereby initiate a chemical process in a very selective manner.

Intense research efforts have been devoted to the development of catalytic systems able to harvest photons in an increasingly efficient manner and to induce selective chemical transformations. ${ }^{16}$ Such systems include small molecule photocatalysts and heterogeneous materials, which can also be combined to achieve synergetic effects. ${ }^{17,18}$ Among these, semiconductors represent a promising class of materials, because they can harvest photons and initiate a charge separation process. ${ }^{19-22}$ This technology has been extensively developed over the last 30 years in the field of photovoltaics, but it has only recently started to be applied to organic synthesis. ${ }^{23}$ Except for some examples, such as graphitic carbon nitrides, $\mathrm{CdS}$, and Bi-based nanomaterials, ${ }^{24-26}$ the most commonly used semiconductors are only activated by ultraviolet (UV) radiation, which is explained by the relatively high energy required to bridge the gap between the valence band (VB) and the conduction band (CB). Upon UV excitation, an electron can reach the $\mathrm{CB}$ (delocalized electron), leaving behind a so-called "hole" $\left(\mathrm{h}^{+}\right)$delocalized in the VB (Figure 1A). This separation of charges is known as "exciton". ${ }^{27}$ The two charges can have three fates: recombine with each other, move through the material (giving rise to electricity), or reach the surface of the semiconductor and promote a redox reaction via single electron transfer (SET). ${ }^{27,28}$ The longer the exciton lifetime is, the higher the probability for SET to happen, instead of charge recombination. As depicted in Figure 1, semiconductors have similarities with soluble visible-light photoredox catalysts,

Received: July 14, 2020

Revised: September 2, 2020

Published: September 2, 2020 

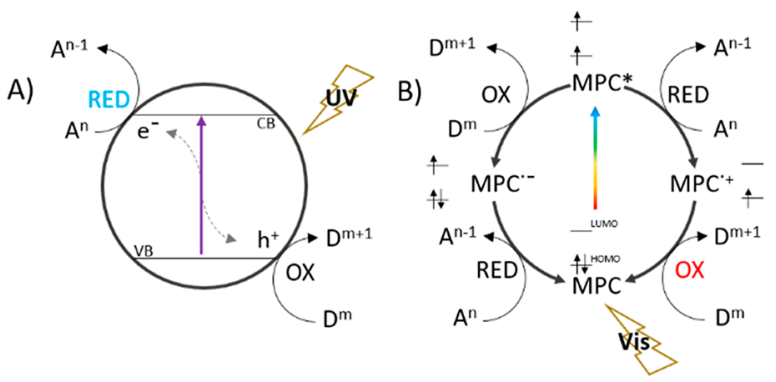

Figure 1. Mechanisms at play in heterogeneous and homogeneous photocatalysts. (A) Upon irradiation, semiconductors can give rise to charge separation: electrons in the $\mathrm{CB}$ create reduction sites on the material surface, while holes in the $\mathrm{VB}$ create oxidation ones. (B) Molecular photocatalysts (MPC) can reach the excited state MPC* upon visible-light absorption. MPC* is a strong redox agent that can follow an oxidative quenching path (clockwise) or a reductive one (anticlockwise).

which are generally working as electron donors (oxidative quenching) or electron acceptors (reductive quenching) upon excitation (Figure 1B). ${ }^{29,30}$ While soluble photoredox catalysts have been extensively developed over the past decade in organic chemistry, the longstanding dependence on UV-light activation has hindered wider applications of semiconductors in synthesis. ${ }^{29-32}$ Such systems are commonly seen as being poorly chemo-compatible, because of the competitive sensitivity to UV light by many functional groups. ${ }^{33}$ In this regard, the synthetic utility of semiconductors remained relatively limited and applications were restricted to simple synthetic schemes and poorly functionalized organic substrates. ${ }^{34-38}$ Nevertheless, more recently, new operating windows have been opened with the discovery and application of the concept of visible-light activation to semiconductors. ${ }^{39-41}$ Visible-light sensitization of semiconductors exploit the same surface modification used in the molecular sensitization of semiconductors employed in the so-called "dye-sensitized solar cells" (DSSCs), which were originally developed decades ago for photovoltaic applications. ${ }^{42}$ This same strategy is now becoming a rapidly growing technology in organic chemistry and synthesis. ${ }^{23,43-50}$

In DSSCs, visible light is harvested by a dye that is anchored on the surface of a "white" semiconductor. Upon reaching an excited state, and if the lowest unoccupied molecular orbital (LUMO) is sufficiently energetic, the dye can inject an electron in the $\mathrm{CB}$ of the semiconductor. As mentioned above, this gives rise to a similar "exciton" but in this case, the separated charges are the oxidized dye $\left(\mathrm{Dye}^{\bullet+}\right)$ and the electron-charged semiconductor. Since the opposite charges are located in different media, backelectron transfer is less likely to happen, making the exciton lifetime relatively long. ${ }^{51}$ Sensitized-semiconductor photocatalysts can use the same electron injection process to generate an exciton (Figure 2A). The electrons injected in the semiconductor behave like electrons in the $\mathrm{CB}$, reducing an electron acceptor $\left(\mathrm{A}^{\mathrm{n}}\right)$ on the surface of the semiconductor. The dye follows an oxidative quenching cycle because upon excitation, a reactive redox species is created (Dye*) which gets oxidized to Dye ${ }^{\bullet+}$ by the semiconductor, acting as the electron acceptor. Anchoring functions such as carboxylate and phosphate groups ensure a good electronic connection between the dye and the semiconductor. ${ }^{52}$ Together with an appropriate disposition of the energy levels $\left(E_{\mathrm{LUMO}}>E_{\mathrm{CB}}\right)$, these account for highly efficient electron injection processes. The interaction of the dye with the reaction media happens only in the secondary redox event
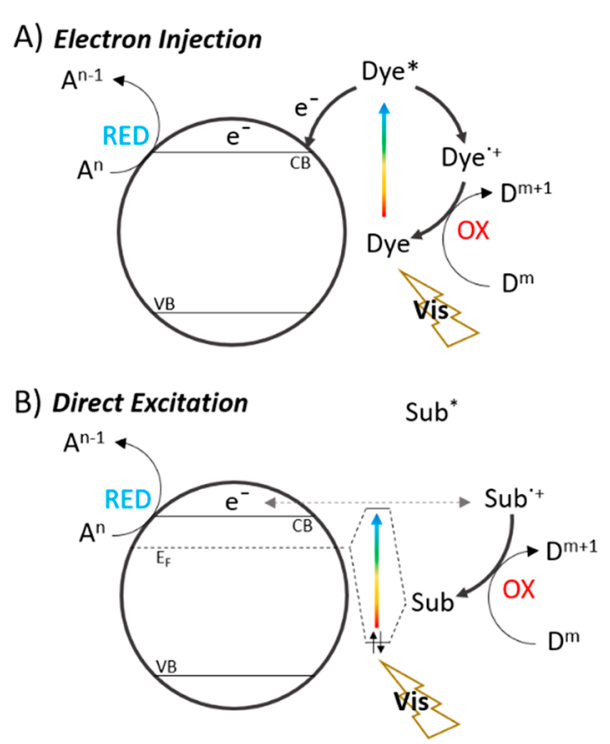

Figure 2. Sensitized semiconductors activated by visible light. (A) A dye molecule reaches an excited state and then injects one electron in the $\mathrm{CB}$. (B) Direct excitation of a surface complex originating from semiconductor-substrate interaction. In this case, the excited state consists of the semiconductor $\mathrm{CB}$ and the organic compound in its oxidized form.

which reduces the Dye ${ }^{\bullet+}$ to the ground state by oxidizing an electron donor $\left(\mathrm{D}^{m}\right)$. Figure 3 reports a comprehensive list of dyes that have been used, to date, to sensitize semiconductors for heterogeneous visible-light photocatalysts in organic synthesis. A diagram showing a comparison of the frontier orbital potentials of some dyes with the semiconductors $\mathrm{CB}$ and $\mathrm{VB}$ helps to visualize the electron flow in a semiconductor-dye redox process (Figure 4). ${ }^{53}$

In addition to electron injection from dyes, another mechanism for the visible-light activation of semiconductors has been recently exploited, taking advantage of direct excitation of a surface complex of the semiconductor with simple organic compounds, such as catechols or salicylic acids, instead of dyes. ${ }^{52,54}$ In this case, neither the organic compound nor the semiconductor is able to absorb visible light: only the surface complex between these two can. The strong interaction between the organic molecule and the semiconductor generates new electronic orbitals, allowing visible-light absorption (Figure 2B). ${ }^{55-57}$ New mixed states originate from the interaction between the Fermi level of the semiconductor and the highest occupied molecular orbital (HOMO) of the organic compound. The energy band gap of the mixed levels is now lower, and the complex can undergo chargetransfer upon photoexcitation with visible light. This directly leads to a charge separation state similar to the one presented in the case of DSSCs (an oxidized organic molecule $\left(\mathrm{Sub}^{\bullet+}\right)$ and the electroncharged semiconductor) but without going through a photoexcited organic molecule. Finally, on the surface of the semiconductor, $\mathrm{A}^{n}$ is reduced by the electrons delocalized in the $\mathrm{CB}$, while $\mathrm{D}^{m}$ is oxidized by $\mathrm{Sub}^{\circ+}$. This photocatalytic mechanism can result in a very selective charge separation with high quantum yields, but it is also characterized by poor light absorption. Because of the labile bond with the semiconductor, in some cases, the organic molecule itself can also act as a reaction substrate, rather than solely as a sensitizer or co-catalyst that is regenerated via the donor oxidation $\left(\mathrm{D}^{m} \rightarrow \mathrm{D}^{m+1}\right)$.

Today, these sensitization mechanisms have been successfully exploited in the field of synthetic chemistry, because they can all ultimately promote SET processes. This is demonstrated 
<smiles>[O]S(=O)(=O)c1cc2c(c(O)c1O)C(=O)c1ccccc1C2=O</smiles>

Alizarin Red S (AR)

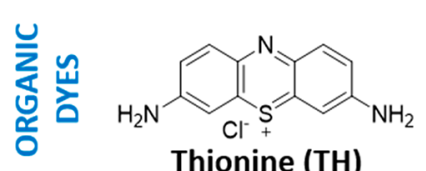

Thionine (TH)<smiles>O=C(O)c1cc2cc3c4c(c2oc1=O)CCCN4CCC3</smiles>

Coumarin (CM)<smiles>[R]c1ccc(C(=O)O)c(-c2c3ccc(=O)cc-3oc3cc(O)ccc23)c1</smiles>

$\mathrm{R}=\mathrm{H}$ Fluorescein (FL)

$\mathrm{R}=\mathrm{COOH}$ Carboxyfluor. (CF)

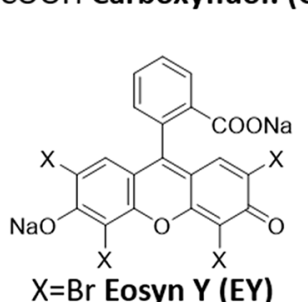

$X=I$ Erythrosin $B$ (EB)<smiles>CCN(CC)c1ccc2c(-c3ccccc3C(=O)O)c3ccc(=[N+](Cl)Cl)cc-3oc2c1</smiles>

Rhodamine B (RB)

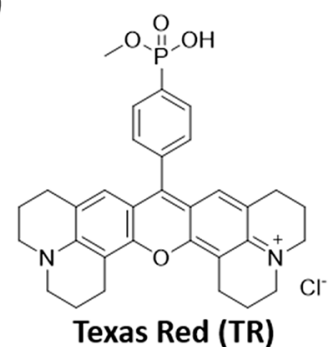

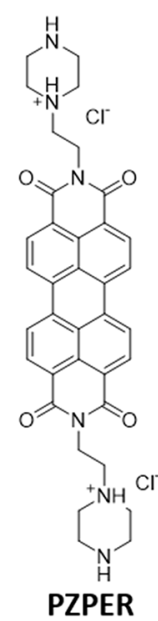

PZPER

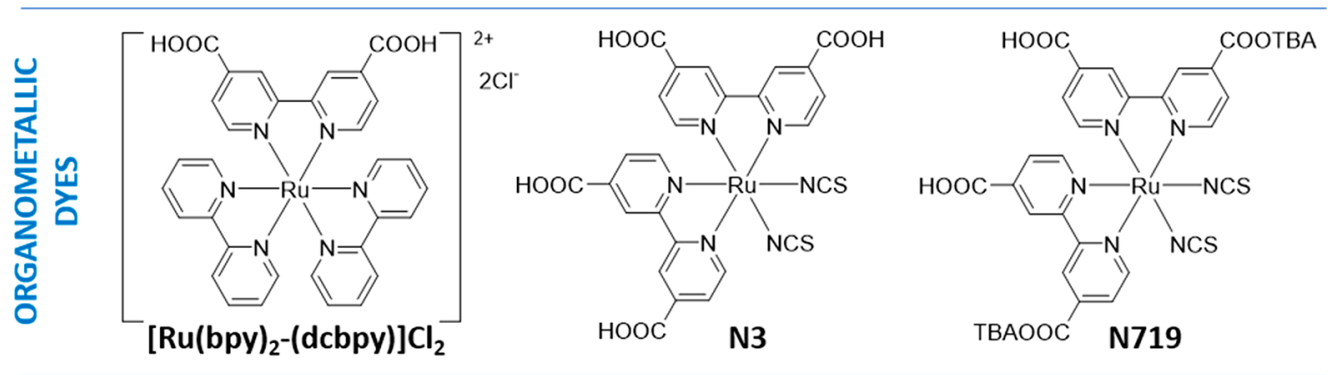

焉

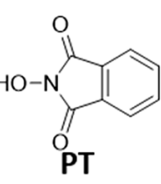<smiles>Oc1cc2ccccc2cc1O</smiles><smiles>C[n+]1cc2cc(O)c(O)cc2cc1[Cl+]</smiles>

Figure 3. Visible-light photosensitizers reported in the reviewed articles. (TBA = tetra- $n$-butylammonium.

throughout this Review, where useful applications in synthetic organic chemistry are presented. Visible-light-sensitized semiconductors display high efficiency, even under low-energy radiation, and can, therefore, promote very sustainable chemical transformations. Moreover, it often requires low amounts of readily available, nontoxic, and inexpensive materials, which is a key driver for the development of green cost-competitive processes. In comparison, soluble photoredox catalysts, which mostly rely on heavy atoms incorporation to efficiently populate triplet states and give rise to SET, can be relatively expensive, and/or rely on harmful or rare materials and, because of their homogeneous nature, are difficult to recycle. ${ }^{58,59}$ Finally, unlike visible-light absorbing semiconductors, the combination of semiconductors and sensitizers also entail the possibility to fine-tune the photocatalyst properties to selectively target the desired organic transformation. Therefore, visible-light activation of semiconductors is a promising photocatalytic approach in organic chemistry and recent developments are summarized in this Review. Note that attention will be given only to visible-light photocatalysts activation where the semiconductor and the sensitizer share the redox activity, and when this synergic interaction triggers the photoreactivity. Systems where inert supports are used to immobilize soluble photocatalysts will not be taken into account. $^{60-66}$

\section{OXIDATIONS}

Oxidations are among the most widely studied reactions with dye-sensitized semiconductors as photocatalysts. A common goal is to replace hazardous or expensive stoichiometric oxidizing reagents with dioxygen. ${ }^{77}$ The oxidation of benzylic positions is one of the first reported applications using these catalytic systems and one of the most commonly explored to date. The scope includes substrates such as alcohols, amines, and sulfides, but more-challenging substrates, such as hydrocarbons, and morecomplex transformations have also been reported.

\section{OXIDATIONS OF ALCOHOLS}

Conventional methods to control the conversion of alcohols to aldehydes may require the use of toxic or corrosive stochiometric reagents, such as $\mathrm{Br}_{2}, \mathrm{CrO}_{3}, \mathrm{KMnO}_{4}$, tert-butyl hydroperoxide, or noble-metal catalysts. ${ }^{43}$

In such scenarios, heterogeneous photocatalysts such as sensitized semiconductors represent a potentially more sustainable alternative. The first report of visible-light photocatalytic oxidation of primary benzylic alcohols 1 to their corresponding aldehydes 2, using semiconductors, was performed by Higashimoto et al. in $2009 .^{78}$ These photocatalytic reactions were performed with nanosized titanium dioxide $\left(\mathrm{TiO}_{2}\right)$ dispersed in acetonitrile $\left(\mathrm{CH}_{3} \mathrm{CN}\right)$ and at room temperature $(\mathrm{rt})$ in the presence of $\mathrm{O}_{2}$ and under blue LED irradiation (emission at ca. $480 \mathrm{~nm}$ ). Since $\mathrm{TiO}_{2}$ by itself only exhibits absorption in the UV region with a band gap transition at ca. $385 \mathrm{~nm}(3.2 \mathrm{eV})$, the authors assigned the absorption in the visible region to the benzyl alcohol- $\mathrm{TiO}_{2}$ surface complex, which can undergo ligand-tometal charge transfer (LMCT). The reaction proceeded with quantitative conversion and high selectivity for benzylic alcohols substituted with both electron-donor groups (EDGs) and electronwithdrawing groups (EWGs) (Scheme 1). Mechanistically, this 


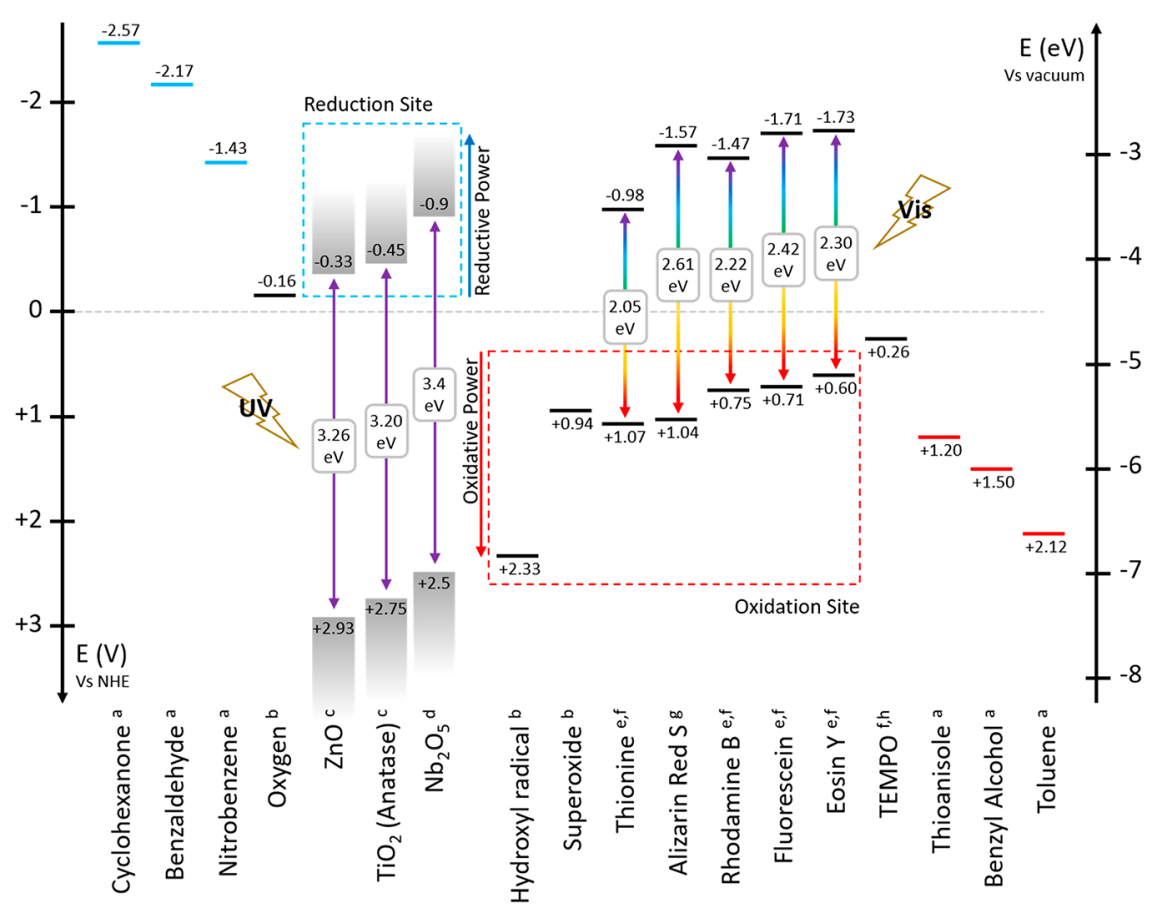

Figure 4. Comparison of band-gaps (in $\mathrm{eV}$ ) of semiconductors with potentials (in V vs NHE) of molecular photocatalyst frontier orbitals and redox potentials of some redox mediators (in black). [Implemented from ref 67. Copyright 2012, John Wiley and Sons.] The electrochemical potentials (in V vs NHE) of reduction (in blue) and oxidation (in red) of some substrates are also shown. [Footnotes: (a) Cyclic voltammetry half-peak potentials registered in $\mathrm{CH}_{3} \mathrm{CN}$ from ref 68. Potentials originally reported relative to SCE were referenced to NHE by subtracting $0.24 \mathrm{~V}{ }^{69}$ (b) Standard redox potentials for the univalent reduction of reactive oxygen species from ref 70 . (c) Band edges of $\mathrm{ZnO}^{71}$ and $\mathrm{TiO}_{2}{ }^{72}$ were originally reported as energy (in $\mathrm{eV}$ vs vacuum) and were converted to potentials (in V vs NHE) by subtracting the reported value from -0.45 . (d) Data taken from ref 73 . (e) Oxidation potentials for the ground state were obtained through cyclic voltammetry in $\mathrm{MeOH}$ from ref 74 . Band gaps originally reported in units of kcal/mol were converted to $\mathrm{eV}$ by dividing by 23.061. Singlet excited state potentials were calculated as $E_{\mathrm{LUMO}}=E_{\mathrm{HOMO}}-E_{\text {band gap }}$. (f) Potentials originally reported relative to $\mathrm{Ag} / \mathrm{AgCl}$ (saturated $\mathrm{KCl}$ ) reference electrode were referenced to NHE by subtracting $0.20 \mathrm{~V} .{ }^{69}(\mathrm{~g})$ Data taken from ref 75 . (h) Data taken from ref 76. Direct comparison of these frontier orbital potentials with electrochemical potentials (of oxidation or reduction of substrates in solution) is not possible without taking into account the latter's distribution functions for electronic energy levels in solution, and the bands banding of the semiconductor's surface. ${ }^{53}$ Since the graphics do not report either of these two phenomena, we advise the use of the figure to compare semiconductors and dyes properties, separately from organic functional groups ones.]

Scheme 1. Visible-Light Photocatalytic Oxidation of Benzyl Alcohols via Direct Excitation of $\mathrm{TiO}_{2}$ Surface Complex
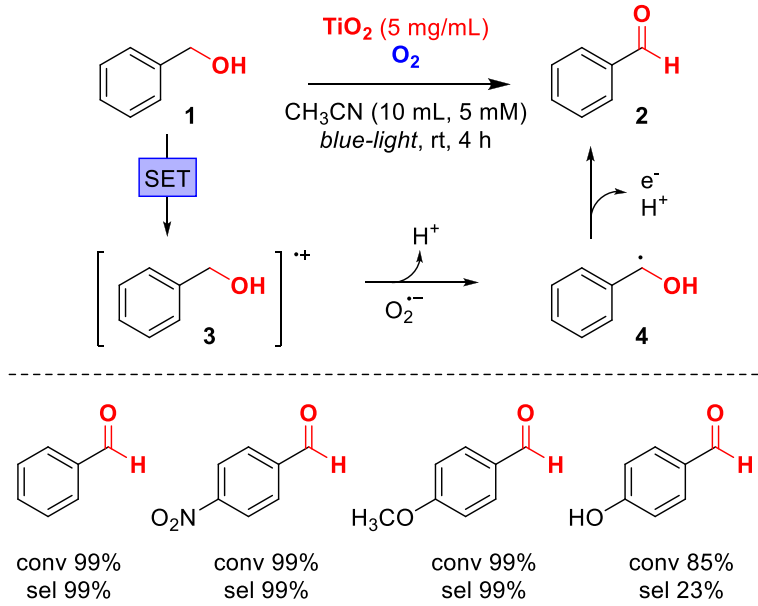

direct excitation can generate the radical cation 3 that can be deprotonated by oxygen superoxide $\left(\mathrm{O}_{2}{ }^{-}\right)$to give the corresponding radical intermediate 4 . A second deprotonation and electron abstraction would give the corresponding aldehyde. A similar reactivity was reported with rutile $\mathrm{TiO}_{2}$ nanorods, but the study was also limited to benzyl alcohol. ${ }^{79} \mathrm{~A}$ follow-up study from the group of Higashimoto broadened the scope of the reaction and rationalized the influence of the substituent in the aromatic ring on the photoreaction rate. ${ }^{80}$ The authors observed that the less delocalized the benzylic radical (4) is (metaorientation of EDG or ortho- and para-orientation of EWG), the more efficient the conversion to the corresponding aldehydes.

Similar reactivity was observed by Tanaka et al. (who used $\mathrm{Nb}_{2} \mathrm{O}_{5}$ ), Wu et al. (using a $\mathrm{ZnTi}$ layered double hydroxide $(\mathrm{ZnTi}-\mathrm{LDH})$ ), and Wang et al. (who used a monolayer titanate nanosheet as a semiconductor). ${ }^{81-83}$ Although $\mathrm{Nb}_{2} \mathrm{O}_{5}, \mathrm{ZnTi}$, and titanate are not able to absorb light at wavelengths above $390 \mathrm{~nm}$, they observed the photo-oxidation of benzylic alcohols 5 proceeding at irradiation in the range of $400-480 \mathrm{~nm}$ and, in the first case, under solvent-free conditions (Scheme 2). While $\mathrm{ZnTi}-\mathrm{LDH}$ performed the selective transformation of benzylic alcohol to benzaldehyde in $4 \mathrm{~h}$ at $25{ }^{\circ} \mathrm{C}$ with a conversion of $39 \%, \mathrm{Nb}_{2} \mathrm{O}_{5}$ enabled a conversion of $67 \%$ and a selectivity of $90 \%$ after $72 \mathrm{~h}$ at $50{ }^{\circ} \mathrm{C}$. In this case, Tanaka et al. claimed that the conversion was intentionally kept low to avoid competitive oxidation of the product to the corresponding carboxylic acid. Regarding the scope of these studies, the $\mathrm{ZnTi}-\mathrm{LDH}$ catalyst was only tested on the oxidation of benzylic alcohol and the monolayer titanate nanosheet catalyst was exclusively tested on the oxidation of furfuryl alcohol. Instead, the $\mathrm{Nb}_{2} \mathrm{O}_{5}$ catalyst was evaluated on a broader scope including the case of secondary alcohols, leading to high conversions and selectivity of up to $96 \%$, 
Scheme 2. Photocatalytic Oxidations of Primary and Secondary Aromatic Alcohols via Direct Excitation of (a) $\mathrm{Nb}_{2} \mathrm{O}_{5}$, (b) ZnTi Layered Double Hydroxide, and (c) a Monolayer Titanate Nanosheet



but after a longer reaction time $(240 \mathrm{~h})$. On the other hand, when the reaction was performed on aliphatic alcohols, a dramatic drop in selectivity and conversion was observed. In a later work, the same authors reported that the presence of a small amount of copper on $\mathrm{Nb}_{2} \mathrm{O}_{5}$ could significantly enhance the reactivity of the catalyst without affecting its selectivity. ${ }^{84}$

Since these seminal discoveries on substrate activation of semiconductors, a large number of research works have been dedicated to improving their visible light absorption. Therefore, many approaches have focused on the method of dye sensitization. Among the most studied, Alizarin Red S (AR) was proven to anchor to the surface of semiconductors such as $\mathrm{TiO}_{2}$ and sensitize it to visible light (see Figure 5B). ${ }^{85}$ Two anchoring groups are often encountered: $\mathrm{SO}_{3}{ }^{-}$or catechol groups (see Figure 5A).

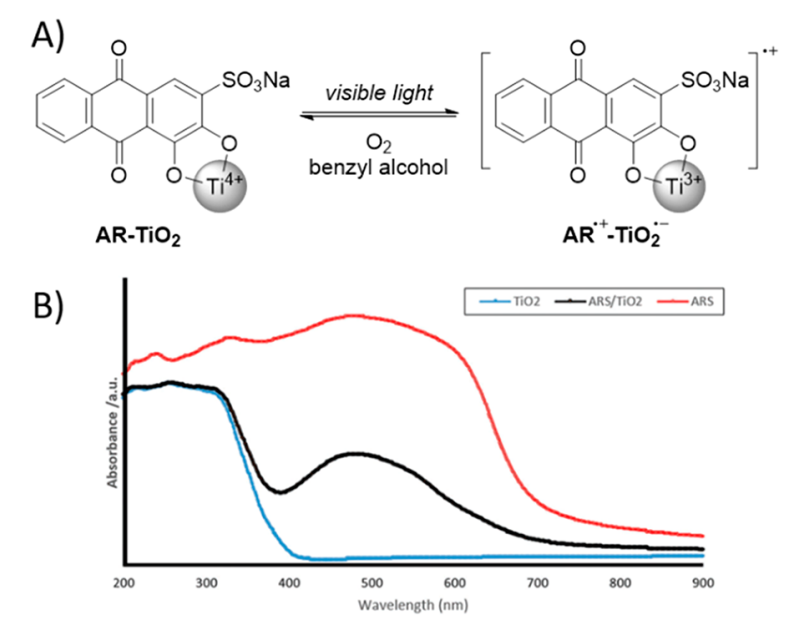

Figure 5. Visible-light sensitization of $\mathrm{TiO}_{2}$ with $\mathrm{AR}$ : (A) one of the possible anchoring interactions and charge separation resulting from photoexcitation and (B) diffuse reflectance spectra of the $\mathrm{AR}, \mathrm{AR}-\mathrm{TiO}_{2}$, and $\mathrm{TiO}_{2}$ powders. [Reprinted with permission from ref 75. Copyright 2018, Royal Society of Chemistry, London.]
Scheme 3. Visible-Light-Induced Selective Oxidation of Alcohols with Air by AR-TiO 2 Photocatalysis

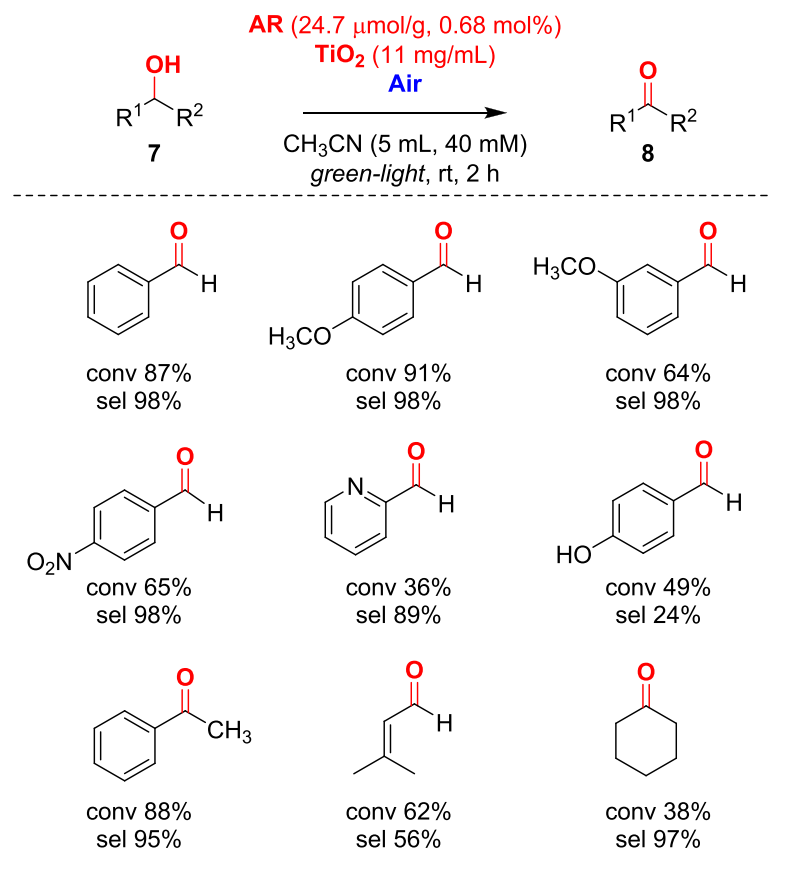

This strategy has been efficiently applied using air instead of pure $\mathrm{O}_{2}$ (Scheme 3). ${ }^{86}$ The authors discovered that the amount of $\mathrm{TiO}_{2}$ was one of the most important parameters affecting the conversion. Indeed, the electron transfer from the $\mathrm{CB}$ to $\mathrm{O}_{2}$ is thought to be the rate-limiting step and higher surface area could increase the contact probability, thereby leading to enhancement in the oxidation rate. No leaching was detected in $\mathrm{CH}_{3} \mathrm{CN}$ in which the dye-sensitized $\mathrm{TiO}_{2}$ nanoparticles dispersed the best. However, partial photobleaching of AR impeded the direct recycling of the photocatalyst and repeating the $\mathrm{AR}-\mathrm{TiO}_{2}$ preparation process was required. In fact, this experimental setup was found to be dependent on the concentration of dye and the authors reported pseudo-first-order reaction kinetics, with respect to the dye. The scope of the reaction revealed that EDG substituents lead to higher conversions, compared to EWG. The system was also shown to work well with secondary benzylic alcohols. On the other hand, heteroaromatic alcohols gave lower conversions (36\%) but high selectivity (89\%) and phenols substituents resulted in lower selectivity (24\%). The reaction performed with moderate yields with allylic alcohols but worked remarkably well with secondary alkyl alcohols. Generally, high selectivity was obtained but oxidation by $\mathrm{AR}-\mathrm{TiO}_{2}$ under visible-light irradiation remains a slow process, and has a major drawback of rapid catalyst deactivation.

Later, Lang and co-workers took advantage of this selective photo-oxidation of benzyl alcohols 1 to aldehydes 2 with $\mathrm{O}_{2}$ on AR-sensitized $\mathrm{TiO}_{2}$ and reported the one-pot, two-step preparation of a broad scope of imines 10. In this methodology, a subsequent condensation step catalyzed by the same $\mathrm{AR}-\mathrm{TiO}_{2}$ was used to combine various anilines 9 with the newly formed aldehydes. ${ }^{87}$ Lewis acid sites of $\mathrm{TiO}_{2}$ can promote the formation of imines from aldehydes and amines with good isolated yields. The stepwise procedure relies first on the photo-oxidation of benzyl alcohols 1 in $\mathrm{CH}_{3} \mathrm{CN}$ in the presence of $\mathrm{AR}-\mathrm{TiO}_{2}$ under $3 \mathrm{~W}$ green LED illumination and $\mathrm{O}_{2}(0.1 \mathrm{MPa})$ at $\mathrm{rt}$ for $2 \mathrm{~h}$. Then, the second step involves the addition of aniline 9, in darkness (Scheme 4). 
Scheme 4. Visible-Light Photocatalytic Synthesis of Imines from Alcohols and Amines on $\mathrm{AR}-\mathrm{TiO}_{2}{ }^{a}$

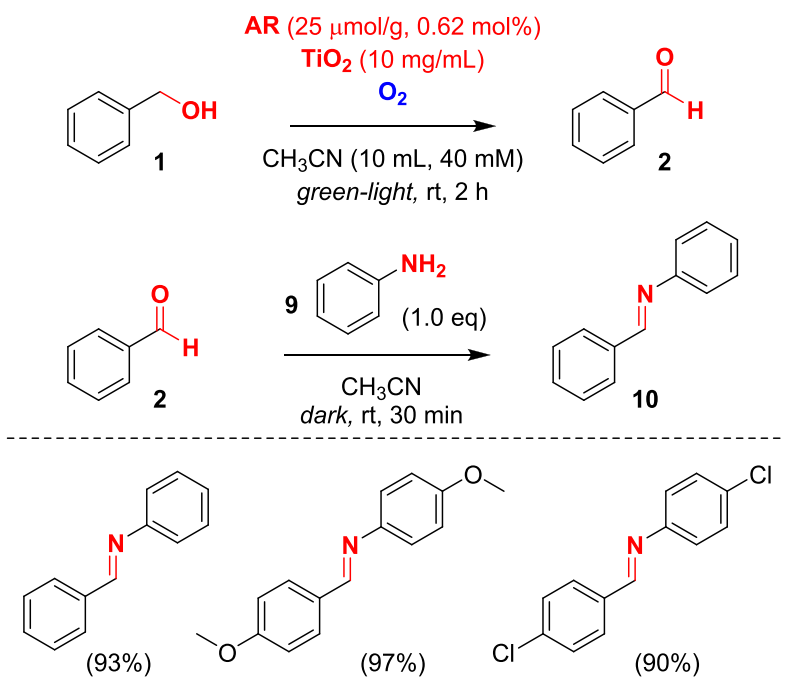

${ }^{a}$ Isolated yields are reported in brackets.

$\mathrm{Wu}$ et al. modified the system reported above using Pddecorated titanate nanosheets. ${ }^{88}$ They could thereby combine the oxidation of aromatic alcohols to aldehydes with the reduction of nitroaryl compounds and demonstrate the formation of anilines in situ. While the alcohol absorption on the semiconductor nanosheets allowed the visible-light absorption, the metal nanoparticles played a central role in the hydrogen transfer between substrates. Finally, photohydrogenation of the imine adduct yielded secondary amines with a selectivity as high as $85 \%$.

A more recent study showed that reduced photobleaching could arise when adding 2,2,6,6-tetramethylpiperidinyloxyl (TEMPO) as a homogeneous co-catalyst. ${ }^{89}$ This strategy was effectively applied to the visible-light oxidations of benzylic alcohols in benzotrifluoride (BTF) at rt, under atmospheric $\mathrm{O}_{2}$ (see Scheme 5). The $\mathrm{AR} / \mathrm{TiO}_{2} / \mathrm{TEMPO}$ triad system transformed EDG-substituted alcohols 7 into the corresponding carbonyl compounds 8 with quantitative yields under visible light, using a $500 \mathrm{~W}$ halogen lamp equipped with a cutoff filter for wavelengths of $<450 \mathrm{~nm}$. EWG seemed to act detrimentally, providing lower conversions. It should also be mentioned that this system exhibited relatively low activity on aliphatic alcohols but allylic alcohols could be oxidized to the corresponding $\alpha, \beta$-unsaturated aldehydes with good yields without concurrent oxidation of the double bond. The turnover number (TON) values were relatively high (up to 665 for benzyl alcohol on a $5 \mathrm{mmol}$ scale). Further development of the system was obtained with the triad 5(6)carboxyfluorescein $(\mathrm{CF}) / \mathrm{TiO}_{2} / \mathrm{TEMPO}$, which was also found to be effective on the oxidation of secondary aromatic alcohols. ${ }^{90}$

TEMPO and its derivatives are good electron donors, which can promptly quench the dye radical arising from the electron injection process, preventing irreversible photobleaching. When quenching the Dye ${ }^{\bullet+}$ species, TEMPO is oxidized to $\mathrm{TEMPO}^{+}$, which then acts as an effective and selective oxidant for an electron donor substrate. When compared to TEMPO-free photocatalytic systems, the role of TEMPO appears more obvious: it shifts the oxidation reaction from a single-electron-transfer process to a two-electron-transfer mechanism operated by TEMPO ${ }^{+}$, which turns into the reduced form TEMPOH. Eventually, TEMPOH can regenerate TEMPO by reacting with $\mathrm{O}_{2}{ }^{--}$(or with another $\mathrm{Dye}^{\bullet+}$ ), and thereby acting as a scavenger against reactive
Scheme 5. Photo-oxidations of Alcohols with the AR/ $\mathrm{TiO}_{2} /$ TEMPO and CF/ $\mathrm{TiO}_{2} / \mathrm{TEMPO}$ Triad Catalysts
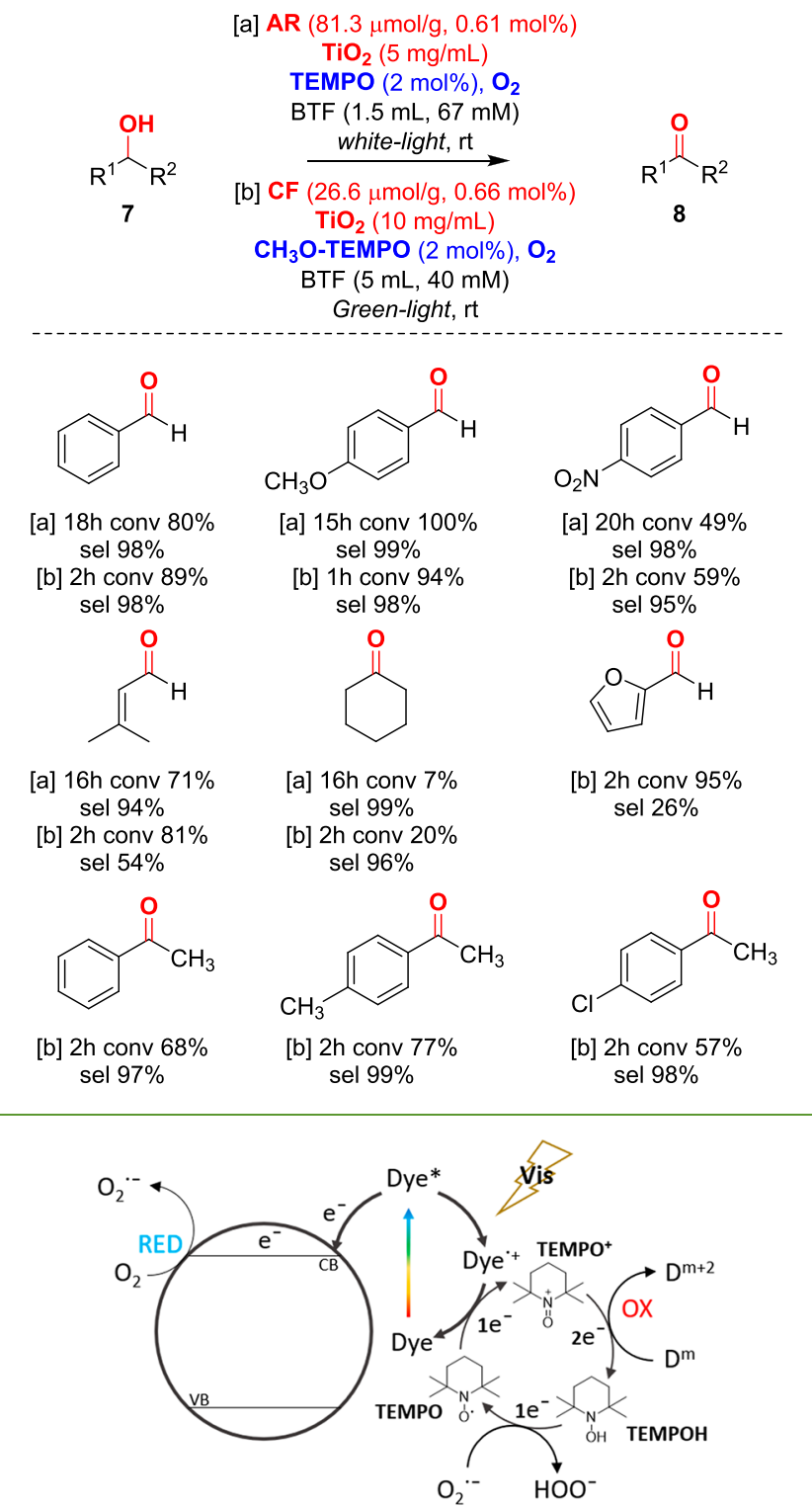

Figure 6. Visible-light-induced two-electron-transfer oxidation in a dye/ semiconductor/TEMPO system.

oxidative species (ROS), which are responsible for lowering selectivity and photocatalyst stability (see Figure 6).

A similar triad system has been proposed by Lang et al., who studied a photocatalytic system using Eosin $\mathrm{Y}(\mathrm{EY})$ as a sensitizer for $\mathrm{TiO}_{2}{ }^{91}$ Together with TEMPO, the photocatalyst was capable of oxidizing benzylic, allylic, and aliphatic alcohols (7) in $\mathrm{CH}_{3} \mathrm{CN}$ under atmospheric $\mathrm{O}_{2}$ pressure and using green or blue LEDs $(3 \mathrm{~W})$. The reactions were completed within a very short time $(1-4 \mathrm{~h})$ and the catalytic system displayed moderate TON values, e.g., $\sim 230$ for the photo-oxidation of benzyl alcohol on a $0.4 \mathrm{mmol}$ scale. A wide substrate scope of alcohols was explored, demonstrating higher reactivity than the dyad $\mathrm{AR}-\mathrm{TiO}_{2}$ system described above. Generally, the reactions proceeded with high conversions and excellent selectivity for any benzylic alcohols, although EWG slightly decreased the reactivity (Scheme 6). Moderate efficiencies were obtained for the oxidation of allylic alcohols and a significant drop in conversion was found with 
Scheme 6. Selective Oxidation of Alcohols with $\mathrm{O}_{2}$ Via the Visible-Light Photocatalysis of $\mathrm{EY} / \mathrm{TiO}_{2}$ and TEMPO

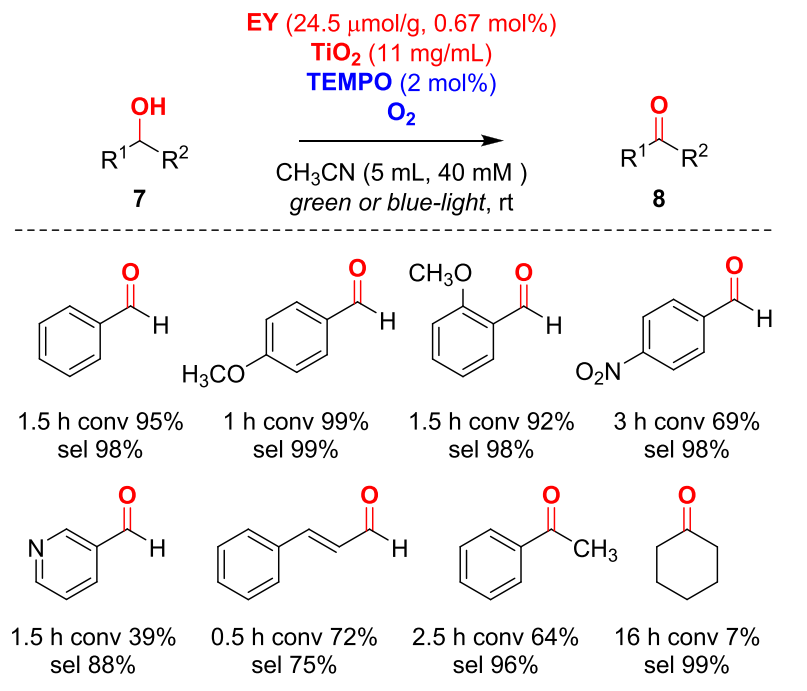

heteroatoms and secondary alcohols, and poor conversion was obtained for the oxidation of aliphatic alcohols.

Robinson et al. replaced $\mathrm{TiO}_{2}$ with $\mathrm{ZnO}$, using $\mathrm{AR}$ as a visiblelight photosensitizer and $\mathrm{AgNO}_{3}$ (18 equiv) as a sacrificial electron acceptor, instead of $\mathrm{O}_{2}$. With this system, they achieved a photo-oxidation process in an aqueous environment. ${ }^{92}$ Oxidations of primary alcohols were completed in $2 \mathrm{~h}$ but with a poor TON $(<100)$. To reduce the environmental and economic costs of stoichiometric $\mathrm{AgNO}_{3}$, the authors demonstrated the possibility to filtrate and recover the metal silver particles after a reaction cycle. Supported by a paramagnetic resonance study, ${ }^{93}$ they attributed the reaction rate enhancement, compared to the previously described $\mathrm{AR} / \mathrm{TiO}_{2} / \mathrm{TEMPO}$ triad, to a more efficient electron injection of $\mathrm{AR}$ with $\mathrm{ZnO}$, compared to $\mathrm{TiO}_{2}$. The AR/ZnO/TEMPO triad also converts allylic alcohols to the corresponding $\alpha, \beta$-unsaturated aldehydes quantitatively and 1-phenylethanol to acetophenone with yields of up to $67 \%$. However, the system remained again poorly effective with aliphatic alcohols. After recognizing that $\mathrm{Ag}$ ions performed as electron acceptors and inhibited the hydrolysis of the adsorbed $\mathrm{AR}$ on $\mathrm{ZnO}, \mathrm{NaNO}_{3}$ was introduced into the catalytic cycle to stabilize the dye. ${ }^{94}$ An electrolytic solution of $\mathrm{AgNO}_{3}$ (1 equiv) and $\mathrm{NaNO}_{3}$ (3 equiv) afforded a supporting electrolyte of high ionic strength to stabilize the dye on the semiconductor surface, drastically reducing the requirement of the silver content (see Scheme 7). The use of silver-sodium electrolyte also allowed us to extend the applicability of this catalytic system to the regioselective oxidations of aliphatic alcohols to aldehydes.

Another alcohol oxidation using a sacrificial electron acceptor was recently developed from Kaboudin et al., who reported the photo-oxidation of aromatic alcohols with nitromethane in an argon environment catalyzed by $\mathrm{P} 25 \mathrm{TiO}_{2}$ under a $400 \mathrm{~nm}$ LED irradiation. $^{95}$

To avoid using a homogeneous co-catalyst such as TEMPO, Cao and Gao developed an "all-in-one" heterogeneous photocatalytic system for the oxidation of benzylic alcohols where $\mathrm{TiO}_{2}$ was functionalized with a polyoxometalate $\left(\mathrm{PW}_{12}\right)$ and thionine $(\mathrm{TH}) .{ }^{96} \mathrm{PW}_{12} \mathrm{O}_{40}{ }^{3-}$ acts as an anchoring group on $\mathrm{TiO}_{2}$ for $\mathrm{TH}$, which interacts via ionic binding and allows $\mathrm{TiO}_{2}$ sensitization under visible-light irradiation. The authors reported the preparation of $\mathrm{TiO}_{2}-\left(\mathrm{PW}_{12}-\mathrm{TH}\right)_{8}$ films ${ }^{97}$ and their use as efficient and selective aerobic oxidation of alcohols (7) under visible-light.
Scheme 7. Photo-oxidation of Alcohols with the $\mathrm{AR} / \mathrm{ZnO} /$ TEMPO Catalyst System and $\mathrm{AgNO}_{3}$ as a Terminal Electron Acceptor $^{a}$

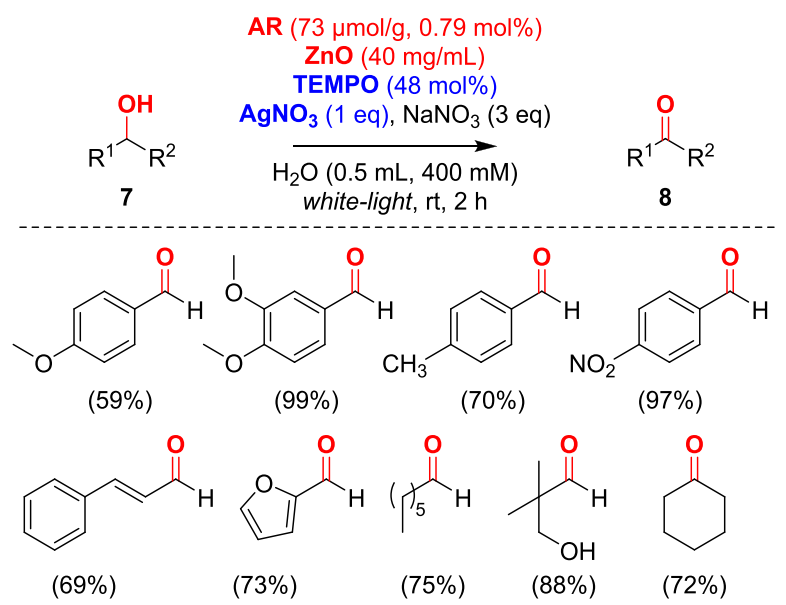

${ }^{a}$ Gas chromatography yields are reported in brackets.

The suspension was irradiated by a $300 \mathrm{~W}$ xenon illuminator system with a UV cutoff filter at $30{ }^{\circ} \mathrm{C}$ (see Scheme 8). The presence of EDG favors the photo-oxidation process, while EWG decreases conversion rates. With heteroaromatic alcohols, allylic alcohols, or secondary aromatic ones, poor conversions but excellent selectivity are reported.

The development of an efficient photocatalytic system for the selective oxidation of aliphatic alcohols was eventually obtained by Parrino and co-workers; they reported a heterogeneous visible-light photocatalyst for the oxidation of small alcohols in the gas-solid regime, using $\mathrm{TiO}_{2} \mathrm{P} 25$ sensitized with a perylene dye. ${ }^{98} N, N^{\prime}$-bis(2-(1-piperazino)ethyl)-3,4,9,10-perylene-tetracarboxylic acid diimide dichloride (PZPER) was reported to efficiently anchor to $\mathrm{TiO}_{2}$ via interaction of the piperazine nitrogen lone pairs on the Lewis acidic sites of $\mathrm{TiO}_{2}$. A $0.56 \%(\mathrm{w} / \mathrm{w})$ loading (PZPER-TiO $)_{2}$ ), estimated to cover around half of the semiconductor surface, was found to be optimal for catalysis in a photoreactor saturated with pure $\mathrm{O}_{2}$. The reactor was irradiated with white light with a radiance of $850 \mathrm{~W} / \mathrm{m}^{2}$, at $40^{\circ} \mathrm{C}$ for $2-5 \mathrm{~h}$ (see Scheme 9). Except for the $\mathrm{CO}_{2}$ produced during methanol oxidation, no byproducts were detected, and the catalyst displayed high stability and a significantly prolonged lifetime.

Scheme 8. Selective Oxidation of Benzyl Alcohols over $\mathrm{TiO}_{2}-\left(\mathrm{PW}_{12}-\mathrm{TH}\right)_{8}$ under Visible-Light Irradiation

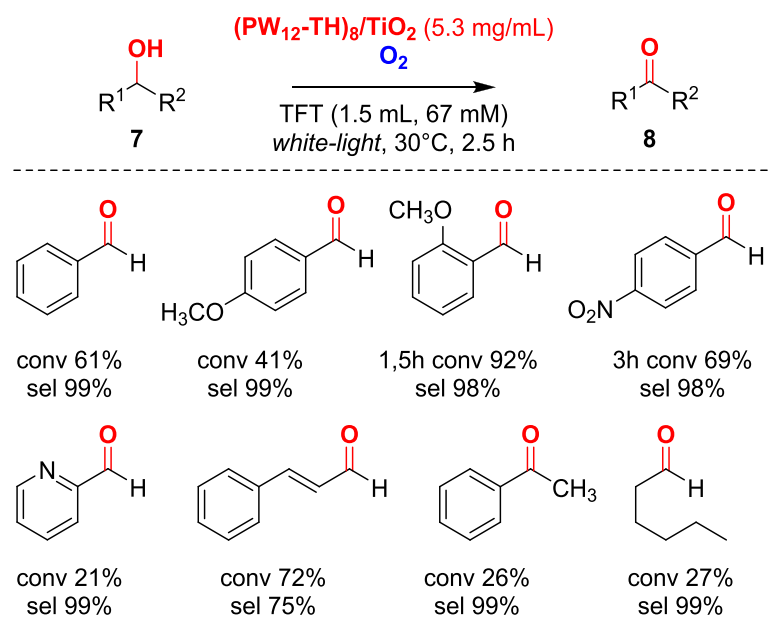

sel $75 \%$ sel $99 \%$ 
Scheme 9. Photo-oxidation of Gaseous Aliphatic Alcohols on $\mathrm{TiO}_{2}$ Sensitized by a Perylene Dye (PZPER)

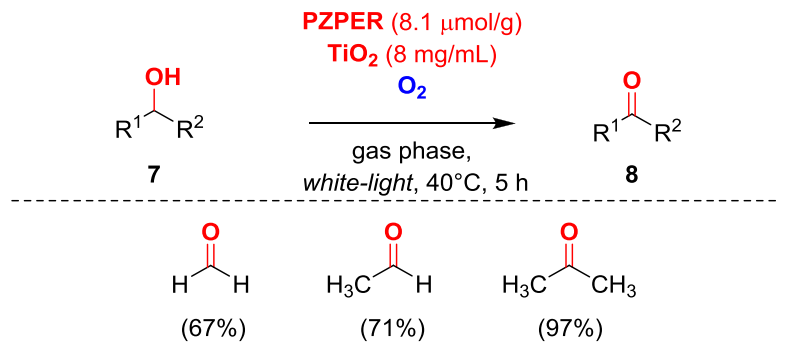

Nowadays, similar systems are proposed for the sunlightpowered biorefinery of bioethanol streams, which represents an attractive example of an eco-green synthesis of valuable commodity chemicals. ${ }^{99}$

\section{OXIDATIONS OF ETHERS}

The work of Cong et al. reported on the photocatalytic oxidation of benzyl ethers (11) to benzoates (12) using ambient air, instead of stoichiometric oxidants, and a photocatalyst composed of $\mathrm{TiO}_{2}$ and EY. ${ }^{100}$ This photocatalyst was applied to a wide range of ethers and demonstrated great functional group tolerance (see Scheme 10). The reaction proceeded with good selectivity in the

Scheme 10. Aerobic Visible-Light Photo-oxidation of Benzyl Ethers with $\mathrm{EY} / \mathrm{TiO}_{2}$ Photocatalyst $^{a}$

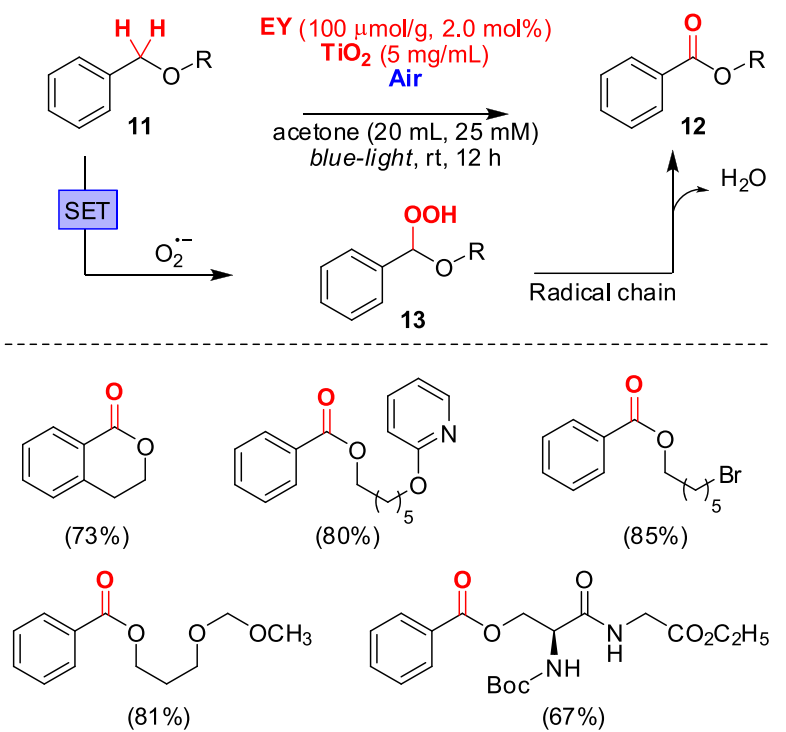

${ }^{a}$ Isolated yields are reported in brackets.

presence of primary, secondary, or tertiary alkyl groups, as well as with competing $\mathrm{C}\left(\mathrm{sp}^{3}\right)-\mathrm{H}$ bonds, such as benzylic positions, alkyl halides, alkyl nitriles, cyclopropyls, epoxides, acetals, and nitroaryls. The scope described was very broad and even included substrates derived from natural products such as benzyl-protected menthol, steroids, amino acids, and sugars. With respect to benzyl ethers analogues, reactions proceeded smoothly also when the phenyl ring was substituted by EDG or EWG or replaced by naphthyl or pyridyl groups. The reaction was found to be a twostep process: the photoactivated dye injects an electron into the $\mathrm{CB}$ and generates $\mathrm{EY}^{\bullet+}$ which undergoes a SET process with the ether, giving rise to a benzylic radical that subsequently reacts with $\mathrm{O}_{2}{ }^{\bullet-}$. The product of this condensation is an isolable hydroperoxy acetal 13 , which is relatively unstable and can undergo a

radical chain mechanism, initiated by the homolytic photocleavage of the $\mathrm{O}-\mathrm{O}$ peroxide bond catalyzed by $\mathrm{TiO}_{2}$.

\section{OXIDATIONS OF AMINES}

Amines are excellent electron donors and therefore commonly used as reducing agents in photocatalysis. Unlike conventional chemistry relying on expensive $\mathrm{Ru}$ catalysts or relatively high temperatures $\left(100{ }^{\circ} \mathrm{C}\right),{ }^{43}$ this reactivity can also be exploited in reactions where the amine $\mathbf{1 4}$ is used as the substrate to generate a radical cation 15 , which evolves into the corresponding $\alpha$-radical 16 and then into the corresponding iminium 17 (see Scheme 11).

Scheme 11. Radical Evolution Pathway in the Oxidation of Primary and Secondary Amines



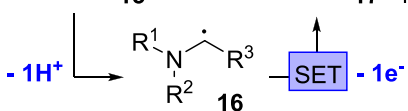

Therefore, these methods are of interest for oxidations and $\mathrm{C}-\mathrm{H}$ functionalization of nitrogenous substrates (see the section entitled "Net Oxidative Couplings").

The work of Tanaka et al. ${ }^{101}$ is the first example of visible-light photocatalytic oxidation of amines 14 with $\mathrm{Nb}_{2} \mathrm{O}_{5}$ as a semiconductor. A similar study was reported later by Zhao et al., using

Scheme 12. Aerobic Photo-oxidations of Primary and Secondary Amines to Imines Catalyzed by (a) $\mathrm{Nb}_{2} \mathrm{O}_{5}$ or (b) $\mathrm{TiO}_{2}$

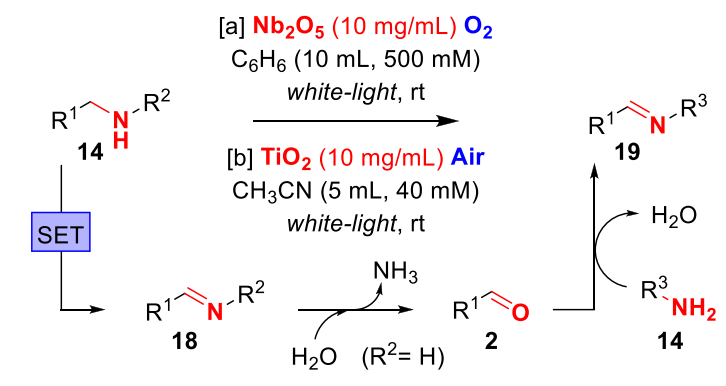

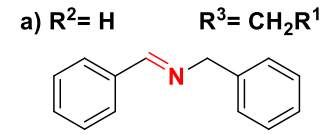

[a] $24 \mathrm{~h}$ conv $21 \%$ sel $97 \%$

[b] $10 \mathrm{~h}$ conv $91 \%$ sel $92 \%$

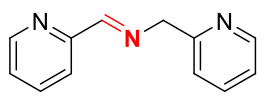

[b] $12 \mathrm{~h}$ conv $77 \%$ sel $86 \%$

b) $R^{2}=$ Alkyl $\quad R^{3}=R^{2}$<smiles>CC(C)/N=C/c1ccccc1</smiles>

[a] $24 \mathrm{~h}$ conv $47 \%$ sel $91 \%$

[b] $4 \mathrm{~h}$ conv $63 \%$ sel $46 \%$

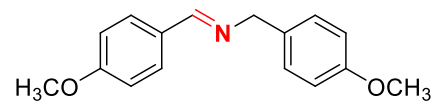

[a] $24 \mathrm{~h}$ conv $29 \%$ sel $94 \%$

[b] $5.5 \mathrm{~h}$ conv $95 \%$ sel $93 \%$

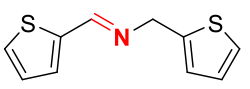

[b] 9 h conv $77 \%$ sel $80 \%$

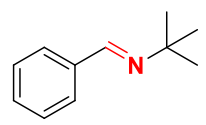

[a] $24 \mathrm{~h}$ conv $13 \%$ sel $87 \%$

[b] 4 h conv $69 \%$

sel $69 \%$ 
$\mathrm{TiO}_{2}$ as a catalyst (Scheme 12). ${ }^{102}$ Although $\mathrm{Nb}_{2} \mathrm{O}_{5}$ and $\mathrm{TiO}_{2}$ show no absorption in the visible range $(\lambda>390 \mathrm{~nm})$, the reaction occurs in the presence of the amine substrate (14) under visible-light irradiation. The formation of an amine/surface complex was suggested to be responsible for this effect, presumably via direct excitation, resulting in electron transfer from the $N 2 p$ orbital of the adsorbed amine to the semiconductor $\mathrm{CB} .{ }^{103,104}$ After photoirradiation and electron transfer, the corresponding imine $\mathbf{1 8}$ is formed. In the case of primary amine oxidations, a dimerization process occurs, leading to the formation of $\mathrm{N}$-benzylidene benzylamine 19 , together with ammonia. In the case of $\mathrm{Nb}_{2} \mathrm{O}_{5}$, the main drawback of this method is that the reactions are slow and performed in benzene. This poor reactivity was shown to be enhanced by using irradiation in the near-UV region $(\lambda>300 \mathrm{~nm})$, thereby demonstrating that a key limiting factor was light absorption. When $\mathrm{TiO}_{2}$ (anatase) was used, the reactivity was enhanced in $\mathrm{CH}_{3} \mathrm{CN}$. The choice of the material and its surface area was shown to be critical for improving the catalytic performances.

In a consecutive approach, Lang et al. therefore elected to use a dye to sensitize the semiconductor and enhance visible-light absorption. They applied their previously developed photocatalytic system, which was composed of adsorbed $\mathrm{AR} / \mathrm{TiO}_{2}$ nanoparticles and TEMPO and the triad polyimide/ $\mathrm{TiO}_{2} / \mathrm{TEMPO}$ to the photo-oxidation of benzylamines (Scheme 13). ${ }^{105,106}$ The reaction was conducted in $\mathrm{CH}_{3} \mathrm{CN}$ and completed within only a few hours. Secondary benzylic amines reacted under identical conditions with good yields. Very recently, the same group

Scheme 13. Visible-Light Photocatalytic Oxidations of Primary Amines with Air by (a) $\mathrm{AR}^{-\mathrm{TiO}_{2}}$ and TEMPO or (b) $\mathrm{TiO}_{2}$ and TEMPO Only

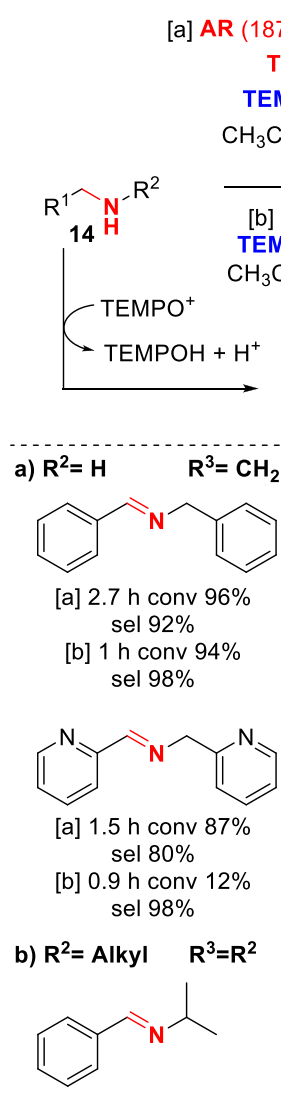

[a] $3.0 \mathrm{~h}$ conv $83 \%$ sel $69 \%$
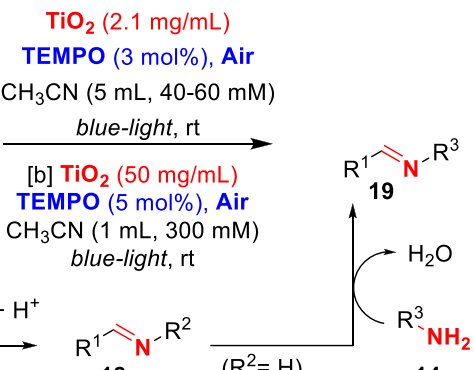
14



[a] $2.5 \mathrm{~h}$ conv $95 \%$ sel $94 \%$

[b] $0.75 \mathrm{~h}$ conv $96 \%$ sel $97 \%$

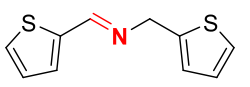

[a] $1.5 \mathrm{~h}$ conv $57 \%$ sel $90 \%$

[b] 0.9 h conv $90 \%$ sel $98 \%$

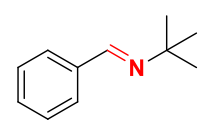

[a] 5.0 h conv $88 \%$ sel $92 \%$

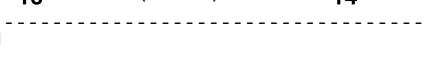

studied the effect of TEMPO on the reaction conducted with unsensitized $\mathrm{TiO}_{2}$, highlighting a further reduction in reaction time (Scheme 13). ${ }^{107}$ They rationalized this observation with the capability of TEMPO to change the reaction path of the photooxidation of amines reaction from a single electron transfer to a two-electron process. After photoexcitation of the surface complex, TEMPO restores the produced radical cation into its original state, to prevent it from being destroyed by ROS. TEMPO turns into $\mathrm{TEMPO}^{+}$and oxidizes benzylamine 14 directly into benzylidene amine 18 through a two-electron dehydrogenation process (see Figure 6). Benzylidene amine then proceeds to the final product 19, following the same reaction path described above. Acting as an electron coupler, TEMPO accelerates the oxidation process and prevents side reactions, because of direct reaction of the excited substrate with the ROS.

The same authors also investigated the LMCT direct excitation mechanism with very simple additives, such as phenols, which are known to alter the nature of semiconductors and produce a bathochromic shift to allow visible-light absorption. ${ }^{102}$ The mixture of colorless phenols with white $\mathrm{TiO}_{2}$ nanoparticles generates a deep yellow color, which suggests the formation of a surface electron donor-acceptor complex. As a result, an electron transfer from the organic molecules into the $\mathrm{CB}$ of $\mathrm{TiO}_{2}$ occurs upon visible-light excitation. The library of sensitizers that have been tested can be expanded to phenols (PH), ${ }^{108}$ catechols (CA), ${ }^{109}$ salicylic acids (SA), ${ }^{110}$ and $N$-hydroxyphthalimide (PT). ${ }^{111}$ In the last case, the phthalic acid ring has a strong deactivation effect and therefore stabilizes the sensitizer against photobleaching. Such systems require no tedious preparation; but, in all cases, the stability of the surface complex against oxidation is poor and requires the addition of TEMPO (Scheme 14).

Scheme 14. Oxidation of Amines via Direct Excitation of $\mathrm{TiO}_{2}$ Sensitized by Simple OH-Containing Aromatic Compounds

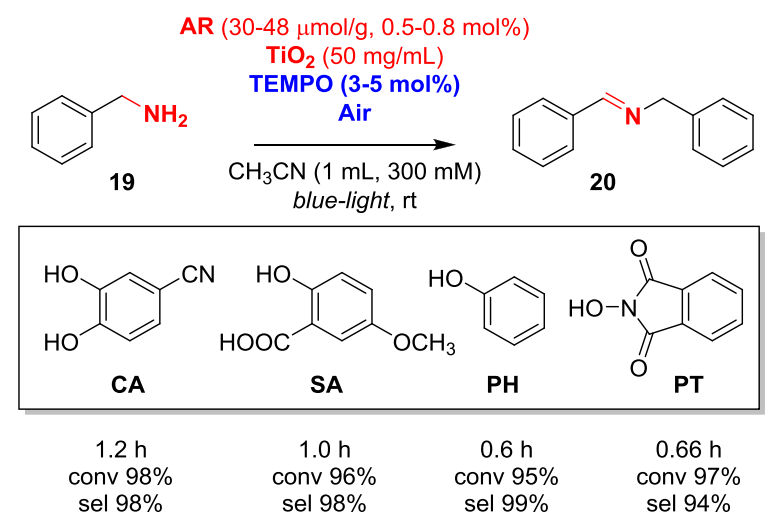

The work from Zhang et al. represents instead a rare example where the diad dye $/ \mathrm{TiO}_{2}$ was exploited without the use of a TEMPO mediator. ${ }^{112}$ They reported a benzothiadiazole-phenyl conjugated microporous copolymer embedding $10 \mathrm{~nm} \mathrm{TiO} 2$ nanoparticles, showing photocatalytic properties toward the oxidation of benzyl amines to secondary imines (and for the oxidation of sulfides to sulfoxides) under blue light.

Bahnemann et al. studied an aerobic dehydrogenation of $N$-heterocycles $(21)$ promoted by $\mathrm{TiO}_{2}$ nanoparticles grafted with noble metals and sensitized toward visible light by means of direct excitation of the $\mathrm{TiO}_{2}$ nanoparticles surface complex with the substrate. ${ }^{113,114}$ In a first setup, the semiconductor nanoparticles were decorated with $\mathrm{Ni}^{2+} / \mathrm{Ni}^{0}$ and 4-amino-TEMPO to increase the yield and improve the selectivity. The authors 
Scheme 15. Photodehydrogenations of Tetrahydroquinolines over Metal-Decorated $\mathrm{TiO}_{2}$ Nanoparticles ${ }^{a}$

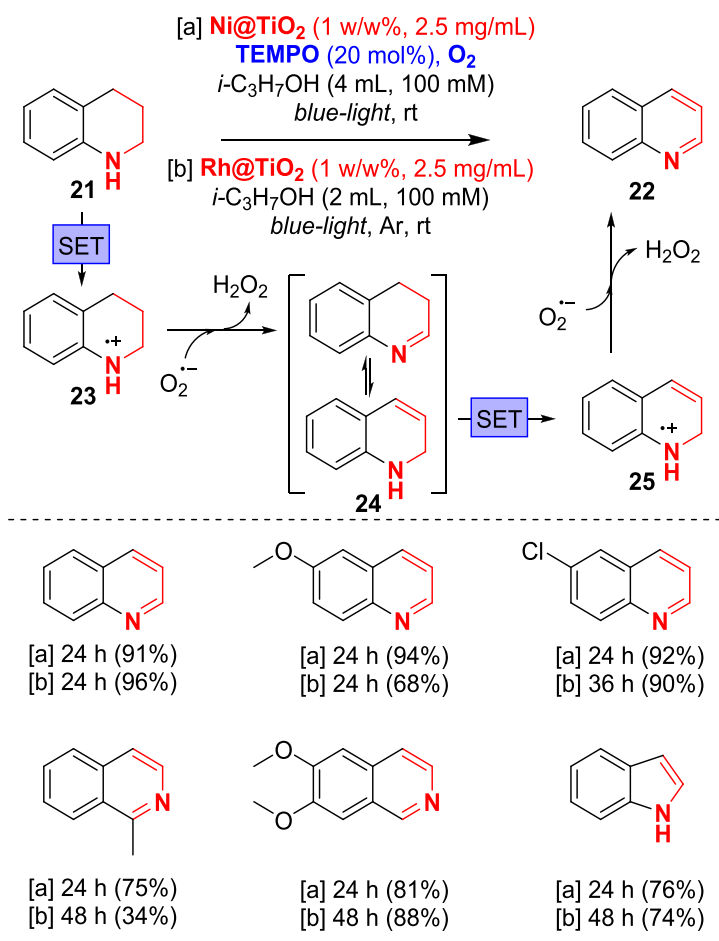

${ }^{a}$ Isolated yields are reported in brackets; main side products were found to be dihydroquinolines.

speculated that $\mathrm{Ni}$ ions possibly serve as an electron shuttle between the $\mathrm{CB}$ of $\mathrm{TiO}_{2}$ and $\mathrm{O}_{2}$, forming the superoxide radical anion responsible for the deprotonation (Scheme 15). On the other hand, 4-amino-TEMPO was found to improve the reaction selectivity by preventing saturation of the $\mathrm{TiO}_{2}$ surface with $\mathrm{H}_{2} \mathrm{O}_{2}$. Recently, the same group developed a second photocatalyst where $\mathrm{Rh}$-photodeposited $\mathrm{TiO}_{2}$ nanoparticles selectively performed acceptor-free dehydrogenations of $\mathrm{N}$-heterocyclic amines under argon atmosphere and visible-light irradiation, with the concomitant generation of molecular hydrogen gas.

More evidence of the strong surface interaction of $\mathrm{N}$-containing organic compounds was provided by Wu et al., who reported two conceptual studies on the photocatalyzed partial oxidation of aniline to nitrosobenzene using semiconductor-based heterogeneous catalysts. ${ }^{115,116}$ The authors reported that alkaline-earthmetal oxides, including $\mathrm{MgO}, \mathrm{CaO}, \mathrm{SrO}$, and $\mathrm{BaO}$, supported on $\mathrm{TiO}_{2}$ nanoparticles were sensitized to visible light, because of direct excitation of the surface complex with the substrate. They hypothesized that tuning the surface basicity of the catalyst would result in effective and selective oxidation of the substrate.

\section{OXIDATIONS OF SULFIDES}

The sustainable and selective oxidation of sulfides (26) to sulfoxides (27) is an important goal, since conventional oxidations with electrophilic reagents, such as peracids, hydrogen peroxide, hypochlorite, sodium periodate, iodosobenzene, peroxy acids, and toxic oxo metal oxidants, may be affected by overoxidation to side products (sulfones). ${ }^{43}$

Chen et al. reported the selective oxidation of sulfides to sulfoxides with molecular oxygen at rt. $^{117}$ The authors first exploited the interaction of a tertiary amine (triethylamine, TEA) and $\mathrm{TiO}_{2}$ to achieve visible-light photoredox catalysis via direct excitation of the surface complex. Besides enhancing the visible-light activation, TEA plays a more significant role as a metal-free redox mediator by shuttling electrons during the oxidation of sulfides. However, as mentioned above, tertiary amines are very unstable under oxidative conditions and the authors selected methanol as an alternative additive to aid in the formation of sulfoxides. The advantage of such a system is that the catalyst is commercial (Scheme 16). The authors report that

Scheme 16. Visible-Light-Induced Oxidation of Sulfides with $\mathrm{O}_{2}$ on $\mathrm{TiO}_{2}$ with TEA as a Sensitizer and Redox Mediator

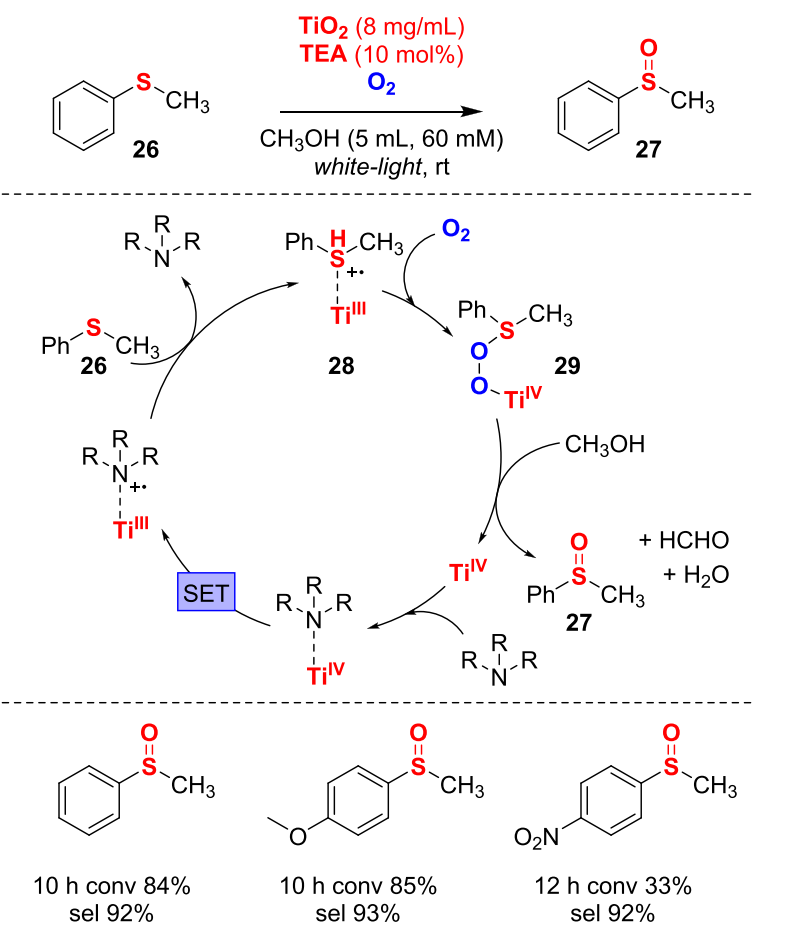

more than $90 \%$ of TEA could be recovered after $10-22 \mathrm{~h}$ of reaction at rt under irradiation with a xenon lamp (cutoff filter $<$ $400 \mathrm{~nm}$ ). The system was tested on several thioanisole derivatives (26) with EDGs reacting well, while EWGs display a lower reactivity and a decreased conversion (especially for the $\mathrm{NO}_{2}$ group).

The TEA- $\mathrm{TiO}_{2}$ system reported by Chen et al. has a very limited visible-light absorbance, leading to long reaction time and the need for a very powerful light source. As reported by the same authors, anchoring a dye such as polyimide or AR on the semiconductor enabled one to improve the performances of the system and use air instead of pure oxygen. ${ }^{118-120}$ The presence of a catalytic amount of TEMPO $(2 \mathrm{~mol} \%)$ was also needed to prevent the rapid photobleaching of the catalyst. Thanks to the dye sensitization, a wide range of wavelengths could be used for this reaction with a reduction of reaction time to $<2 \mathrm{~h}$. Other triad photocatalytic systems making use of $\mathrm{AR} /$ hollow $\mathrm{TiO}_{2}$ Octahedrons/ TEMPO, 1,2-dihydroxyanthraquinone (1,2-DHA)/ $\mathrm{TiO}_{2} / \mathrm{TEMPO}$, polydopamine/ $\mathrm{TiO}_{2} / \mathrm{TEMPO}$ or Erythrosin B (EB)/Titanate nanotube/TEMPO are reported to perform the oxidation of sulfides to sulfoxides with the same mechanism and similar reduction in reaction times (see Scheme 17). ${ }^{85,121-123}$

It is also worth mentioning the application of a similar technology to the preparation of symmetrical and unsymmetrical disulfides, through visible-light photocatalytic oxidation of thiols with $\mathrm{TiO}_{2} \cdot{ }^{124,125}$ The visible-light sensitization was supposed to occur by means of direct excitation, drastically reducing the 
Scheme 17. Selective Aerobic Oxidation of Organic Sulfides with Air Photocatalyzed by EB/Titanate Nanotubes/TEMPO



kinetics of the aerobic oxidation step. The mild operating conditions make this approach very attractive for applications to biomolecule modifications. In addition, the facile catalyst recuperation allowed a continuous-flow application. Notably, the substrates with EWGs are reported to undergo a complete transformation within $<10 \mathrm{~min}$.

\section{OXIDATIONS OF MIXED SUBSTRATES}

Chen et al. reported an elegant concept where two photocatalytic oxidations are combined in a single operation to drive selectivity. In this reaction system, the oxidation of thioanisole 27 was performed in the presence of benzylamine 19 and methanol. ${ }^{126}$ As benzylamine was mixed with $\mathrm{TiO}_{2}$, a redshift in the absorption occurred, suggesting the formation of an amine $-\mathrm{TiO}_{2}$ surface complex and allowing the reaction to be activated by visible light. Direct excitation of the complex releases the amine radical cation, which, in turn, is capable of activating the oxidation of thioanisole assisted by methanol, as reported earlier in this work, in the section entitled "Oxidations of Sulfides". As a result, formaldehyde is produced and reacts with 2 equiv of benzylamine 19 to give the intermediate 33 , which can itself interact with the semiconductor and undergo a second photo-oxidation event to produce the formamide product 32 (Scheme 18). Interestingly, when methanol is replaced by a redox-inert organic solvent such as $\mathrm{CH}_{3} \mathrm{CN}$, benzylamine is oxidized to the corresponding imine, while thioanisole remains almost unconverted. The dependence on protic solvents confirmed the requirement of proton assistance in the formation of the sulfoxide. The reaction was conducted in a methanol solution with a thioanisole/benzylamine ratio of $3: 1$. Anatase was suspended in the reaction mixture, which was irradiated for $4 \mathrm{~h}$ with a $300 \mathrm{~W}$ filtered xenon lamp under $0.1 \mathrm{MPa}$ of $\mathrm{O}_{2}$. The authors reported that the reaction could also proceed in air instead of pure $\mathrm{O}_{2}$, albeit at a slightly slower conversion rate. The reaction has a large functional group tolerance and proceeds always with high conversions and selectivity to the corresponding sulfoxides and formamides. Strong EWG, such as $\mathrm{NO}_{2}$, were found to significantly reduce the conversion rate.

\section{OXIDATIONS OF HYDROCARBONS}

The selective synthesis of aldehydes by benzylic $\mathrm{C}-\mathrm{H}$ oxidation usually requires the use of corrosive and harmful reagents such as hypochlorites, iodoxybenzoic acid, or $\mathrm{KMnO}_{4} / \mathrm{MnO}_{2}$. Performing such direct oxidation with photocatalysis and dioxygen would represent an interesting milder procedure.

Recently, Tanaka and co-workers reported the highly challenging visible-light photo-oxidation of aromatic hydrocarbons with $\mathrm{Nb}_{2} \mathrm{O}_{5} \cdot{ }^{127}$ When heated at high temperatures $\left(200-500^{\circ} \mathrm{C}\right)$, this semiconductor recovers its strong Lewis acidity by removing the adsorbed water layer. Once activated, the semiconductor was brought back to rt under dry atmosphere and was found capable of undergoing weak adsorption of noncoordinating substrates such as toluene (34) on the surface through $\pi$ interaction. ${ }^{128,129}$ This interaction enables the appearance of a new LMCT band in the visible region. Upon irradiation, charge separation occurs and enables electrons to be injected in the $\mathrm{CB}$ of $\mathrm{Nb}_{2} \mathrm{O}_{5}$, which generates the aromatic radical cation 35. The $\mathrm{O}_{2}$ also adsorbed on the $\mathrm{Nb}_{2} \mathrm{O}_{5}$ surface reacts with the excited electrons in the $\mathrm{CB}$ to form the superoxide anion, which deprotonates the benzylic $\mathrm{C}-\mathrm{H}$ bond of the toluene radical cation to give a benzylic radical 36. This intermediate is promptly converted to the corresponding benzylperoxy radical 37 by the addition of $\mathrm{O}_{2}$. The authors suggest that the formed benzylperoxy radical evolves via a Russell-like intermediate to benzaldehyde (2) and water, while, interestingly, the corresponding benzylic alcohol was not isolated

Scheme 18. Synergic Aerobic Oxidation of Thioanisole and Benzylamine on $\mathrm{TiO}_{2}$ in Methanol under Visible-Light Irradiation

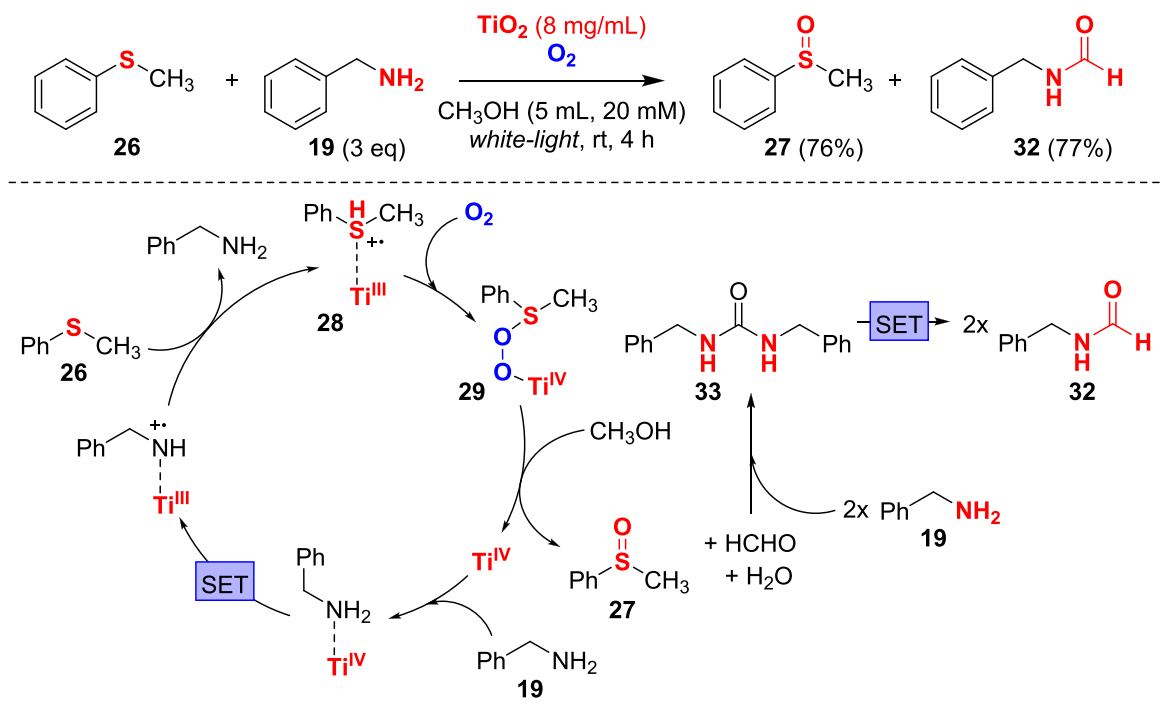


Scheme 19. Photo-oxidation of Toluene via Direct Excitation on the $\mathrm{Nb}_{2} \mathrm{O}_{5}$ Surface, With Visible Light

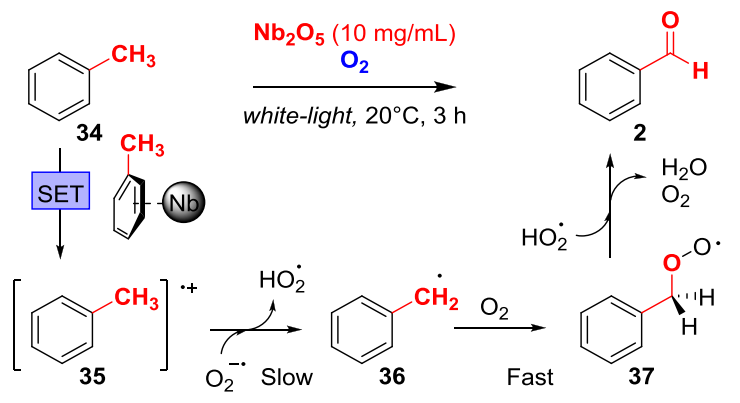

(Scheme 19). As the formation of the benzyl radical 36 was not confirmed, the authors speculated that the $\mathrm{O}_{2}$ intercalation into the benzyl radical is very fast, while the cleavage of the $\mathrm{C}-\mathrm{H}$ bond remains the rate-determining step.

Other functionalizations of alkanes have been reported such as in the photosulfoxidations of $n$-heptane and cyclohexane with visible light by Kisch et al. ${ }^{130,131}$ In these cases, the semiconductor $\left(\mathrm{TiO}_{2}\right)$ is used to allow visible-light activation, because of the formation of a surface complex with $\mathrm{SO}_{2}$.

\section{REDUCTIONS}

In reduction reactions, the substrate is the electron acceptor instead of $\mathrm{O}_{2}$. To close the catalytic cycle, the Dye ${ }^{\bullet+}$ must be reduced after electron injection and, therefore, requires the use of a sacrificial electron donor (SED). The redox potentials of the SED are to be taken into account, to match with the HOMO levels of the dyes.

\section{REDUCTIONS OF CARBONYLS}

Photocatalysis with sensitized semiconductors can also replace the use of strong reducing agents such as lithium aluminum hydride, avoiding the need for inert atmosphere, exothermic handling, and for the disposal of large amounts of salts as side products. $^{132}$

Miyabe and co-workers compared the reactivity of dyesensitized $\mathrm{TiO}_{2}$ catalysts in the presence of TEA $(+1.20 \mathrm{~V}$ vs. $\mathrm{NHE}$ ) as a reductive quencher to perform the heterogeneous photohydrogenation of aromatic ketones (6). Various organic dyes such as fluorescein (Fl), Rhodamine $\mathrm{B}(\mathrm{RB})$, and a series of coumarin (CM) dyes were tested. ${ }^{133,134}$ When $\mathrm{TiO}_{2}$ was used alone, only $32 \%$ of conversion was observed, while the dyesensitized systems furnished quantitative reduction within $96 \mathrm{~h}$. The limited substrate scope of fluorinated acetophenones was tested with $\mathrm{Fl}-\mathrm{TiO}_{2}$ and $\mathrm{RB}-\mathrm{TiO}_{2}$, as depicted on Scheme 20. The

Scheme 20. Photocatalytic Reduction of Acetophenones Using Dye-Sensitized $\mathrm{TiO}_{2}$ under Visible-Light Irradiation

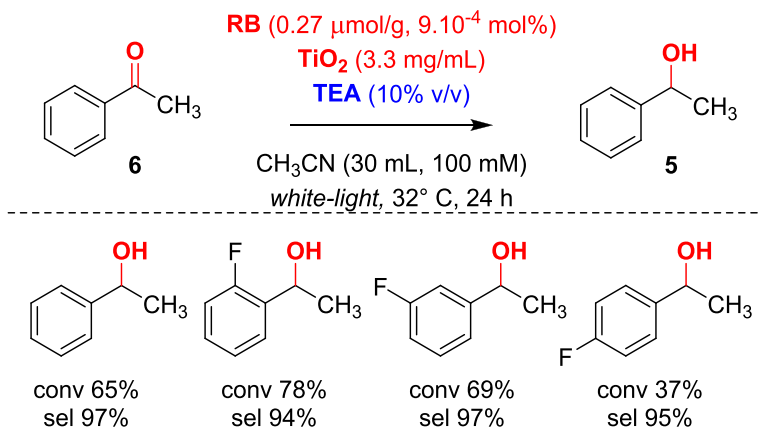

catalysts were recycled after use, albeit with a rapid decrease in reactivity, because of photobleaching. In the case of the parasubstituted fluorinated acetophenone, a competitive defluorination reaction occurred. Interestingly, this side reaction did not happen with pure $\mathrm{TiO}_{2}$ as a catalyst.

Later, Kominami et al. reported a photocatalytic system composed of 2,3-dihydroxynaphthalene (2,3-DN) and $\mathrm{TiO}_{2}{ }^{135}$ The catechol group is able to anchor on the titania surface and to induce visible-light sensitization through the formation of a charge-transfer complex. ${ }^{136}$ This strategy was used to achieve the selective and almost quantitative reductions of benzaldehydes 2 to their corresponding benzylic alcohols $\mathbf{1}$. They noticed that $\mathrm{TiO}_{2}$ powders suspended in a methanol solution containing 2,3-DN immediately changed color from white to pale yellow, because of the formation of the visible-light-absorbing surface complex. Triethanolamine (TEOA) was used to regenerate the oxidized catechol and also to deliver a source of protons for the reaction. In a typical run, $2,3-\mathrm{DN} / \mathrm{TiO}_{2}$ was suspended in $\mathrm{CH}_{3} \mathrm{CN}$ and benzaldehyde and TEOA were added under argon, and then irradiated with blue LED while stirring at $25{ }^{\circ} \mathrm{C}$ (see Scheme 21). The photoinjected electrons in the CB showed good

Scheme 21. Chemoselective Reduction of Aromatic Aldehydes with 2,3-DN/ $\mathrm{TiO}_{2}$ under Visible-Light Irradiation

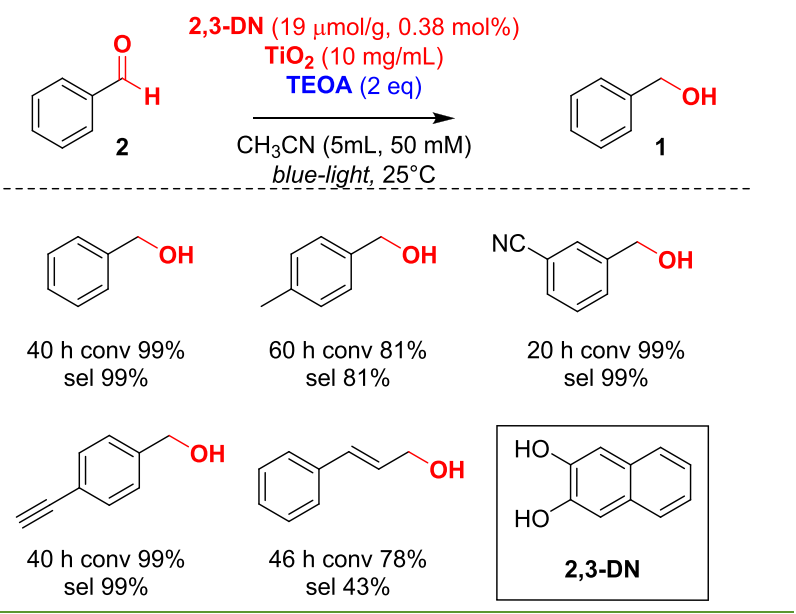

selectivity for the reduction of aldehyde groups, even in the presence of highly sensitive functional groups such as halogens or unsaturated $\mathrm{C}-\mathrm{C}$ and $\mathrm{C}-\mathrm{N}$ bonds. EDGs in the para-position were shown to reduce the reaction rate, providing limited conversions.

\section{REDUCTIONS OF NITRO GROUPS}

Aromatic nitration followed by reduction to give aniline derivatives is an important industrial synthetic route. However, it requires hydrogenation, which is catalyzed by rare-earth transition-metal catalysts. ${ }^{132}$ Therefore, sensitized semiconductors represent a potentially more sustainable class of catalysts.

In this regard, Kominami et al. explored the possibility of developing a noble-metal-free and $\mathrm{H}_{2}$-free photocatalytic system, with the aim of expanding the substrate scope to compounds bearing sensitive functional groups to classical catalytic hydrogenation conditions. ${ }^{137}$ They took advantage of the high chemoselectivity of the $\mathrm{TiO}_{2}$ photogenerated electrons toward the nitro group of aromatics, using the same photosensitization with 2,3-DN. The potential of electrons in the $\mathrm{TiO}_{2} \mathrm{CB}$ generated by UV irradiation was already reported to be appropriate for the reduction of nitro groups. ${ }^{138}$ In these transformations, the 
corresponding nitro compounds $\mathbf{3 8}$ are reduced to the corresponding anilines 19 via the formation of nitroso (39) and hydroxylamine (40) intermediates. The authors hypothesized that such a mechanism also could occur using the 2,3-DN-sensitized $\mathrm{TiO}_{2}$ photocatalytic system (Scheme 22). A spectrophotometric

Scheme 22. $\mathrm{H}_{2}$ - and Noble-Metal-Free Photoreduction of Nitroaromatics with Reducible Groups, Catalyzed by 2,3-DN/ $\mathrm{TiO}_{2}$

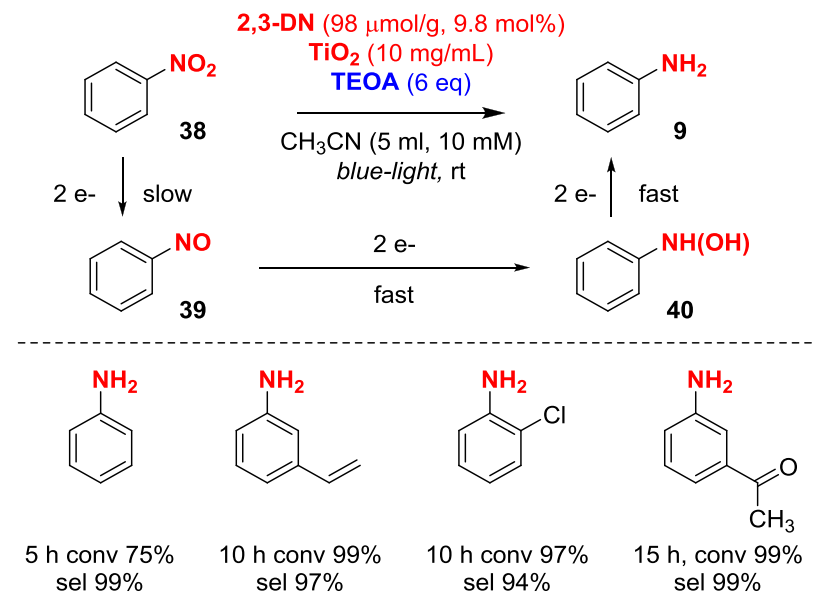

investigation proved that the reduction was induced by photonic absorption of 2,3-DN/TiO 2 . Nitroso and hydroxyamino intermediates (namely, 39 and 40) were not detected but the authors suggested that the rate of reduction of these could be higher than that of the ones detected and/or that such intermediates could remain strongly adsorbed on the surface of $\mathrm{TiO}_{2}$. They highlighted that the reaction rate was largely affected by the adsorption sites available on the surface of the photocatalyst: therefore, a large photocatalyst surface is fundamental for high efficiency, and an excess of 2,3-DN reduces the performances of the photocatalyst. This was explained with the large number of electrons required to complete the reduction, making substrate adsorption a dominant factor for the reaction to progress. The authors also demonstrated that such a catalytic system proceeds with very high chemoselectivity.

Similarly, Yamashita et al. prepared $\mathrm{TiO}_{2}$ functionalized with Pt nanoparticles, which, upon sensitization with 2,3-DN, could catalyze the visible-light photocatalytic reduction of nitrobenzene 38 to aniline 19. ${ }^{139}$ The modified semiconductor was obtained by photodeposition of $\mathrm{Pt}$ nanoparticles from a deaerated aqueous methanol mixture of $\mathrm{TiO}_{2}$ nanoparticles and $\mathrm{H}_{2} \mathrm{PtCl}_{6}$ under UV light. The average diameter of the Pt particles was determined to be ca. $3.4 \mathrm{~nm}$, and the content was determined to be $1 \mathrm{wt} \%$. The noble metal was proposed to abstract electrons from the $\mathrm{CB}$ to catalyze $\mathrm{H}_{2}$ evolution. The authors explored different hydroxynaphthalenes as sensitizers reporting that, again, adjacent hydroxyl groups are more suited for the formation of stable bidentate structures; in particular, 2,3-DN/Pt@TiO 2 showed a higher yield for the nitrobenzene reduction. They also observed a color change upon immersion of $\mathrm{Pt}-\mathrm{TiO}_{2}$ into the solution of 2,3-DN, indicating an LMCT between the surface Ti atoms and the naphthol responsible for the photocatalyst direct excitation. The photocatalytic reduction of nitrobenzene in the presence of the photocatalyst and TEOA in $\mathrm{CH}_{3} \mathrm{CN}$ yielded aniline with $43 \%$ conversion and $75 \%$ selectivity under argon and visible-light irradiation by a filtered xenon arc lamp in just $2 \mathrm{~h}$ (Scheme 23).
Scheme 23. Photocatalytic Reduction of Nitrobenzene with Platinized $\mathrm{TiO}_{2}$ Sensitized with Hydroxynaphthalenes

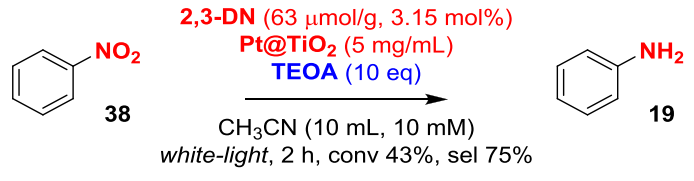

König et al. reported a photocatalytic system bearing analogies with well-established systems used in the dye-sensitized solar cell field to reduce nitro compounds (38). Here, $\mathrm{TiO}_{2}$ is sensitized with a bipyridyl-ruthenium organometallic dye (N3) ${ }^{140}$ and coupled with a platinum salt used as a precatalyst to form colloidal Pt in situ (see Scheme 24). TEOA was also used as an

Scheme 24. Photoreduction of Nitrobenzenes with N3-Sensitized $\mathrm{TiO}_{2}$ Photocatalyst and In Situ Pt Colloids Co-catalyst ${ }^{a}$

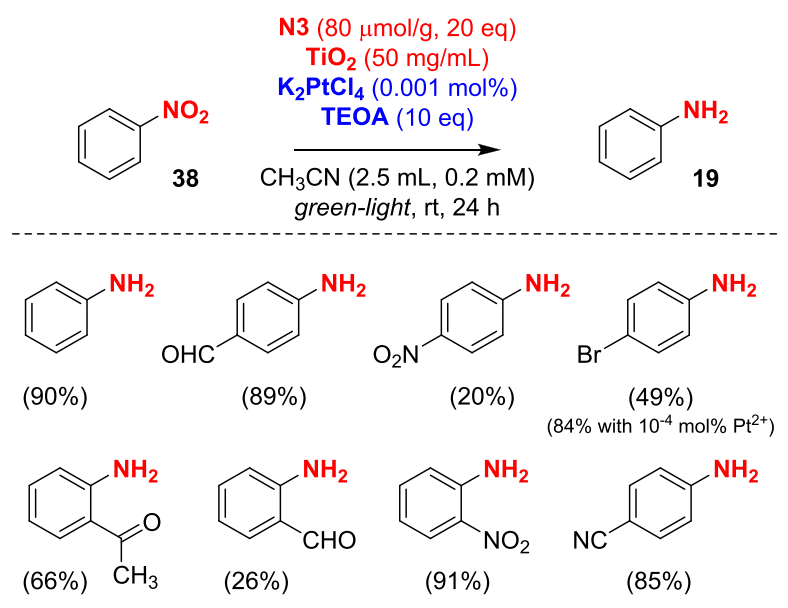

${ }^{a}$ Yields determined by gas chromatography are reported in brackets.

electron and proton source. The amount of $\mathrm{K}_{2} \mathrm{PtCl}_{4}$ was found to be a key driver in enhancing conversion and selectivity in the reductions of nitrobenzene derivatives to the corresponding anilines. A range of $\mathrm{K}_{2} \mathrm{PtCl}_{4}$ loadings from $0.0001 \mathrm{~mol} \%$ to $0.5 \mathrm{~mol} \%$ was reported by the authors. The reaction was not sensitive to radical scavengers, suggesting a nonradical mechanism. Based on this, the authors suggested a reaction mechanism where, upon visible-light irradiation, the $\mathrm{Ru}$ dye is excited to an excited singlet that undergoes intersystem crossing to form a long-lasting triplet state. The excited dye injects an electron into the CB. This electron is transferred to the $\mathrm{Pt}$ center, which is acting as a weak temporary electron scavenger and produces $\mathrm{H}_{2}$ by abstracting one proton from TEOA. TEOA is also responsible for the reduction of the dye to its ground state, while the radical-free reduction of 4-nitrophenol is facilitated by the developed $\mathrm{H}_{2}$ pressure. In a subsequent study, the same authors demonstrated also that traces amounts of urea derivatives could enhance the reaction rate by catalyzing the proton transfer process. ${ }^{141}$

Ananthakrishnan et al. studied a modification of the system reported by König, exploiting $\mathrm{ZnO}$ as a semiconductor instead of the more common $\mathrm{TiO}_{2}$, to perform the $\mathrm{H}_{2}$-mediated transformation of 4-nitrophenol $41(0.02 \mathrm{mM})$ in 4-aminophenol 42. ${ }^{142} \mathrm{ZnO}$ was sensitized with the complex bis(2,20-bipyridyl)(4,40-dicarboxy-2,20-bipyridyl)ruthenium(II) chloride ([Ru(bpy) $\left.)_{2}(\mathrm{dcbpy})\right] \mathrm{Cl}_{2}$ ) (see Scheme 25$)$, the authors explained that the carboxylic functions operate as anchoring groups, 
Scheme 25. Ru(II)-Complex-Sensitized $\mathrm{ZnO}$ for Photocatalytic Reduction of 4-Nitrophenol in the Presence of Pt(II) Co-catalyst

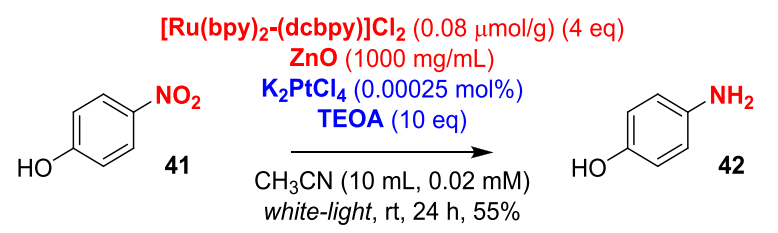

although, in this case, the reported surface coverage was 3 orders of magnitude lower than the one reported for the $\mathrm{N} 3$ dye. The photocatalyst still required $\mathrm{K}_{2} \mathrm{PtCl}_{4}$ as a co-catalyst $(2.5 \times$ $10^{-4} \mathrm{~mol} \%$ ) and TEOA as an electron and proton donor $(0.2 \mathrm{mM})$; interestingly, the authors also noticed that the moisture helped the photocatalytic reduction, by acting as a source of protons. Finally, X-ray photoelectron spectroscopy studies of the photocatalyst after use revealed that, unlike the previously reported system, the Pt clusters were deposited on the surface of $\mathrm{ZnO}$.

\section{REDUCTIONS OF ALKYNES}

Recently, Kominami's research group reported that 2,3-DN could also be used to sensitize $\mathrm{TiO}_{2}$ nanoparticles functionalized with copper in order to promote the visible-light diastereoselective semihydrogenation of alkynes 43 to cis-alkenes $\mathbf{4 4} .^{143}$ Photodeposition of $\mathrm{Cu}$ from $\mathrm{CuCl}_{2}$ water/methanol solution on the preformed 2,3-DN/ $\mathrm{TiO}_{2}$ afforded the photocatalyst having two functionalizations: the organic one for visible-light responsiveness, and the metallic one for the semihydrogenation activity. Therefore, as the 2,3-DN/ $\mathrm{TiO}_{2}$ complex generates electrons in the $\mathrm{CB}$ of $\mathrm{TiO}_{2}$ under visible-light irradiation, $\mathrm{Cu}$ abstracts the charges and catalyzes the activation of $\mathrm{H}^{+}$from water. The active hydrogen species perform the reduction on the metal surface ensuring selectivity toward the cis-diastereomers. The authors detected $\mathrm{H}_{2}$ evolution as a competitive process happening on the same active sites as the ones performing the semihydrogenation. By increasing the reaction temperature to $56{ }^{\circ} \mathrm{C}$, the reaction rate would be more affected by the frequency factor, which is higher in the case of the semihydrogenation reaction, instead of the activation energy favoring $\mathrm{H}_{2}$ evolution. They proved the reaction to be photocatalyzed by 2,3-DN/Cu@ $\mathrm{TiO}_{2}$, showing a good overlap between the action spectra and the photocatalyst absorption and measured a TON of 250, with respect to the dye, on a larger reaction scale $(110 \mathrm{mM})$. Exploring polyfunctional substrates in the reaction scope allowed the authors to study the chemoselectivity of the semihydrogenation reaction for both terminal and internal alkynes against other competitive processes, such as the oxidation of alcohols or the reductive elimination of halogenated groups (see Scheme 26). Finally, the authors tested the stability of the photocatalyst and demonstrated a recyclability of at least 4 reaction cycles without losing efficiency and selectivity.

\section{COUPLING REACTIONS}

Net Oxidative Couplings. Examples of applications of sensitized semiconductors for the visible-light photocatalyzed $\mathrm{C}-\mathrm{C}$ and $\mathrm{C}-$ heteroatom bond formations are still relatively limited but are expected to be increasingly developed, because of the importance of such transformations in organic synthesis. ${ }^{144,145}$

Rueping et al. investigated a three-component, Ugi-type reaction for the $\alpha$-functionalization of $N, N$-dimethylaniline (45)
Scheme 26. Visible-Light Photocatalytic Semihydrogenation Alkynes in a Water- $\mathrm{CH}_{3} \mathrm{CN}$ Suspension of 2,3-DN/Cu@ $\mathrm{TiO}_{2}$

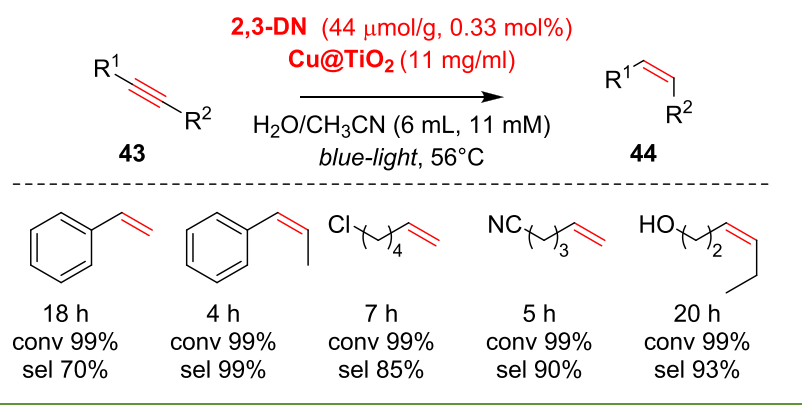

yielding $\alpha$-amino amides (47). ${ }^{146}$ The first step of this cascade reaction is the photocatalytic oxidation of a tertiary aniline into the corresponding iminium ion $\mathbf{4 8}$ via direct excitation of the $\mathrm{TiO}_{2}$-amine complex. After this first key step, a nucleophilic attack of isocyanide 46 generates the nitrilium ion 49. This nitrilium ion is trapped by water, affording the amide 47 after hydrolysis. The general procedure for the photocatalytic synthesis consisted of irradiation with an $11 \mathrm{~W}$ lamp of a suspension of $\mathrm{TiO}_{2}$ in a solution of 2 equiv of the tertiary aniline and 1 equiv of isocyanide in $\mathrm{H}_{2} \mathrm{O}$ /dioxane (see Scheme 27). One of

Scheme 27. Synthesis of $\alpha$-Amino Amides Via Ugi-Type Reaction Initiated by Visible-Light Photocatalytic Oxidation on $\mathrm{TiO}_{2}{ }^{a}$

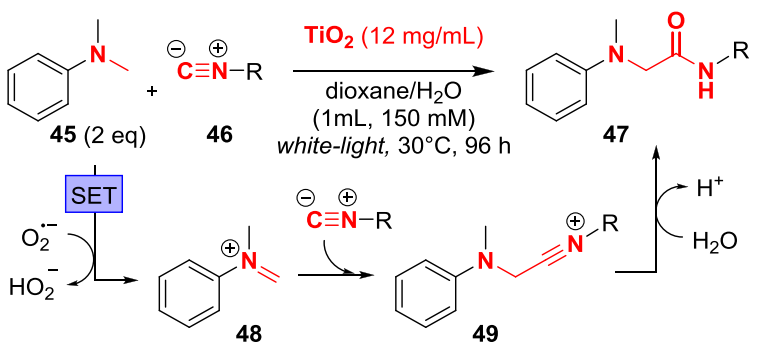<smiles>Cc1ccc(S(=O)(=O)CNC(=O)CN(C)c2ccc(Cl)cc2)cc1</smiles><smiles>COC(=O)CNC(=O)CN(C)c1ccccc1</smiles>

${ }^{a}$ Isolated yields are reported in brackets.

the drawbacks of the synthesis is the relatively long reaction time ( $\sim 4$ days) but conveniently, several anilines and different isocyanides were successfully reacted, providing the desired $\alpha$-amino amides in moderate to good yields and good functional group tolerances.

The same group also reported a set of photocatalytic reactions for the oxidative dehydrogenative cross-coupling of tetrahydroisoquinoline $\mathbf{5 0}$ with four different nucleophiles, photocatalyzed by sensitized semiconductors. In these examples, the absorption of visible light is due to the interaction between the semiconductor and the substrate itself. ${ }^{147}$ This induces an oxidative process that results in the formation of an iminium ion, which is trapped by a nucleophile. $\mathrm{TiO}_{2}$ was used in the presence of 
nitromethane to give the oxidative aza-Henry reaction to $\beta$-nitro amines 51. Acetone gave the oxidative Mannich reaction to $\beta$-amino ketones 52 and potassium cyanide yielded $\alpha$-amino nitriles 53. In the presence of $\mathrm{ZnO}$ and diethyl phosphite, a similar process was achieved, namely, a phosphonylation reaction to give amino-phosphonates 54 (Scheme 28). Even if it is not

Scheme 28. From Top to Bottom: Oxidative Aza-Henry Reaction, Oxidative Mannich Reaction, Oxidative Cyanation, and Oxidative Phosphonylation of Tetrahydroisoquinoline Photocatalyzed by Dye-Sensitized Semiconductors under Visible Light

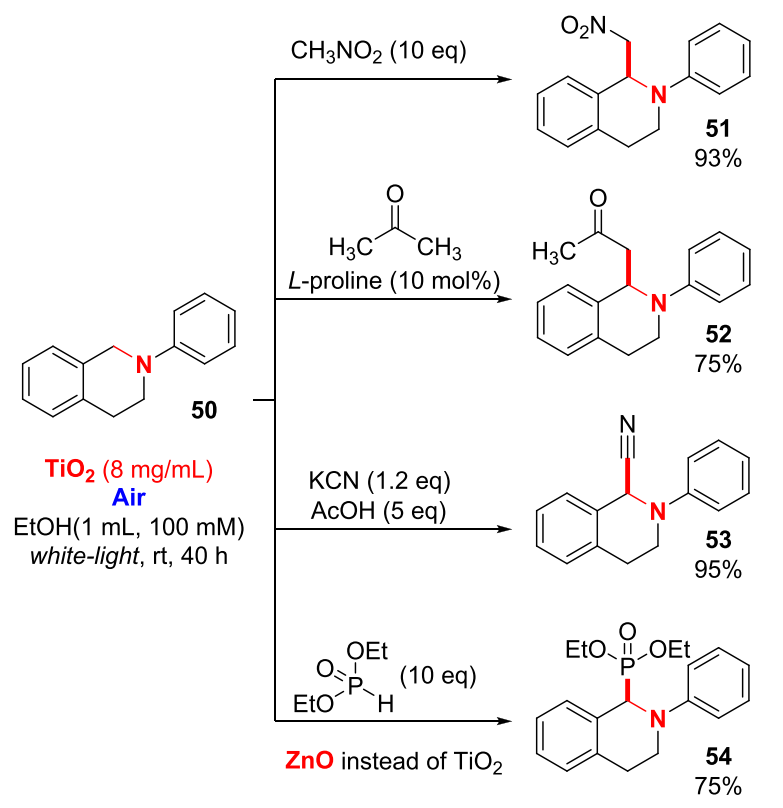

reported by the authors, one can assume that the visible-light photo-oxidation occurs because of the direct excitation of the semiconductor-amine surface complex under air at atmospheric pressure, acting as the final electron acceptor. This mechanism was recently reported by others. ${ }^{148}$ Interestingly, the semiconductor was used in stoichiometric amounts, but the reaction could also be performed under catalytic conditions and an efficient recycling was demonstrated after multiple consecutive catalytic cycles performed without any loss in reactivity and selectivity.

In a similar manner, Opatz et al. recently reported a panchromatic photocatalytic oxidative cyanation of tertiary amines 14 to $\alpha$-cyano amines 55 using $\mathrm{TiO}_{2}$ sensitized with a quinolinium chromophore, absorbing UV to visible and near-infrared light. ${ }^{149}$ This work reports one of the first examples of molecule specifically designed to perform visible-light sensitization of a semiconductor to perform photocatalysis. 6,7-Dihydroxy-2-methylisoquinolinium (DHMIQ) was rationally designed to display both the properties of a chromophore and those of a complexing agent. This catalytic system enables faster photoconversion, compared to the previous ones, following the path of direct excitation of the semiconductor surface complex. $\mathrm{DHMIQ} / \mathrm{TiO}_{2}$ was found to be able to oxidize the tertiary amine $\mathbf{1 4}$ to the corresponding radical cation 15, even under low-energy-wavelengths activation. Moreover, the low photobleaching allowed one to reach high TONs with no need for a TEMPO co-catalyst (Scheme 29) The superoxide radical produced on the $\mathrm{TiO}_{2}$ surface displaces $\mathrm{CN}^{-}$ from trimethylsilyl cyanide (TMSCN) to form a trimethylsilylperoxo species, which can then abstract a $\mathrm{H}^{\bullet}$ radical from 15 to generate an iminium ion 16. The nucleophilic addition of $\mathrm{CN}^{-}$
Scheme 29. Proposed Mechanism for the Oxidative Cyanation of Tertiary Amines Catalyzed by DHMIQSensitized $\mathrm{TiO}_{2}{ }^{a}$

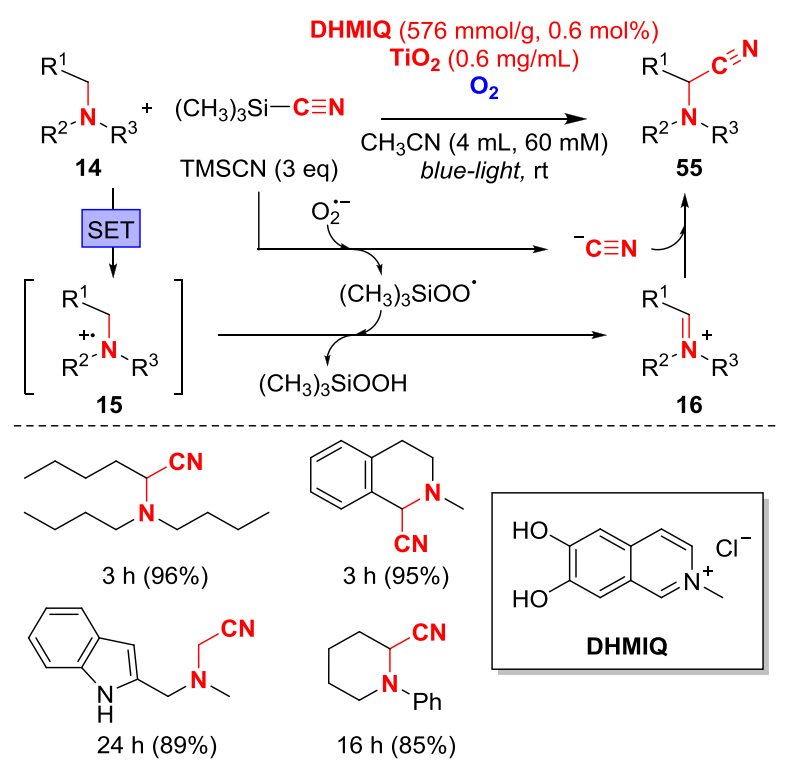

${ }^{a}$ Isolated yields are reported in brackets.

on 16 gives the product 55. In a typical reaction, the catalyst was suspended in the substrate solution in dry $\mathrm{CH}_{3} \mathrm{CN}$ and the solution was saturated with oxygen. After the addition of TMSCN ( 3 equiv), the solution was irradiated with a $100 \mathrm{~W}$ blue LED for $3 \mathrm{~h}$. The authors reported that water can decrease yields, because of the formation of a hydration shell passivating the polar nanoparticles of sensitized $\mathrm{TiO}_{2}$ and hampering surface reactions. Moreover, they tested the reaction with other light sources and, surprisingly, also IR radiation at $850 \mathrm{~nm}$ gave photocyanation, accounting for the very broad absorption spectrum of the $\mathrm{TiO}_{2}$-DHMIQ photocatalyst, which could also be recovered and reused several times with moderate drops in yields.

Similarly, an $\mathrm{AR} / \mathrm{TiO}_{2}$ photocatalyst was recently employed to perform the thiocyanation of electron-rich aromatic compounds via direct functionalization of $\mathrm{sp}^{2} \mathrm{C}-\mathrm{H}$ bonds. ${ }^{150}$ Considering the redox potentials, the authors proposed a different mechanism, relying on the SET from the $\mathrm{AR}^{\bullet+}$ species with a thiocyanate anion to produce a thiocyanate radical, which attacks the arene and affords the products.

A more multivalent functionalization was studied by Cong et al., who reported a decarboxylative alkylation of $\mathrm{N}$-aryl tetrahydroisoquinolines $\mathbf{5 0}$ on the benzylic position under the irradiation with blue light, using EB-sensitized $\mathrm{TiO}_{2}$ as a catalyst. ${ }^{151}$ $\mathrm{N}$-hydroxyphthalimide esters $\mathbf{5 6}$ were used as precursors for unactivated alkyl radicals to obtain the tetrahydro-isoquinolines derivatives 57. According to the authors, under visible-light irradiation, the photoexcited $\mathrm{EB}$ would inject an electron into the $\mathrm{CB}$ of $\mathrm{TiO}_{2}$ and then reduce the starting material 56, via a hydrogen-bond-assisted electron transfer, to generate the radical anion intermediate 59. Homolytic cleavage of the $\mathrm{N}-\mathrm{O}$ bond of intermediate 59, followed by the release of phthalimide anion and $\mathrm{CO}_{2}$, should afford an alkyl radical. The other starting material would quench the oxidized form of EB, generating a radical cation intermediate, which, upon deprotonation, could form a benzylic radical 58. Finally, the radical-radical coupling would provide product 57 (Scheme 30). Protic solvents were found to play a critical role in assisting the reduction at the $\mathrm{CB}$, 
Scheme 30. Decarboxylative Alkylation of Tetrahydroisoquinolines Using EB-Sensitized $\mathrm{TiO}_{2}$ as a Visible Photocatalyst

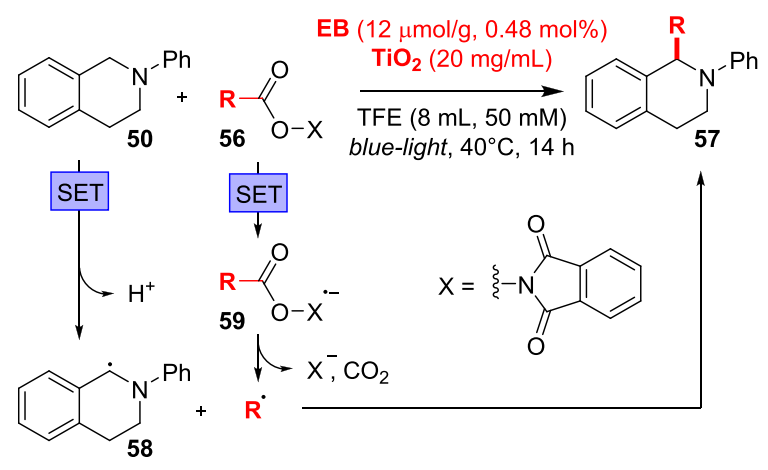<smiles>CC(C)C1c2ccccc2CCN1c1ccccc1</smiles>

$(85 \%)$<smiles>c1ccc(N2CCc3ccccc3C2C2CCC2)cc1</smiles>

$(90 \%)$<smiles>CC(C)(C)C1c2ccccc2CCN1c1ccccc1</smiles>

$(74 \%)$<smiles>O=C1CCC(C2c3ccccc3CCN2c2ccccc2)CC1</smiles>

$(44 \%)$<smiles>c1ccc(CCCC2c3ccccc3CCN2c2ccccc2)cc1</smiles>

$(87 \%)$

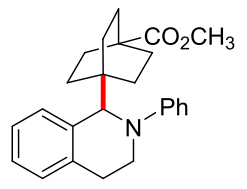

$(54 \%)$ with 2,2,2-trifluoroethanol (TFE) affording the highest yield. The reaction was irradiated with two blue LEDs and the temperature was maintained at $40^{\circ} \mathrm{C}$. EDG and EWG substituents of the $\mathrm{N}$-phenyl moieties of tetrahydro-isoquinolines were welltolerated, as well as the bulkier naphthyl group. Notably, satisfactory yields could be obtained, regardless of the steric hindrance of the alkyl groups, and a wide range of functional groups were found to be compatible.

Hosseini-Sarvari et al. studied the reaction of $N, N$-dimethylanilines $\mathbf{4 5}$ with maleimides $\mathbf{6 0}$ to prepare tetrahydroquinolines $\mathbf{6 1}$ through a visible-light-promoted [4+2] cyclization catalyzed by $\mathrm{AR} / \mathrm{TiO}_{2}{ }^{75}$ A computational analysis confirmed the feasibility of electron injection of the excited $A R$ and subsequent quenching of $\mathrm{AR}^{\bullet+}$ by aniline 45 . The authors proposed that the obtained cationic radical evolves via deprotonation to the $\alpha$-amino radical 62. At this stage, the $\alpha$-amino radical reacts with maleimide 60 via a nonconcerted radical cycloaddition that terminates with electron and proton separation, yielding the product 61 (Scheme 31). Interestingly, during the optimization of the reaction, the authors explored various conditions, reporting higher performances in an air environment rather than with pure oxygen, and yields under sunlight irradiation were found to be as good as those obtained with blue LEDs. The scope of the reaction was expanded by reacting the same aniline substrate with different maleimides, and vice versa. Substituents in the aniline ring were shown to have a greater impact on the reaction yields than $\mathrm{N}$-substituents on the maleimide ring. In particular, electron-rich anilines gave high yields, while strong EWG-substituted ones, such as nitro groups, were found to be unreactive.

Another example of the previously discussed capability of aromatic compounds lacking electron-rich substituents to be able to complex the semiconductor surfaces (see the section titled "Oxidation of Hydrocarbons"), was reported by Yoshida et al.; they studied the selective oxidative cross-coupling between
Scheme 31. Visible-Light Aerobic Cyclization of Tertiary Anilines with Maleimides Photocatalyzed by $\mathrm{AR}^{-\mathrm{TiO}_{2}}{ }^{a}$

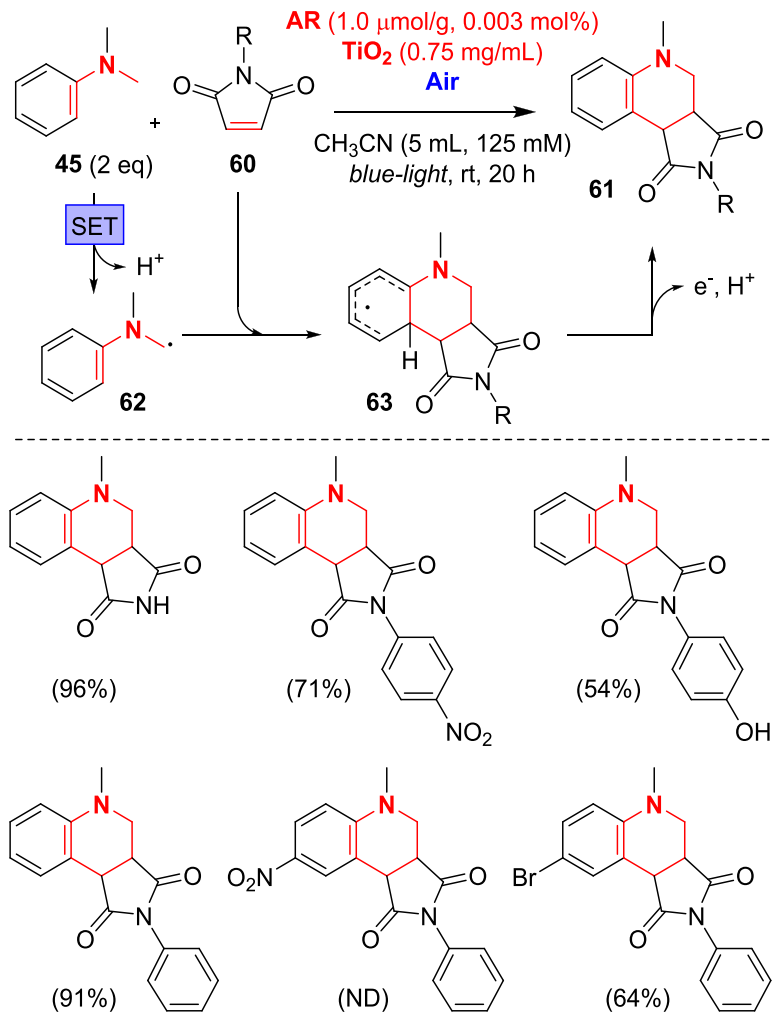

${ }^{a}$ Isolated yields are reported in brackets.

benzene (64) and cyclohexane (65) photocatalyzed by Pd decorated $\mathrm{TiO}_{2}$ nanoparticles under visible-light irradiation (Scheme 32). ${ }^{152}$ Interestingly, the authors compared the process performed with the same catalyst under visible light and UV light. The first light source yielded almost only the cross-coupling product 66 , because of a more selective radical activation preventing homocoupling of benzene or cyclohexene, which was instead detected with UV-light irradiation. While $\mathrm{TiO}_{2}$ accepts an electron and releases the phenyl radical cation, the $\mathrm{Pd}$ co-catalyst accelerates the addition of the cyclohexyl radical 68 to benzene and the proton reduction to $\mathrm{H}_{2}$. Note that the authors do not mention the possibility that visiblelight absorption could arise from the functionalization of $\mathrm{TiO}_{2}$ with Pd nanoparticles.

Scheme 32. Radical Oxidative Cross-Coupling Activated under Visible-Light Irradiation

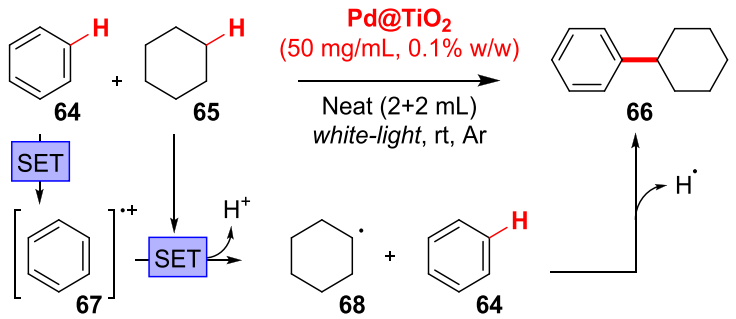

Redox Neutral Couplings. The anti-Markovnikov addition of thiols to alkenes or alkynes known as the thiol-ene coupling stands out as a landmark example of radical reactions. This transformation is known to occur under UV-light irradiation and recent developments using organometallic homogeneous photocatalysts have enabled activation with visible light. ${ }^{153,154}$ More 
recently, Greaney et al. reported that semiconductors such as $\mathrm{TiO}_{2}$ could significantly accelerate the radical thiol-ene coupling under visible-light irradiation. ${ }^{155}$ An excess of thiols 67 (4 equiv) can react with the unactivated alkenes 68, using $\mathrm{TiO}_{2} \mathrm{P} 25$ under visible-light irradiation (Scheme 33). The reaction was tested in

Scheme 33. Visible-Light-Promoted Thiol-ene Reaction Using $\mathrm{TiO}_{2}{ }^{a}$

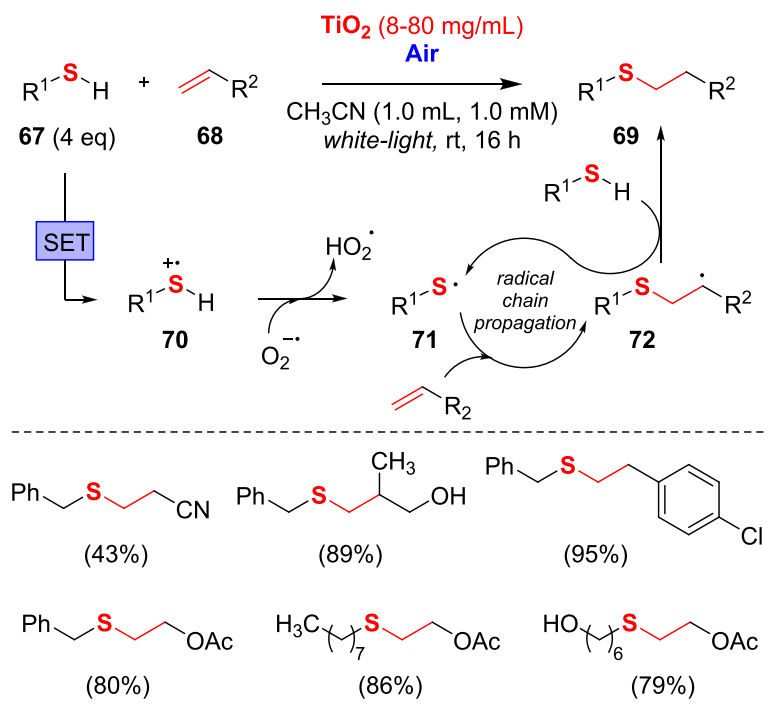

${ }^{a}$ Isolated yields are reported in brackets.

$\mathrm{CH}_{3} \mathrm{CN}$ and $\mathrm{CH}_{2} \mathrm{Cl}_{2}$, and under solvent-free conditions, and appeared to perform almost equally well in all cases, while whitelight resulted in higher conversions, compared to blue LED light. The authors suggested that aromatic thiols could engage visiblelight activation through LMCT with $\mathrm{TiO}_{2}$, as recently proven also for other semiconductors. ${ }^{156}$ Then holes in the VB could be reductively quenched by the thiol, generating a thiyl radical cation (70), while the electrons in the $\mathrm{CB}$ would reduce oxygen to $\mathrm{O}_{2}{ }^{\bullet-}$. The superoxide can then easily deprotonate the thiyl radical cation yields a thiyl radical 71 and initiate the thiol-ene reaction and chain propagation through the alkyl radical 72 . The reaction scope shows a broad functional group tolerance and improved yields compared to reactions performed without $\mathrm{TiO}_{2}$. However, the catalytic system remains sensitive to sterically hindered substrates.

Recently, Scaiano and Yoon reported the heterogeneous Diels-Alder reaction of indoles 73 with electron-rich dienes $\mathbf{7 4}$ (see Scheme 34), ${ }^{157}$ which is a transformation that was originally developed by Steckhan and co-workers under homogeneous conditions. ${ }^{158}$ The visible-light absorption $(460 \mathrm{~nm})$ of the surface indole $/ \mathrm{TiO}_{2}$ complex is able to trigger the cycloaddition process via SET from the indole to the semiconductor. ${ }^{159}$ The indole radical-cation undergoes a $[4+2]$ radical cyclization with 1,3-cyclohexadiene 74. After cyclization, the tetrahydrocarbazole radical-cation can oxidize another indole molecule, creating a radical chain propagation. Alternatively, one of the electrons previously injected in the $\mathrm{CB}$ of $\mathrm{TiO}_{2}$ could reduce the radicalcation, thereby terminating the radical reaction. The tetrahydrocarbazole intermediate is eventually trapped by acylation to give the tetracyclic product. Since the Diels-Alder adduct has a lower oxidation potential $\left(E_{1 / 2}=0.46 \mathrm{vs}\right.$. $\left.S C E\right)$, compared to the starting material $\left(E_{1 / 2}=1.07 \mathrm{~V}\right.$ vs. $\left.S C E\right)$, acylation is necessary to avoid overoxidation. The product 75 was isolated in $60 \%$ yield and an endo:exo ratio of 3.6:1. A further improvement of the
Scheme 34. $\mathrm{TiO}_{2}$-Catalyzed Photochemical Diels-Alder Reaction between Indole and 1,3-Cyclohexadiene ${ }^{a}$
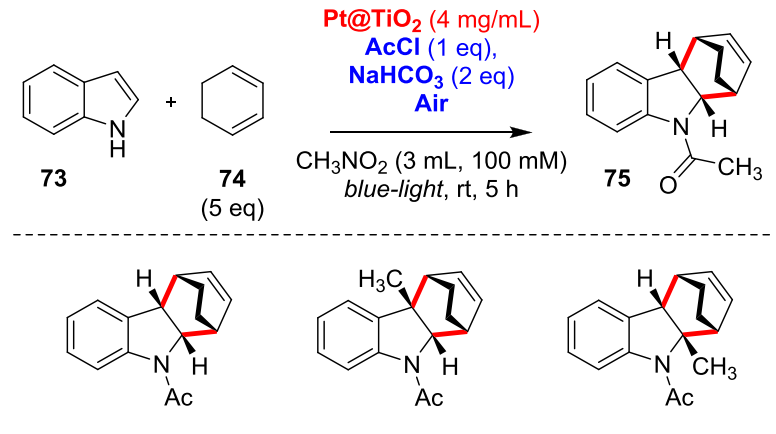

$(72 \%)$

$$
\text { endo/exo }=3.6: 1
$$<smiles>CN1c2ccccc2[C@@]2(C)C3C=CC(C3)[C@]12C</smiles><smiles>CC(C)N1c2ccccc2C2(CC3C=CC2CC3)C1(C)C</smiles>

$(11 \%)$<smiles>CN1c2cc(Cl)ccc2[C@@]2(C)C3C=CC(C3)[C@H]12</smiles>
endo:exo $=2.7: 1$

traces<smiles>CC(C)(C)OC(=O)N1c2ccccc2[C@@]2(C)C3C=CC(C3)[C@H]12</smiles>

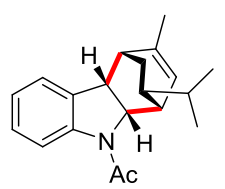

$(56 \%)$ endo: $\mathrm{exo}=3.2: 1$ endo: $\operatorname{exo}=2.9: 1$

$(52 \%)$ endo: exo $=2.1: 1$

${ }^{a}$ Isolated yields are reported in brackets; endo:exo ratios were determined by ${ }^{1} \mathrm{H}$ NMR analysis of the crude reaction mixture.

reaction scope was performed by modifying the heterogeneous catalyst with Pt nanoparticles acting as inhibitors for the electron hole-pair recombination and thereby enhancing, to some extent, the performances of the semiconductor. ${ }^{160}$

Rueping et al. reported a reaction using diazonium salts 76 to perform the direct arylation of heteroaromatic substrates 77 with $\mathrm{TiO}_{2}$ and visible light. The method uses alcohols as solvents and allows the preparation of a large array of aryl-heteroarenes $\mathbf{7 8}$ in good yields. ${ }^{161}$ Right after mixing the reactants, the authors observed a rapid color change of the reaction solution (from colorless to yellow). They investigated the reaction kinetics via UV-vis absorption spectroscopy, which revealed that the diazonium salt reacted with the solvent to give an azoether intermediate 79 absorbing at $412 \mathrm{~nm}$. By comparing the kinetics recorded with and without $\mathrm{TiO}_{2}$, they could demonstrate that the semiconductor is not only responsible for the confinement of the azoether on the surface, forming surface complex $\mathbf{8 0}$ through trans-etherification, but also for catalyzing the formation of the azoether itself. Sensitization of $\mathrm{TiO}_{2}$ by the azoether can absorb visible light, which, upon SET, causes the decomposition of $\mathbf{8 0}$, releasing $\mathrm{N}_{2}$ and generating the aryl radical 81 . The addition of the aryl radical onto the heteroaromatic 77 delivers the radical intermediate 82, which undergoes oxidation with the electron holes in the semiconductor VB releasing 83. Rearomatization of the carbenium ion $\mathbf{8 3}$ gives the product $\mathbf{7 8}$. Operatively, the diazonium salt $(500 \mathrm{mM})$ and $\mathrm{TiO}_{2}(40 \mathrm{mg} / \mathrm{mL})$ were mixed in a $1: 1$ solution $(2 \mathrm{~mL})$ of ethanol and heteroarene and reacted for $12 \mathrm{~h}$ at $\mathrm{rt}$ under irradiation from a compact fluorescent lamp. The reaction was performed in an argon environment, because $\mathrm{O}_{2}$ would compete with the azoether formation for the electron charge transfer in the $\mathrm{TiO}_{2} \mathrm{CB}$ (see Scheme 35). The authors suggested a possible reaction of the substrate with both the electrons in the $\mathrm{CB}$ and the holes in the $\mathrm{VB}$. Moreover, $\mathrm{TiO}_{2}$ acts both with a catalytic effect in the synthesis of the azoether and the photocatalytic one in the radical coupling.

Another example of $\mathrm{C}-\mathrm{C}$ bond formation taking advantage of aryl diazonium salts was reported by Wang et al., who coupled these radical precursors with aryl alkynes to obtain $\alpha$-chloro aryl 
Scheme 35. Visible-Light and $\mathrm{TiO}_{2}$-Mediated Direct Arylation of Arenes with Diazonium Salts under an Argon Inert Atmosphere ${ }^{a}$
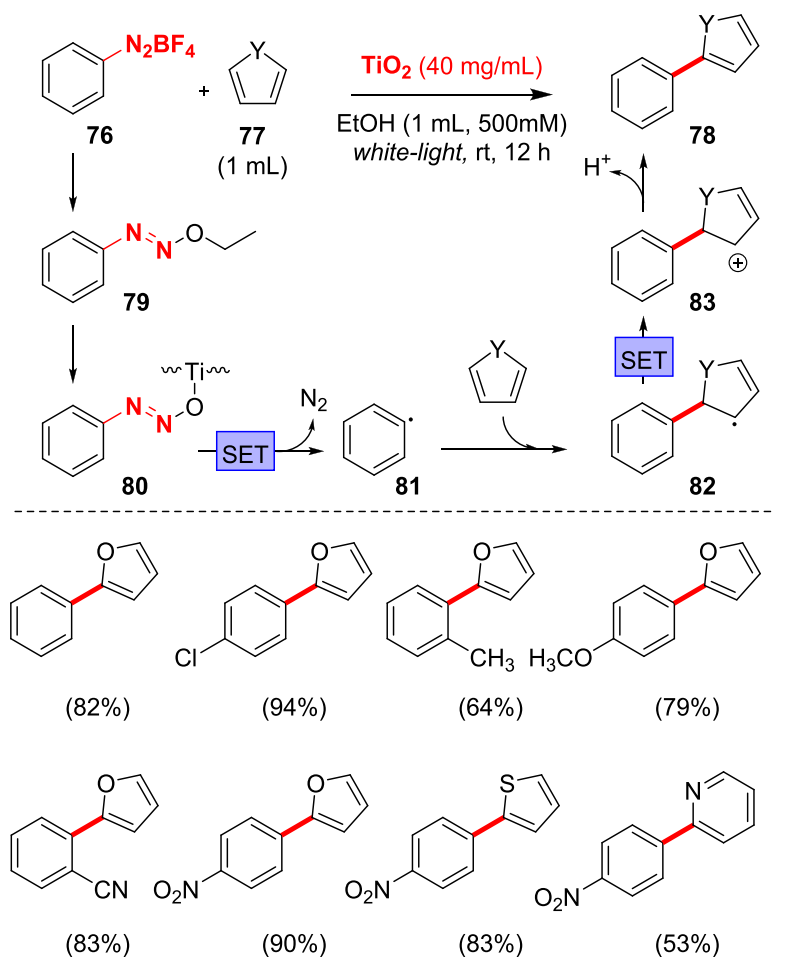

${ }^{a}$ Isolated yields are reported in brackets. $\left(\mathrm{Y}=\mathrm{O}, \mathrm{S}\right.$, or $\left.\mathrm{NCH}_{2}\right)$.

ketones in the presence of a ternary composite photocatalyst made of polyaniline (PANI), graphitic carbon nitride $\left(\mathrm{g}-\mathrm{C}_{3} \mathrm{~N}_{4}\right)$, and $\mathrm{TiO}_{2}{ }^{162}$ Both PANI and $\mathrm{g}-\mathrm{C}_{3} \mathrm{~N}_{4}$ can absorb visible-light and trigger an electron cascade from the excited state into the $\mathrm{CB}$ of the semiconductor (see Figure 7). The process presumably

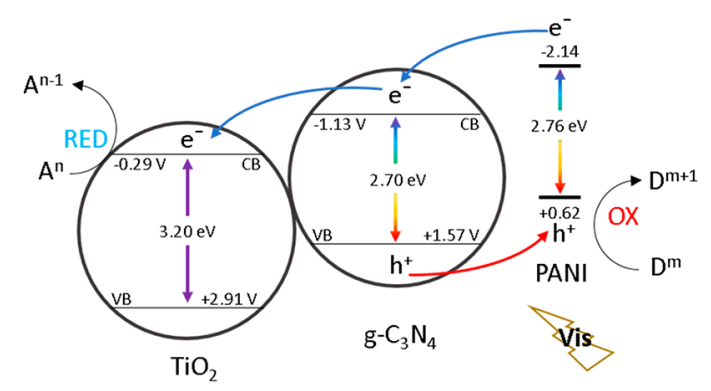

Figure 7. $\mathrm{PANI} / \mathrm{g}-\mathrm{C}_{3} \mathrm{~N}_{4} / \mathrm{TiO}_{2}$ composite: potentials are referenced to NHE.

occurs stepwise via the photoexcitation of PANI and subsequent electron cascade. Holes would flow in the opposite direction, so electron-hole pairs are efficiently separated, and the recombination process is hindered.

On the electron-rich $\mathrm{TiO}_{2}$ surface, reduction of the diazonium salt $\mathbf{7 6}$ to the aryl radical $\mathbf{8 1}$ initiates the radical reaction, which proceeds with the incorporation of $\mathbf{8 4}$. Molecular oxygen, a proton from the solvent, and the $\mathrm{Cl}^{-}$anion are presumed to participate in the radical propagation reaction that eventually terminates with SET oxidation of $\mathbf{9 0}$ operated by $\mathrm{PANI}^{+}$. The quench of the reaction with TEMPO, acting as a radical scavenger, and other benchmark experiments supported the proposed radical pathway. The synergistic effect of the three components in the photocatalyst was proved by the poor yield obtained performing the reaction simply adding $\mathrm{PANI}, \mathrm{g}-\mathrm{C}_{3} \mathrm{~N}_{4}$, and $\mathrm{TiO}_{2}$ to the reaction mixture. In a typical photoreaction, the aryl diazonium tetrafluoroborate, aryl alkyne, $\mathrm{NaCl}$, and $\mathrm{PANI}-\mathrm{g}-\mathrm{C}_{3} \mathrm{~N}_{4}-\mathrm{TiO}_{2}$ were dispersed in methanol $(2 \mathrm{~mL})$. The mixture was then irradiated with a $14 \mathrm{~W}$ CFL and stirred at rt under the oxygen atmosphere (1 atm) for $16 \mathrm{~h}$ (see Scheme 36). Only the diazonium salts

Scheme 36. Photocatalyzed Synthesis of $\alpha$-Chloro Aryl Ketones with Polyaniline/g- $\mathrm{C}_{3} \mathrm{~N}_{4} / \mathrm{TiO}_{2}$ Composite ${ }^{a}$

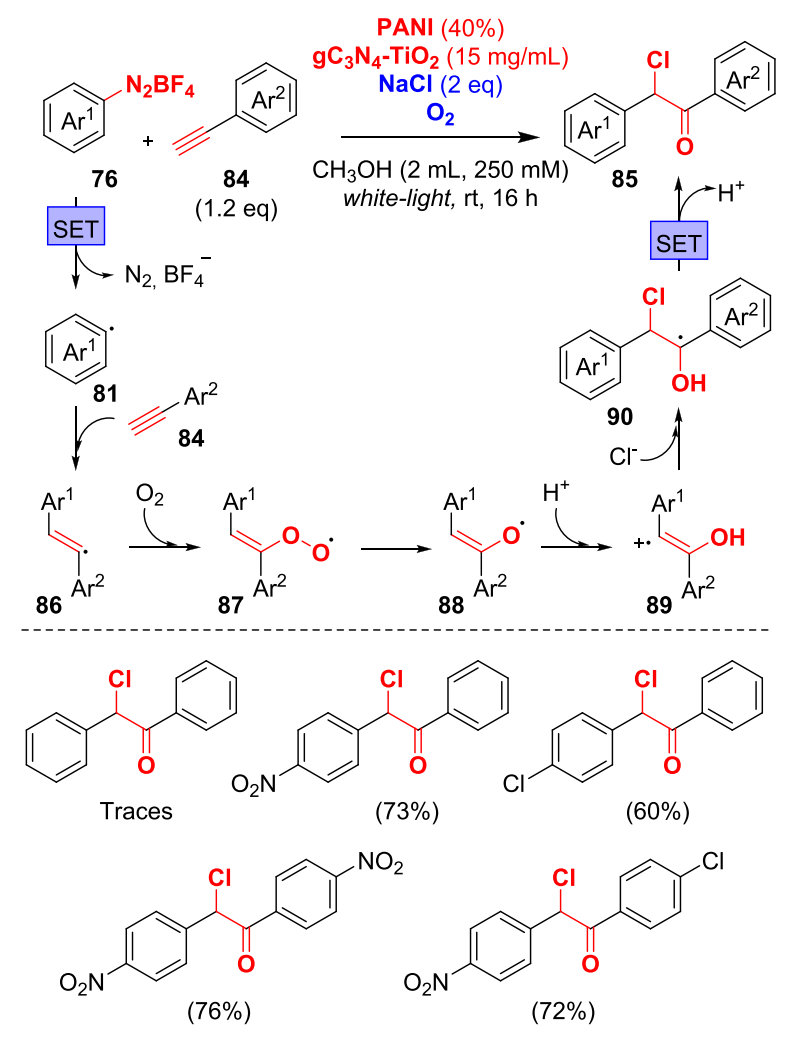

${ }^{a}$ Isolated yields are reported in brackets.

containing EWG reacted with phenylacetylene, because of the low oxidation potential of $\mathrm{PANI}^{+}$, which is unable to oxidize intermediate 90 when an EDG is present. In the case of aromatic alkynes, the reaction proceeds with good functional group tolerance, regardless of EWG or EDG. However, aliphatic alkynes do not react.

The authors demonstrated that the PANI/g- $\mathrm{C}_{3} \mathrm{~N}_{4} / \mathrm{TiO}_{2}$ catalyst was highly stable with a reusability of up to eight cycles without a substantial loss of activity. They further expanded the application of the catalytic system, achieving achieving $\mathrm{C}-\mathrm{H}$ arylation of heteroarenes, enol acetates, and benzoquinones. In a subsequent related study exploiting the same catalytic system, the diazonium salt was generated in situ combining anilines 9 with tert-butyl nitrite $\left(t\right.$-BuONO) and methanesulfonic acid $\left(\mathrm{CH}_{3} \mathrm{SO}_{3} \mathrm{H}\right)$ under aqueous conditions. ${ }^{163}$ The application of the PANI/g- $\mathrm{C}_{3} \mathrm{~N}_{4} /$ $\mathrm{TiO}_{2}$ catalyst was expanded to $\mathrm{C}-\mathrm{H}$ arylation of heteroarenes (77), enol acetates (91), and benzoquinones (93) (see Scheme 37).

In recent years, the same group used the PANI/g- $\mathrm{C}_{3} \mathrm{~N}_{4} / \mathrm{TiO}_{2}$ composite to catalyze the synthesis of unsymmetrical ureas via the photocatalyzed oxidative decarboxylation of oxamic acids under visible-light irradiation, followed by the reaction with an aromatic amine. ${ }^{164}$ This protocol required the use of a hypervalent iodine oxidant (benziodoxole acetate, BI-OAc) but avoided the direct use of environmentally unfriendly isocyanates. 
Scheme 37. C-H Arylation Reactions Catalyzed by a PANI/ g- $\mathrm{C}_{3} \mathrm{~N}_{4} / \mathrm{TiO}_{2}$ Composite ${ }^{a}$

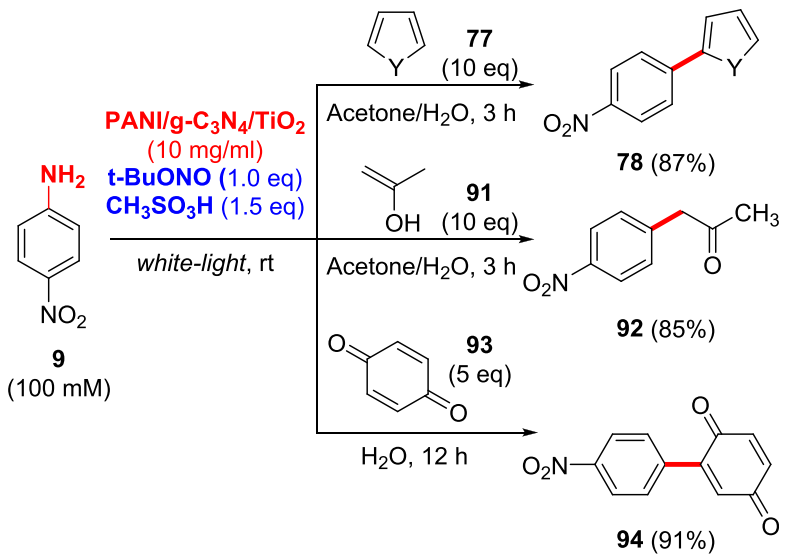

${ }^{a}$ Yields are reported in brackets. $(\mathrm{Y}=\mathrm{O}, \mathrm{S}$, or $\mathrm{N}-\mathrm{Boc})$.

Scheme 38. Enantioselective Michael Addition/

Oxyamination of Aldehydes with $\mathrm{N} 719 / \mathrm{TiO}_{2}$ and Organocatalyst $^{a}$

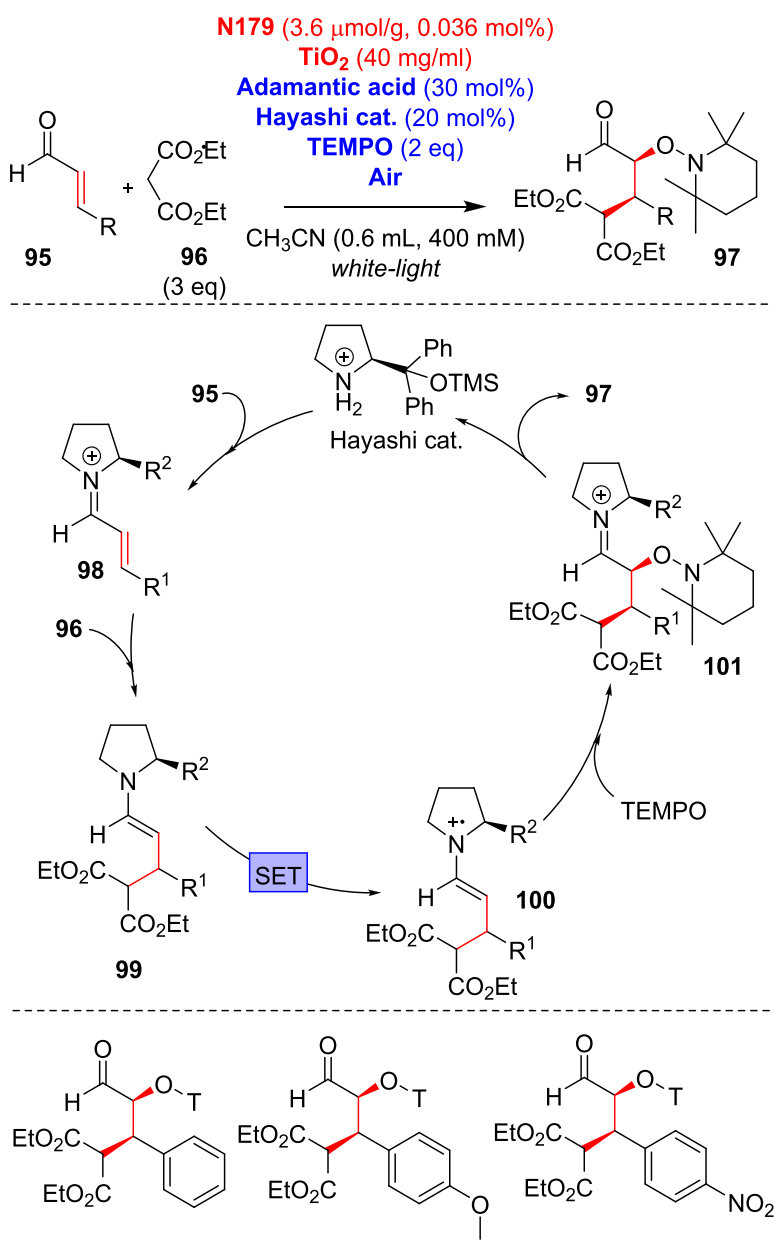

$(80 \%, 99 \%,>95 \%) \quad(79 \%, 98 \%,>95 \%)$

$(53 \%, 99 \%,>95 \%)$

${ }^{a}$ Yields, enantiomeric excess, and diastereomeric excess are reported in brackets. ( $\mathrm{T}=\mathrm{TEMPO})$.

Another example of $\mathrm{C}-\mathrm{N}$ coupling was reported by Shimakoshi and co-workers, who studied the amide formation from trichlorinated organic compounds and trialkylamine photocatalyzed by a
Scheme 39. Enantioselective Alkylation Using MacMillan's Chiral Secondary Amine and $\mathrm{TR} / \mathrm{TiO}_{2}$ as Photocatalysts ${ }^{a}$
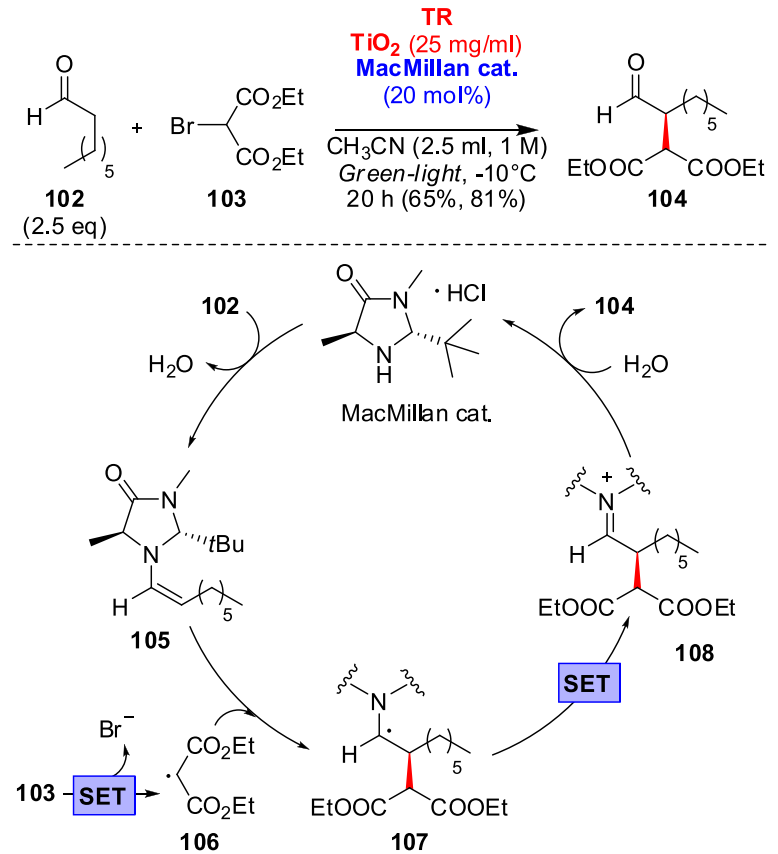

${ }^{a}$ Isolated yields and enantiomeric excess are reported in brackets.

hybrid catalyst composed of vitamin- $\mathrm{B}_{12}$ complex and Rh-ionmodified $\mathrm{TiO}_{2}{ }^{165}$

Enantioselective Transformations. The ability of semiconductors to catalyze enantioselective reactions under visible light was first reported in 2012 by the independent works of two research groups.

Jang et al. took advantage of a Michael-type organocatalyzed process to transfer chirality in a photocatalyzed reaction with a semiconductor. They used an organometallic bipyridine ruthenium complex (N719) grafted on $\mathrm{TiO}_{2}$, a design originally developed for DSSC devices where the electron transfer step between the dye and the semiconductor is fully optimized. ${ }^{166}$ The Hayashi-Jørgensen catalyst was used as a chiral amine, in combination with a carboxylic acid, to transfer chirality during the enantioselective addition of diethyl malonate (96) to an $\alpha, \beta$-unsaturated aldehyde (95). Then, a subsequent diastereoselective $\alpha$-hydroxyamination occurs after a SET process photocatalyzed by the semiconductor. The addition of TEMPO and hydrolysis of the imine afforded the desired product 97 (Scheme 38). The yields were lower when $\mathrm{N} 719$ or $\mathrm{TiO}_{2}$ were used separately, which confirmed the benefits afforded by the combination of the two components. Remarkably, and as in the next example, the amine is not oxidized under these reaction conditions, which enables the reaction to occur with high TONs and high selectivity.

In the meantime, König et al. developed a stereoselective organocatalyzed and photocatalyzed alkylation of aliphatic aldehydes. ${ }^{67}$ In this approach, the enantioselective alkylation of an enamine (105 derived from the condensation of octanal (102) and MacMillan's chiral imidazolidinone organocatalyst) with diethylbromomalonate $\mathbf{1 0 3}$ occurred in the presence of a dyesensitized semiconductor photocatalyst and visible light. This approach was notoriously pioneered by MacMillan in 2008, using $\mathrm{Ru}(\mathrm{bpy})_{3}$ as a photocatalyst. ${ }^{167}$ This new process also bears similarities with the photocatalyst-free blue-light direct photoexcitation of enamines reported later by the Melchiorre group. ${ }^{168}$ In this case, König et al. used Phos-Texas Red (TR) dye to 
sensitize $\mathrm{TiO}_{2}$, which allowed the reaction to operate in $\mathrm{CH}_{3} \mathrm{CN}$ under green or blue light irradiation, yielding the $\alpha$-substituted aldehydes 104 in moderate yields but with high enantioselectivity (Scheme 39).

\section{CONCLUSION}

In the past few years, intense research efforts have been devoted to organic sensitized semiconductors as visible-light photocatalysts in organic synthesis, because of their low cost, high availability, and potentially low toxicity. A large part of these developments has been dedicated to the development of oxidation reactions, but these catalysts also show great promise for reductions, where high chemoselectivity can be achieved. In addition, an increasing number of new examples of coupling reactions, involving $\mathrm{C}-\mathrm{X}$ and $\mathrm{C}-\mathrm{C}$ bond formation, are appearing in the literature, including very promising results in asymmetric catalysis and new developments in cooperative catalysis with transition metals. ${ }^{169,170}$ This demonstrates that sensitized semiconductors, capable of harvesting low-energy visible light to even lower energy infrared light, can achieve excellent performance and broad functional group compatibility. The modular nature of these photocatalysts and the compatibility with different reaction environments, including aqueous media, and additives are the key features for such adaptability.

Among all semiconductors, $\mathrm{TiO}_{2}$ remains the most studied and the best-known semiconductor photocatalyst, but other metal oxides are progressively emerging, such as $\mathrm{Nb}_{2} \mathrm{O}_{5}$ or $\mathrm{ZnO}$. Other than these inorganic semiconductors, the use of organic polymers (such as imidepolyaniline, polyamide, or polydopamine) is currently suggested as a novel research line in the field of heterogeneous photocatalysis. ${ }^{171}$ Several works reviewed herein report that the properties of these semiconductors, such as the nature of the crystalline phase and the surface area are largely affecting the photocatalytic efficiencies. Optimizing the photocatalyst loading is not straightforward, because the balance between dye loading for light absorption and surface active-sites available for the reaction to occur is relatively narrow. Therefore, the screening of different qualities of nanomaterials (which are also highly depending on the source and/or on the commercial supplier) and a careful characterization of the BET surface of the semiconductor and dye-loading are crucial parameters to take into account when assessing the reactivity of photocatalysts.

Organic and organometallic dyes enable extension of the absorption of light by semiconductors to lower energy wavelengths with higher extinction coefficients. When designing such assembled systems, the comparison of the energy levels can be useful to predict the feasibility of the electron injection into the $\mathrm{CB}$. However, once this process has been initiated, the dye radical-cation generated is very sensitive to oxidants, which leads to rapid photobleaching. Since the dye is generally intended to be used in low amounts, finding appropriate conditions to improve its stability in a highly oxidative media is a crucial issue. So far, the strategy employing TEMPO as a co-catalyst has proven to be the most reliable one, but it also introduces several complications, such as additional purifications. Therefore, alternative approaches, such as more stable dyes, should be developed. Solving stability issues could also allow further integration in continuous flow reactors, which could offer interesting synergies for future applications. ${ }^{172}$ Similarly, the replacement of stoichiometric tertiary amines as additives in photocatalyzed reductions with greener and/or catalytic conditions would be highly desirable to improve the E-factor of these processes.
On the other hand, several electron-rich uncolored small molecules have been shown to be capable of sensitizing semiconductors through LMCT. This is easily detected experimentally by the appearance of a coloration upon addition of the organic compounds. Catechols and amines are among the most effective noncolored sensitizers, but other molecules, as simple as toluene, were reported to form charge transfer complexes if the semiconductor surface is appropriately activated. This strategy extends the photocatalytic properties of nanomaterials to blue light and even to higher activation wavelengths with an appropriately designed sensitizer. The synergy between semiconductors and organic molecules can be detected by spectroscopic investigation and by recording an action spectrum of the assembled photocatalytic system. Still, the role and reactivity of LMCT sensitizers remains also underexplored, leaving room for further investigation. Future research to rationalize and control the engagement of LMCT sensitizers has great potential.

Finally, the variety of reactions and experimental conditions highlighted in this Review provide some guidelines for performing such photoreactions. $\mathrm{CH}_{3} \mathrm{CN}$ was found to be the most sustainable solvent to find compromise between substrates solubility and photocatalyst dispersibility but sometimes, reactions can also be performed under solvent-free conditions. Room for improvement exists, such as by enhancing concentrations $\left(10^{-2}-10^{-1} \mathrm{M}\right)$ and demonstrating some scale-up potentials. Such issues could be solved by exploring specific stirring methods or reaction vessels, or by using continuous flow technologies. ${ }^{173,174}$ The light source power $\left(10-10^{2} \mathrm{~W}\right)$ should be balanced with a cooling system to counter the thermal effect on the reaction, since it would compromise the selectivity: indeed, cooling the mixture from rt down to $-10^{\circ} \mathrm{C}$ was reported to improve the stereoselectivity of coupling reactions. Regarding this topic, the measurement of the incident light intensity (rather than reporting the nominal power of the light source) would be more valuable to better characterize the efficiencies of these reactions.

Overall, we hope this Review has highlighted some important features of sensitized semiconductors with an overview of mechanisms, reaction scopes, potential drawbacks, and possibilities for further development in the field. We hope this will help to drive future advancement in the development of more sustainable synthetic organic chemistry with applications to pharmaceutical, agrochemical, and fine chemical manufacturing.

\section{ASSOCIATED CONTENT}

\section{SI Supporting Information}

The Supporting Information is available free of charge at https://pubs.acs.org/doi/10.1021/acssuschemeng.0c05179.

Data table (pdf)

\section{AUTHOR INFORMATION}

\section{Corresponding Authors}

Daniele Franchi - Department of Chemistry, KTH Royal Institute of Technology, SE-10044 Stockholm, Sweden; Consiglio Nazionale delle Ricerche - Istituto di Chimica dei Composti Organometallici (CNR-ICCOM), 50019 Sesto Fiorentino, Firenze, Italy; @ orcid.org/0000-0003-2811-247X; Email: danielef@kth.se

Zacharias Amara - Equipe de Chimie Moleculaire, Laboratoire GBCM, EA7528, Conservatoire National des Arts et Metiers, HESAM Université, 75003 Paris, France; (1) orcid.org/00000001-6824-1116; Email: zacharias.amara@lecnam.net

Complete contact information is available at:

https://pubs.acs.org/10.1021/acssuschemeng.0c05179 


\section{Notes}

The authors declare no competing financial interest. Biographies

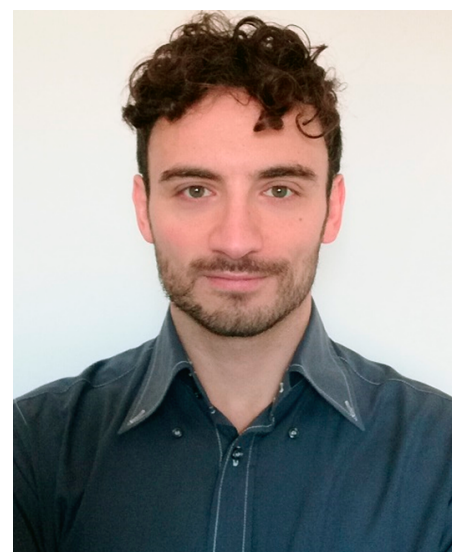

Daniele Franchi received his Ph.D. in organic chemistry in 2017 from the University of Florence (UniFI), under the supervision of Dr. Alessandro Mordini. During his time there, he worked on DSSC stability and organic dyes design. In 2018, he became a postdoctoral researcher at the Royal Institute of Technology (HTH) of Stockholm to work in the research group of Prof. Licheng Sun, on the synthesis of new holetransporting materials for perovskite solar cells. In 2020, he was appointed Researcher at the Italian National Council of Researches (CNR-ICCOM). His current research interests are green chemistry processes for $\mathrm{CO}_{2}$ and $\mathrm{N}_{2}$ fixation, and photocatalytic reactions for fine organic chemicals and solar fuels production.

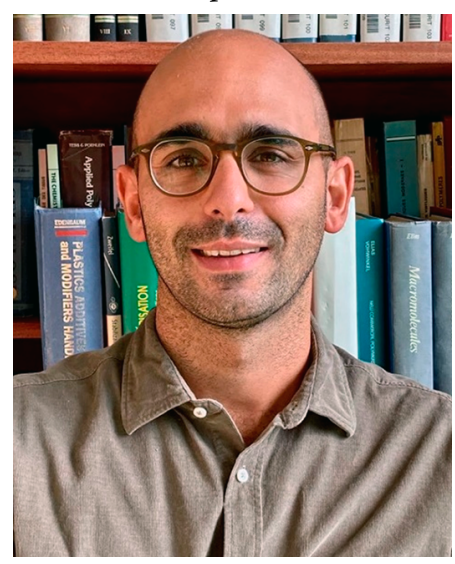

Zacharias Amara graduated with a Ph.D. in organic chemistry in 2012 from the University of Paris-Sud. He then moved to the UK to work as a postdoctoral researcher in green chemistry at the University of Nottingham. In 2015, he returned to Paris to start his independent career as an assistant professor at the National Conservatory of Arts and Crafts (Engineering School), where he teaches organic and formulation chemistry. His research interests lie in the development of more sustainable chemistry, mainly using photochemical activation, heterogeneous photocatalysis, and continuous flow processing. In 2017, he received an Ignition Award from the ACS Green Chemistry Institute and in 2018, a grant from the Bill and Melinda Gates Foundation to conduct a research program on the development of new routes to the antimalarial drug artemisinin.

\section{ABBREVIATIONS}

DSSC, dye-sensitized solar cell; LED, light-emitting diode; VB, valence band; $\mathrm{CB}$, conduction band; $\mathrm{SET}$, single electron transfer; MPC, molecular photocatalyst; HOMO, highest occupied molecular orbital; LUMO, lowest unoccupied molecular orbital; $\mathrm{A}^{\mathrm{n}}$, electron acceptor; $\mathrm{D}^{\mathrm{m}}$, electron donor; $\Phi$, quantum yield; $\mathrm{CH}_{3} \mathrm{CN}$, acetonitrile; rt, room temperature; LMCT, ligand-to-metal charge transfer; EDG, electron-donor group; EWG, electron-withdrawing group; NHE, normal hydrogen electrode; TEMPO, 2,2,6,6-tetramethylpiperidinyloxyl; BTF, benzotrifluoride; TON, turnover number; ROS, reactive oxidative species; $\mathrm{PW}_{12}$, polyoxometalate; TEA, triethylamine; TMSCN, trimethylsilyl cyanide; PANI, polyaniline; $t$-BuONO, tert-butyl nitrite; $\mathrm{CH}_{3} \mathrm{SO}_{3} \mathrm{H}$, methanesulfonic acid; TFE, 2,2,2trifluoroethanol; SED, sacrificial electron donor; TEOA, triethanolamine; $\mathrm{Ph}$, phenyl; Ar, general aromatic fragment; eq, equivalent(s)

\section{REFERENCES}

(1) Balzani, V.; Bergamini, G.; Ceroni, P. Light: A Very Peculiar Reactant and Product. Angew. Chem., Int. Ed. 2015, 54 (39), 11320-11337.

(2) Lee, C.; Lee, S.; Kim, G.-U.; Lee, W.; Kim, B. J. Recent Advances, Design Guidelines, and Prospects of All-Polymer Solar Cells. Chem. Rev. 2019, 119, 8028.

(3) Jena, A. K.; Kulkarni, A.; Miyasaka, T. Halide Perovskite Photovoltaics: Background, Status, and Future Prospects. Chem. Rev. 2019, 119 (5), 3036-3103.

(4) Ahmed, M.; Dincer, I. A Review on Photoelectrochemical Hydrogen Production Systems: Challenges and Future Directions. Int. J. Hydrogen Energy 2019, 44 (5), 2474-2507.

(5) Saraswat, S. K.; Rodene, D. D.; Gupta, R. B. Recent Advancements in Semiconductor Materials for Photoelectrochemical Water Splitting for Hydrogen Production Using Visible Light. Renewable Sustainable Energy Rev. 2018, 89 (March), 228-248.

(6) Wang, Z.; Li, C.; Domen, K. Recent Developments in Heterogeneous Photocatalysts for Solar-Driven Overall Water Splitting. Chem. Soc. Rev. 2019, 48 (7), 2109-2125.

(7) Ran, J.; Jaroniec, M.; Qiao, S.-Z. Cocatalysts in SemiconductorBased Photocatalytic $\mathrm{CO}_{2}$ Reduction: Achievements, Challenges, and Opportunities. Adv. Mater. 2018, 30 (7), 1704649.

(8) Li, X.; Yu, J.; Jaroniec, M.; Chen, X. Cocatalysts for Selective Photoreduction of $\mathrm{CO}_{2}$ into Solar Fuels. Chem. Rev. 2019, 119 (6), $3962-4179$.

(9) Wang, C.; Sun, Z.; Zheng, Y.; Hu, Y. H. Recent Progress in Visible Light Photocatalytic Conversion of Carbon Dioxide. J. Mater. Chem. A 2019, 7 (3), 865-887.

(10) Chu, C.; Ryberg, E. C.; Loeb, S. K.; Suh, M.-J.; Kim, J.-H. Water Disinfection in Rural Areas Demands Unconventional Solar Technologies. Acc. Chem. Res. 2019, 52, 1187-1195.

(11) Gao, M.; Zhu, L.; Peh, C. K.; Ho, G.W. Solar Absorber Material and System Designs for Photothermal Water Vaporization towards Clean Water and Energy Production. Energy Environ. Sci. 2019, 12 (3), 841-864.

(12) Ge, J.; Zhang, Y.; Heo, Y.-J.; Park, S.-J. Advanced Design and Synthesis of Composite Photocatalysts for the Remediation of Wastewater: A Review. Catalysts 2019, 9 (2), 122.

(13) Sayama, K. Production of High-Value-Added Chemicals on Oxide Semiconductor Photoanodes under Visible Light for Solar ChemicalConversion Processes. ACS Energy Lett. 2018, 3 (5), 1093-1101.

(14) Zhao, Y.; Waterhouse, G. I. N.; Chen, G.; Xiong, X.; Wu, L.-Z.; Tung, C.-H.; Zhang, T. Two-Dimensional-Related Catalytic Materials for Solar-Driven Conversion of $\mathrm{CO}_{\mathrm{x}}$ into Valuable Chemical Feedstocks. Chem. Soc. Rev. 2019, 48 (7), 1972-2010.

(15) Kampouri, S.; Stylianou, K. C. Dual-Functional Photocatalysis for Simultaneous Hydrogen Production and Oxidation of Organic Substances. ACS Catal. 2019, 9 (5), 4247-4270.

(16) König, B. Photocatalysis in Organic Synthesis - Past, Present, and Future. Eur. J. Org. Chem. 2017, 2017 (15), 1979-1981.

(17) Dalle, K. E.; Warnan, J.; Leung, J. J.; Reuillard, B.; Karmel, I. S.; Reisner, E. Electro- and Solar-Driven Fuel Synthesis with First Row Transition Metal Complexes. Chem. Rev. 2019, 119 (4), 2752-2875.

(18) Shimakoshi, H.; Hisaeda, Y. A Hybrid Catalyst for Light-Driven Green Molecular Transformations. ChemPlusChem 2017, 82 (1), 1829. 
(19) Bloh, J. Z.; Marschall, R. Heterogeneous Photoredox Catalysis: Reactions, Materials, and Reaction Engineering. Eur.J. Org. Chem. 2017, 2017 (15), 2085-2094.

(20) Spasiano, D.; Marotta, R.; Malato, S.; Fernandez-Ibañez, P.; Di Somma, I. Solar Photocatalysis: Materials, Reactors, Some Commercial, and Pre-Industrialized Applications. A Comprehensive Approach. Appl. Catal., B 2015, 170-171, 90-123.

(21) Parrino, F.; Bellardita, M.; García-López, E. I.; Marcì, G.; Loddo, V.; Palmisano, L. Heterogeneous Photocatalysis for Selective Formation of High-Value-Added Molecules: Some Chemical and Engineering Aspects. ACS Catal. 2018, 8 (12), 11191-11225.

(22) Marcelino, R. B. P.; Amorim, C. C. Towards Visible-Light Photocatalysis for Environmental Applications: Band-Gap Engineering versus Photons Absorption—a Review. Environ. Sci. Pollut. Res. 2019, 26 (5), 4155-4170.

(23) Riente, P.; Noël, T. Application of Metal Oxide Semiconductors in Light-Driven Organic Transformations. Catal. Sci. Technol. 2019, 9 (19), 5186-5232.

(24) Akhundi, A.; Badiei, A.; Ziarani, G. M.; Habibi-Yangjeh, A.; Muñoz-Batista, M. J.; Luque, R. Graphitic Carbon Nitride-Based Photocatalysts: Toward Efficient Organic Transformation for ValueAdded Chemicals Production. Mol. Catal. 2020, 488, 110902.

(25) He, R.; Xu, D.; Cheng, B.; Yu, J.; Ho, W. Review on Nanoscale BiBased Photocatalysts. Nanoscale Horizons 2018, 3 (5), 464-504.

(26) Li, J.-Y.; Li, Y.-H.; Qi, M.-Y.; Lin, Q.; Tang, Z.-R.; Xu, Y.-J. Selective Organic Transformations over Cadmium Sulfide-Based Photocatalysts. ACS Catal. 2020, 10 (11), 6262-6280.

(27) Kisch, H. Semiconductor Photocatalysis-Mechanistic and Synthetic Aspects. Angew. Chem., Int. Ed. 2013, 52 (3), 812-847.

(28) Kisch, H.; Hopfner, M. Novel Organic Syntheses Through Semiconductor Photocatalysis. In Electron Transfer in Chemistry; Wiley-VCH Verlag GmbH: Weinheim, Germany, 2001; pp 232275. DOI: $10.1002 / 9783527618248 . c h 52$.

(29) Prier, C. K.; Rankic, D. A.; MacMillan, D. W. C. Visible Light Photoredox Catalysis with Transition Metal Complexes: Applications in Organic Synthesis. Chem. Rev. 2013, 113 (7), 5322-5363.

(30) Marzo, L.; Pagire, S. K.; Reiser, O.; König, B. Visible-Light Photocatalysis: Does It Make a Difference in Organic Synthesis? Angew. Chem., Int. Ed. 2018, 57 (32), 10034-10072.

(31) Romero, N. A.; Nicewicz, D. A. Organic Photoredox Catalysis. Chem. Rev. 2016, 116 (17), 10075-10166.

(32) Corrigan, N.; Shanmugam, S.; Xu, J.; Boyer, C. Photocatalysis in Organic and Polymer Synthesis. Chem. Soc. Rev. 2016, 45 (22), 61656212.

(33) Yoon, T. P.; Ischay, M. A.; Du, J. Visible Light Photocatalysis as a Greener Approach to Photochemical Synthesis. Nat. Chem. 2010, 2 (7), 527-532.

(34) Chen, J.; Cen, J.; Xu, X.; Li, X. The Application of Heterogeneous Visible Light Photocatalysts in Organic Synthesis. Catal. Sci. Technol. 2016, 6 (2), 349-362.

(35) Chen, L.; Tang, J.; Song, L.; Chen, P.; He, J.; Au, C.; Yin, S. Heterogeneous Photocatalysis for Selective Oxidation of Alcohols and Hydrocarbons. Appl. Catal., B 2019, 242, 379-388.

(36) Kou, J.; Lu, C.; Wang, J.; Chen, Y.; Xu, Z.; Varma, R. S. Selectivity Enhancement in Heterogeneous Photocatalytic Transformations. Chem. Rev. 2017, 117 (3), 1445-1514.

(37) Ma, D.; Zhai, S.; Wang, Y.; Liu, A.; Chen, C. Synthetic Approaches for $\mathrm{C}-\mathrm{N}$ Bonds by $\mathrm{TiO}_{2}$ Photocatalysis. Front. Chem. 2019, 7, Article 365.

(38) Ma, D.; Liu, A.; Li, S.; Lu, C.; Chen, C. TiO 2 Photocatalysis for CC Bond Formation. Catal. Sci. Technol. 2018, 8 (8), 2030-2045.

(39) Palmisano, G.; García-López, E.; Marcì, G.; Loddo, V.; Yurdakal, S.; Augugliaro, V.; Palmisano, L. Advances in Selective Conversions by Heterogeneous Photocatalysis. Chem. Commun. 2010, 46 (38), 7074.

(40) Higashimoto, S. Titanium-Dioxide-Based Visible-Light-Sensitive Photocatalysis: Mechanistic Insight and Applications. Catalysts 2019, 9 (2), 201
(41) Luciani, G.; Imparato, C.; Vitiello, G. Photosensitive Hybrid Nanostructured Materials: The Big Challenges for Sunlight Capture. Catalysts 2020, 10 (1), 103.

(42) Gong, J.; Sumathy, K.; Qiao, Q.; Zhou, Z. Review on DyeSensitized Solar Cells (DSSCs): Advanced Techniques and Research Trends. Renewable Sustainable Energy Rev. 2017, 68 (December), 234246.

(43) Zhang, X.; Rakesh, K. P.; Ravindar, L.; Qin, H. Visible-Light Initiated Aerobic Oxidations: A Critical Review. Green Chem. 2018, 20 (21), 4790-4833.

(44) Michelin, C.; Hoffmann, N. Photosensitization and Photocatalysis-Perspectives in Organic Synthesis. ACS Catal. 2018, 8 (12), 12046-12055.

(45) Leow, W. R.; Chen, X. Surface Complexation for Photocatalytic Organic Transformations. Bull. Chem. Soc. Jpn. 2019, 92 (3), 505-510.

(46) Lang, X.; Chen, X.; Zhao, J. Heterogeneous Visible Light Photocatalysis for Selective Organic Transformations. Chem. Soc. Rev. 2014, 43 (1), 473-486.

(47) Đorđević, V.; Sredojević, D. N.; Dostanić, J.; Lončarević, D.; Ahrenkiel, S. P.; Svrakić, N.; Brothers, E.; Belić, M.; Nedeljković, J. M. Visible Light Absorption of Surface-Modified $\mathrm{Al}_{2} \mathrm{O}_{3}$ Powders: A Comparative DFT and Experimental Study. Microporous Mesoporous Mater. 2019, 273, 41-49.

(48) Gu, Q.; Jia, Q.; Long, J.; Gao, Z. Heterogeneous Photocatalyzed C-C Cross-Coupling Reactions Under Visible-Light and Near-Infrared Light Irradiation. Chem CatChem 2019, 11 (2), 669-683.

(49) Hao, H.; Zhang, L.; Wang, W.; Zeng, S. Modification of Heterogeneous Photocatalysts for Selective Organic Synthesis. Catal. Sci. Technol. 2018, 8 (5), 1229-1250.

(50) Gong, M.; Kim, J. K.; Zhao, X.; Li, Y.; Zhang, J.; Huang, M.; Wu, Y. Visible-Light-Induced $\alpha$-Oxyamination of 1,3-Dicarbonyls with TEMPO via a Photo(Electro)Catalytic Process Applying a DSSC Anode or in a DSSC System. Green Chem. 2019, 21 (13), 3615-3620.

(51) Ponseca, C. S.; Chábera, P.; Uhlig, J.; Persson, P.; Sundström, V. Ultrafast Electron Dynamics in Solar Energy Conversion. Chem. Rev. 2017, 117 (16), 10940-11024.

(52) Macyk, W.; Szaciłowski, K.; Stochel, G.; Buchalska, M.; Kuncewicz, J.; Łabuz, P. Titanium(IV) Complexes as Direct $\mathrm{TiO}_{2}$ Photosensitizers. Coord. Chem. Rev. 2010, 254 (21-22), 2687-2701.

(53) Gerischer, H. Charge Transfer Processes at SemiconductorElectrolyte Interfaces in Connection with Problems of Catalysis. Surf. Sci. 1969, 18 (1), 97-122.

(54) Zhang, G.; Kim, G.; Choi, W. Visible Light Driven Photocatalysis Mediated via Ligand-to-Metal Charge Transfer (LMCT): An Alternative Approach to Solar Activation of Titania. Energy Environ. Sci. 2014, 7 (3), 954.

(55) Parrino, F.; De Pasquale, C.; Palmisano, L. Influence of SurfaceRelated Phenomena on Mechanism, Selectivity, and Conversion of $\mathrm{TiO}_{2}$-Induced Photocatalytic Reactions. ChemSusChem 2019, 12 (3), 589-602.

(56) Kim, G.; Choi, W. Charge-Transfer Surface Complex of EDTA$\mathrm{TiO}_{2}$ and Its Effect on Photocatalysis under Visible Light. Appl. Catal., $B$ 2010, 100 (1-2), 77-83.

(57) Tian, Q.; Wang, C.; Chen, C.; Li, X.; Weng, S.; Zheng, Y.; Liu, P.; Zhuang, J. Synergetic Effects of the Interfacial Dyadic Structure on the Interfacial Charge Transfer between Surface-Complex and $\mathrm{TiO}_{2}$. Appl. Surf. Sci. 2019, 496, 143711.

(58) Koziar, J. C.; Cowan, D. O. Photochemical Heavy-Atom Effects. Acc. Chem. Res. 1978, 11 (9), 334-341.

(59) Twilton, J.; Le, C.; Zhang, P.; Shaw, M. H.; Evans, R. W.; MacMillan, D. W. C. The Merger of Transition Metal and Photocatalysis. Nat. Rev. Chem. 2017, 1 (7), 0052.

(60) Dongare, P.; MacKenzie, I.; Wang, D.; Nicewicz, D. A.; Meyer, T. J. Oxidation of Alkyl Benzenes by a Flavin Photooxidation Catalyst on Nanostructured Metal-Oxide Films. Proc. Natl. Acad. Sci. U. S. A. 2017, 114 (35), 9279-9283.

(61) Gu, X.; Li, X.; Chai, Y.; Yang, Q.; Li, P.; Yao, Y. A Simple MetalFree Catalytic Sulfoxidation under Visible Light and Air. Green Chem. 2013, 15 (2), 357. 
(62) Guo, S.; Zhang, H.; Huang, L.; Guo, Z.; Xiong, G.; Zhao, J. Porous Material-Immobilized Iodo-Bodipy as an Efficient Photocatalyst for Photoredox Catalytic Organic Reaction to Prepare Pyrrolo[2,1a]Isoquinoline. Chem. Commun. 2013, 49 (77), 8689.

(63) Kurfiřt, M.; Špačková, J.; Svobodová, E.; Cibulka, R. Flavin Derivatives Immobilized on Mesoporous Silica: A Versatile Tool in Visible-Light Photooxidation Reactions. Monatsh. Chem. 2018, 149 (4), 863-869.

(64) Xiao, L.; Huang, Y.; Luo, Y.; Yang, B.; Liu, Y.; Zhou, X.; Zhang, J. Organic Cotton Photocatalysis. ACS Sustainable Chem. Eng. 2018, 6 (11), 14759-14766.

(65) Tambosco, B.; Segura, K.; Seyrig, C.; Cabrera, D.; Port, M.; Ferroud, C.; Amara, Z. Outer-Sphere Effects in Visible-Light Photochemical Oxidations with Immobilized and Recyclable Ruthenium Bipyridyl Salts. ACS Catal. 2018, 8 (5), 4383-4389.

(66) Terra, J. C. S.; Desgranges, A.; Monnereau, C.; Sanchez, E. H.; De Toro, J. A.; Amara, Z.; Moores, A. Photocatalysis Meets Magnetism: Designing Magnetically Recoverable Supports for Visible-Light Photocatalysis. ACS Appl. Mater. Interfaces 2020, 12 (22), 24895-24904.

(67) Cherevatskaya, M.; Neumann, M.; Füldner, S.; Harlander, C.; Kümmel, S.; Dankesreiter, S.; Pfitzner, A.; Zeitler, K.; König, B. VisibleLight-Promoted Stereoselective Alkylation by Combining Heterogeneous Photocatalysis with Organocatalysis. Angew. Chem., Int. Ed. 2012, 51 (17), 4062-4066.

(68) Roth, H.; Romero, N.; Nicewicz, D. Experimental and Calculated Electrochemical Potentials of Common Organic Molecules for Applications to Single-Electron Redox Chemistry. Synlett 2016, 27 (05), 714-723.

(69) Smith, T. J.; Stevenson, K. J. Reference Electrodes. In Handbook of Electrochemistry; Elsevier, 2007; pp 73-110, DOI: 10.1016/B978044451958-0.50005-7.

(70) Mailloux, R. J.; Willmore, W. G. S-Glutathionylation Reactions in Mitochondrial Function and Disease. Front. Cell Dev. Biol. 2014, 2, Article 68.

(71) Jain, G.; Macias-Montero, M.; Velusamy, T.; Maguire, P.; Mariotti, D. Porous Zinc Oxide Nanocrystalline Film Deposition by Atmospheric Pressure Plasma: Fabrication and Energy Band Estimation. Plasma Processes Polym. 2017, 14 (12), 1700052.

(72) Fujisawa, J.; Eda, T.; Hanaya, M. Comparative Study of Conduction-Band and Valence-Band Edges of $\mathrm{TiO}_{2}, \mathrm{SrTiO}_{3}$, and $\mathrm{BaTiO}_{3}$ by Ionization Potential Measurements. Chem. Phys. Lett. 2017, $685,23-26$.

(73) Lopes, O. F.; Paris, E. C.; Ribeiro, C. Synthesis of $\mathrm{Nb}_{2} \mathrm{O}_{5}$ Nanoparticles through the Oxidant Peroxide Method Applied to Organic Pollutant Photodegradation: A Mechanistic Study. Appl. Catal., B 2014, 144, 800-808.

(74) Shen, T.; Zhao, Z.-G.; Yu, Q.; Xu, H.-J. Photosensitized Reduction of Benzil by Heteroatom-Containing Anthracene Dyes. J. Photochem. Photobiol., A 1989, 47 (2), 203-212.

(75) Hosseini-Sarvari, M.; Koohgard, M.; Firoozi, S.; Mohajeri, A.; Tavakolian, H. Alizarin Red $\mathrm{S}-\mathrm{TiO}_{2}$-Catalyzed Cascade $\mathrm{C}\left(\mathrm{Sp}^{3}\right)-\mathrm{H}$ to $\mathrm{C}\left(\mathrm{Sp}^{2}\right)-\mathrm{H}$ Bond Formation/Cyclization Reactions toward Tetrahydroquinoline Derivatives under Visible Light Irradiation. New J. Chem. 2018, 42 (9), 6880-6888.

(76) Reid, L. M.; Li, T.; Cao, Y.; Berlinguette, C. P. Organic Chemistry at Anodes and Photoanodes. Sustain. Energy Fuels 2018, 2 (9), 19051927.

(77) Lang, X.; Ma, W.; Chen, C.; Ji, H.; Zhao, J. Selective Aerobic Oxidation Mediated by $\mathrm{TiO}_{2}$ Photocatalysis. Acc. Chem. Res. 2014, 47 (2), 355-363.

(78) Higashimoto, S.; Kitao, N.; Yoshida, N.; Sakura, T.; Azuma, M.; Ohue, H.; Sakata, Y. Selective Photocatalytic Oxidation of Benzyl Alcohol and Its Derivatives into Corresponding Aldehydes by Molecular Oxygen on Titanium Dioxide under Visible Light Irradiation. J. Catal. 2009, 266 (2), 279-285.

(79) Li, C.-J.; Xu, G.-R.; Zhang, B.; Gong, J. R. High Selectivity in Visible-Light-Driven Partial Photocatalytic Oxidation of Benzyl Alcohol into Benzaldehyde over Single-Crystalline Rutile $\mathrm{TiO}_{2}$ Nanorods. Appl. Catal., B 2012, 115-116, 201-208.
(80) Higashimoto, S.; Suetsugu, N.; Azuma, M.; Ohue, H.; Sakata, Y. Efficient and Selective Oxidation of Benzylic Alcohol by $\mathrm{O}_{2}$ into Corresponding Aldehydes on a $\mathrm{TiO}_{2}$ Photocatalyst under Visible Light Irradiation: Effect of Phenyl-Ring Substitution on the Photocatalytic Activity. J. Catal. 2010, 274 (1), 76-83.

(81) Zou, J.; Wang, Z.; Guo, W.; Guo, B.; Yu, Y.; Wu, L. Photocatalytic Selective Oxidation of Benzyl Alcohol over ZnTi-LDH: The Effect of Surface OH Groups. Appl. Catal., B 2020, 260, 118185.

(82) Wang, H.; Song, Y.; Xiong, J.; Bi, J.; Li, L.; Yu, Y.; Liang, S.; Wu, L. Highly Selective Oxidation of Furfuryl Alcohol over Monolayer Titanate Nanosheet under Visible Light Irradiation. Appl. Catal., B 2018, 224, 394-403.

(83) Shishido, T.; Miyatake, T.; Teramura, K.; Hitomi, Y.; Yamashita, H.; Tanaka, T. Mechanism of Photooxidation of Alcohol over $\mathrm{Nb}_{2} \mathrm{O}_{5}$.J. Phys. Chem. C 2009, 113 (43), 18713-18718.

(84) Furukawa, S.; Tamura, A.; Shishido, T.; Teramura, K.; Tanaka, T. Solvent-Free Aerobic Alcohol Oxidation Using $\mathrm{Cu} / \mathrm{Nb}_{2} \mathrm{O}_{5}$ : Green and Highly Selective Photocatalytic System. Appl. Catal., B 2011, 110, 216 220.

(85) Hao, H.; Li, X.; Lang, X. Anthraquinones as Photoredox Active Ligands of $\mathrm{TiO}_{2}$ for Selective Aerobic Oxidation of Organic Sulfides. Appl. Catal., B 2019, 259, 118038.

(86) Li, X.; Shi, J.; Hao, H.; Lang, X. Visible Light-Induced Selective Oxidation of Alcohols with Air by Dye-Sensitized $\mathrm{TiO}_{2}$ Photocatalysis. Appl. Catal., B 2018, 232 (2010), 260-267.

(87) Xu, H.; Shi, J.-L.; Hao, H.; Li, X.; Lang, X. Visible Light Photocatalytic Aerobic Oxidative Synthesis of Imines from Alcohols and Amines on Dye-Sensitized $\mathrm{TiO}_{2}$. Catal. Today 2019, 335, 128-135.

(88) Song, Y.; Wang, H.; Liang, S.; Yu, Y.; Li, L.; Wu, L. One-Pot Synthesis of Secondary Amine via Photoalkylation of Nitroarenes with Benzyl Alcohol over Pd/Monolayer $\mathrm{H}_{1.07} \mathrm{Ti}_{1.73} \mathrm{O}_{4} \cdot \mathrm{H}_{2} \mathrm{O}$ Nanosheets. J. Catal. 2018, 361, 105-115.

(89) Zhang, M.; Chen, C.; Ma, W.; Zhao, J. Visible-Light-Induced Aerobic Oxidation of Alcohols in a Coupled Photocatalytic System of Dye-Sensitized $\mathrm{TiO}_{2}$ and TEMPO. Angew. Chem., Int. Ed. 2008, 47 (50), 9730-9733.

(90) Wang, N.; Shi, J.-L.; Hao, H.; Yuan, H.; Lang, X. Cooperative Photocatalytic Selective Aerobic Oxidation of Alcohols on Anatase $\mathrm{TiO}_{2}$. Sustain. Energy Fuels 2019, 3 (7), 1701-1712.

(91) Zhang, Y.; Wang, Z.; Lang, X. Merging Visible Light Photocatalysis of Dye-Sensitized $\mathrm{TiO}_{2}$ with TEMPO: The Selective Aerobic Oxidation of Alcohols. Catal. Sci. Technol. 2017, 7 (21), 4955-4963.

(92) Jeena, V.; Robinson, R. S. Convenient Photooxidation of Alcohols Using Dye Sensitised Zinc Oxide in Combination with Silver Nitrate and TEMPO. Chem. Commun. 2012, 48 (2), 299-301.

(93) Jeena, V.; Robinson, R. S. Convenient Photooxidation of Alcohols Using Dye Sensitised Semiconductors in Combination with Silver Nitrate and TEMPO - an Electron Paramagnetic Resonance Study. Dalt. Trans. 2012, 41 (11), 3134.

(94) Underwood, T. M.; Robinson, R. S. Enhancing the Photo-Efficacy of an Organic Visible-Light-Activated Chromophore (Alizarin Red S) on Zinc Oxide with a Ag-Na Electrolyte to Photo-Transform Aromatic and Aliphatic Alcohols. RSC Adv. 2019, 9 (42), 24259-24266.

(95) Rahimi Niaraki, A.; Saraee, M. R.; Kazemi, F.; Kaboudin, B. Chemoselective Photocatalytic Oxidation of Alcohols to Aldehydes and Ketones by Nitromethane on Titanium Dioxide under Violet $400 \mathrm{Nm}$ LED Light Irradiation. Org. Biomol. Chem. 2020, 18 (12), 2326-2330.

(96) Yang, X.; Zhao, H.; Feng, J.; Chen, Y.; Gao, S.; Cao, R. VisibleLight-Driven Selective Oxidation of Alcohols Using a Dye-Sensitized $\mathrm{TiO}_{2}$-Polyoxometalate Catalyst. J. Catal. 2017, 351, 59-66.

(97) Yang, Z.; Gao, S.; Li, H.; Cao, R. Synthesis and Visible Light Photocatalytic Properties of Polyoxometalate-Thionine Composite Films Immobilized on Porous $\mathrm{TiO}_{2}$ Microspheres. J. Colloid Interface Sci. 2012, 375 (1), 172-179.

(98) Guarisco, C.; Palmisano, G.; Calogero, G.; Ciriminna, R.; Di Marco, G.; Loddo, V.; Pagliaro, M.; Parrino, F. Visible-Light Driven Oxidation of Gaseous Aliphatic Alcohols to the Corresponding Carbonyls via $\mathrm{TiO}_{2}$ Sensitized by a Perylene Derivative. Environ. Sci. Pollut. Res. 2014, 21 (19), 11135-11141. 
(99) Clarizia, L.; Andreozzi, R.; Apuzzo, J.; Di Somma, I.; Marotta, R. Efficient Acetaldehyde Production and Recovery upon Selective $\mathrm{Cu}$ / $\mathrm{TiO}_{2}$-Photocatalytic Oxidation of Ethanol in Aqueous Solution. Chem. Eng. J. 2020, 393, 123425.

(100) Ren, L.; Yang, M.-M.; Tung, C.-H.; Wu, L.-Z.; Cong, H. VisibleLight Photocatalysis Employing Dye-Sensitized Semiconductor: Selective Aerobic Oxidation of Benzyl Ethers. ACS Catal. 2017, 7 (12), 8134-8138.

(101) Furukawa, S.; Ohno, Y.; Shishido, T.; Teramura, K.; Tanaka, T. Selective Amine Oxidation Using $\mathrm{Nb}_{2} \mathrm{O}_{5}$ Photocatalyst and $\mathrm{O}_{2}$. ACS Catal. 2011, 1 (10), 1150-1153.

(102) Lang, X.; Ma, W.; Zhao, Y.; Chen, C.; Ji, H.; Zhao, J. VisibleLight-Induced Selective Photocatalytic Aerobic Oxidation of Amines into Imines on $\mathrm{TiO}_{2}$. Chem. - Eur. J. 2012, 18 (9), 2624-2631.

(103) Mogal, S. I.; Shah, D. O.; Mukherjee, T.; Shripathi, T.; Mishra, M. K. Enhanced Photocatalytic Efficiency of a Least Active $\mathrm{Ag}-\mathrm{TiO}_{2}$ by Amine Adsorption. ACS Omega 2018, 3 (10), 12802-12812.

(104) Naniwa, S.; Tyagi, A.; Yamamoto, A.; Yoshida, H. Visible-Light Photoexcitation of Pyridine Surface Complex, Leading to Selective Dehydrogenative Cross-Coupling with Cyclohexane. Phys. Chem. Chem. Phys. 2018, 20 (45), 28375-28381.

(105) Wang, Z.; Lang, X. Visible Light Photocatalysis of DyeSensitized $\mathrm{TiO}_{2}$ : The Selective Aerobic Oxidation of Amines to Imines. Appl. Catal., B 2018, 224 (October), 404-409.

(106) Sheng, W.; Shi, J.-L.; Hao, H.; Li, X.; Lang, X. Polyimide-TiO ${ }_{2}$ Hybrid Photocatalysis: Visible Light-Promoted Selective Aerobic Oxidation of Amines. Chem. Eng. J. 2020, 379, 122399.

(107) Li, X.; Lang, X. Cooperative Smart $\mathrm{TiO}_{2}$ Photocatalysis and TEMPO Catalysis: Visible Light-Mediated Selective Aerobic Oxidation of Amines. J. Chem. Phys. 2020, 152 (4), 044705.

(108) Shi, J. L.; Hao, H.; Lang, X. Phenol-TiO 2 Complex Photocatalysis: Visible Light-Driven Selective Oxidation of Amines into Imines in Air. Sustain. Energy Fuels 2019, 3 (2), 488-498.

(109) Shi, J. L.; Hao, H.; Lia, X.; Lang, X. Merging the catechol-TiO2 complex photocatalyst with TEMPO for selective aerobic oxidation of amines into imines. Catal. Sci. Technol. 2018, 8, 3910-3917.

(110) Li, X.; Xu, H.; Shi, J.-L.; Hao, H.; Yuan, H.; Lang, X. Salicylic Acid Complexed with $\mathrm{TiO}_{2}$ for Visible Light-Driven Selective Oxidation of Amines into Imines with Air. Appl. Catal., B 2019, 244 (November), $758-766$.

(111) Hao, H.; Shi, J.-L.; Xu, H.; Li, X.; Lang, X. N-Hydroxyphthalimide- $\mathrm{TiO}_{2}$ Complex Visible Light Photocatalysis. Appl. Catal., $B$ 2019, 246, 149-155.

(112) Ayed, C.; Huang, W.; Li, R.; da Silva, L. C.; Wang, D.; Suraeva, O.; Najjar, W.; Zhang, K. A. I. Conjugated Microporous Polymers with Immobilized $\mathrm{TiO}_{2}$ Nanoparticles for Enhanced Visible Light Photocatalysis. Part. Part. Syst. Charact. 2018, 35 (1), 1700234.

(113) Balayeva, N. O.; Zheng, N.; Dillert, R.; Bahnemann, D. W. Visible-Light-Mediated Photocatalytic Aerobic Dehydrogenation of NHeterocycles by Surface-Grafted $\mathrm{TiO}_{2}$ and 4-Amino-TEMPO. ACS Catal. 2019, 9 (12), 10694-10704.

(114) Balayeva, N. O.; Mamiyev, Z.; Dillert, R.; Zheng, N.; Bahnemann, D. W. Rh/ $\mathrm{TiO}_{2}$-Photocatalyzed Acceptorless Dehydrogenation of N-Heterocycles upon Visible-Light Illumination. ACS Catal. 2020, 10 (10), 5542-5553.

(115) Chen, J.; Xiong, J.; Song, Y.; Yu, Y.; Wu, L. Synthesis of Nitrosobenzene via Photocatalytic Oxidation of Aniline over $\mathrm{MgO} /$ $\mathrm{TiO}_{2}$ under Visible Light Irradiation. Appl. Surf. Sci. 2018, 440, 12691276.

(116) Chen, J.; Shen, C.; Guo, B.; Yu, Y.; Wu, L. Photocatalytic Oxidation of Aniline over $\mathrm{MO} / \mathrm{TiO}_{2}(\mathrm{M}=\mathrm{Mg}, \mathrm{Ca}, \mathrm{Sr}, \mathrm{Ba})$ under Visible Light Irradiation. Catal. Today 2019, 335, 312-318.

(117) Lang, X.; Hao, W.; Leow, W. R.; Li, S.; Zhao, J.; Chen, X. Tertiary Amine Mediated Aerobic Oxidation of Sulfides into Sulfoxides by Visible-Light Photoredox Catalysis on $\mathrm{TiO}_{2}$. Chem. Sci. 2015, 6 (8), 5000-5005.

(118) Hao, H.; Wang, Z.; Shi, J.-L.; Li, X.; Lang, X. Improving the Visible Light Photocatalytic Aerobic Oxidation of Sulfides into
Sulfoxides on Dye-Sensitized $\mathrm{TiO}_{2}$. ChemCatChem 2018, 10 (20), $4545-4554$

(119) Lang, X.; Zhao, J.; Chen, X. Visible-Light-Induced Photoredox Catalysis of Dye-Sensitized Titanium Dioxide: Selective Aerobic Oxidation of Organic Sulfides. Angew. Chem., Int. Ed. 2016, 55 (15), 4697-4700.

(120) Sheng, W.; Shi, J.-L.; Hao, H.; Li, X.; Lang, X. Selective Aerobic Oxidation of Sulfides by Cooperative Polyimide-Titanium Dioxide Photocatalysis and Triethylamine Catalysis. J. Colloid Interface Sci. 2020, $565,614-622$.

(121) Wang, F.; Sun, L.; Li, Y.; Zhan, W.; Wang, X.; Han, X. Hollow Anatase $\mathrm{TiO}_{2}$ Octahedrons with Exposed High-Index $\{102\}$ Facets for Improved Dye-Sensitized Photoredox Catalysis Activity. Inorg. Chem. 2018, 57 (8), 4550-4555.

(122) Shi, J.-L.; Lang, X. Assembling Polydopamine on $\mathrm{TiO}_{2}$ for Visible Light Photocatalytic Selective Oxidation of Sulfides with Aerial $\mathrm{O}_{2}$. Chem. Eng. J. 2020, 392, 123632.

(123) Ma, X.; Lang, X. Titanate Nanotube Confined Merger of Organic Photocatalysis and TEMPO Catalysis for Highly Selective Aerobic Oxidation of Sulfides. Sustain. Energy Fuels 2020, 4 (4), 17541763.

(124) Bottecchia, C.; Erdmann, N.; Tijssen, P. M. A.; Milroy, L.-G.; Brunsveld, L.; Hessel, V.; Noël, T. Batch and Flow Synthesis of Disulfides by Visible-Light-Induced $\mathrm{TiO}_{2}$ Photocatalysis. ChemSusChem 2016, 9 (14), 1781-1785.

(125) Xu, H.; Shi, J.-L.; Lyu, S.; Lang, X. Visible-Light Photocatalytic Selective Aerobic Oxidation of Thiols to Disulfides on Anatase $\mathrm{TiO}_{2}$. Chin. J. Catal. 2020, 41 (10), 1468-1473.

(126) Lang, X.; Leow, W. R.; Zhao, J.; Chen, X. Synergistic Photocatalytic Aerobic Oxidation of Sulfides and Amines on $\mathrm{TiO}_{2}$ under Visible-Light Irradiation. Chem. Sci. 2015, 6 (2), 1075-1082.

(127) Tamai, K.; Murakami, K.; Hosokawa, S.; Asakura, H.; Teramura, K.; Tanaka, T. Visible-Light Selective Photooxidation of Aromatic Hydrocarbons via Ligand-to-Metal Charge Transfer Transition on $\mathrm{Nb}_{2} \mathrm{O}_{5}$. J. Phys. Chem. C 2017, 121 (41), 22854-22861.

(128) Qiao, S.; Liu, X.; Zhou, Y.; Wang, H.; Zhang, L.; Wang, W. Selective Transfer Hydrogenation of Cinnamaldehyde with Alcohol on Amorphous $\mathrm{TiO}_{2}$ Catalysts: Competitive Adsorption between $\mathrm{H}_{2} \mathrm{O}$ and Carbonyl. ChemistrySelect 2020, 5 (17), 5162-5165.

(129) Biedrzycki, J. J.; Livraghi, S.; Corazzari, I.; Mino, L.; Spoto, G.; Giamello, E. On the Redox Mechanism Operating along C 2 H 2 SelfAssembly at the Surface of $\mathrm{TiO}_{2}$. Langmuir 2015, 31 (1), 569-577.

(130) Parrino, F.; Ramakrishnan, A.; Kisch, H. SemiconductorPhotocatalyzed Sulfoxidation of Alkanes. Angew. Chem., Int. Ed. 2008, 47 (37), 7107-7109.

(131) Parrino, F.; Ramakrishnan, A.; Damm, C.; Kisch, H. VisibleLight-Induced Sulfoxidation of Alkanes in the Presence of Titania. ChemPlusChem 2012, 77 (8), 713-720.

(132) Smith, M. B. Reduction. In Organic Synthesis; Elsevier, 2010; pp 347-490, DOI: 10.1016/B978-1-890661-40-3.50004-1.

(133) Kohtani, S.; Nishioka, S.; Yoshioka, E.; Miyabe, H. DyeSensitized Photo-Hydrogenation of Aromatic Ketones on Titanium Dioxide under Visible Light Irradiation. Catal. Commun. 2014, 43, 6165.

(134) Kohtani, S.; Mori, M.; Yoshioka, E.; Miyabe, H. Photohydrogenation of Acetophenone Using Coumarin Dye-Sensitized Titanium Dioxide under Visible Light Irradiation. Catalysts 2015, 5 (3), 1417-1424.

(135) Fukui, M.; Tanaka, A.; Hashimoto, K.; Kominami, H. Visible Light-Induced Heterogeneous Meerwein-Ponndorf-Verley-Type Reduction of an Aldehyde Group over an Organically Modified Titanium Dioxide Photocatalyst. Chem. Commun. 2017, 53 (30), 4215-4218.

(136) Liu, C.; Hu, J.; Zhu, F.; Zhan, J.; Du, L.; Tung, C.; Wang, Y.

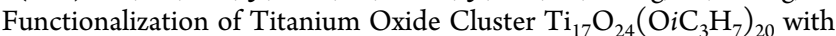
Catechols: Structures and Ligand-Exchange Reactivities. Chem. - Eur. J. 2019, 25 (65), 14843-14849.

(137) Yamamoto, Y.; Fukui, M.; Tanaka, A.; Hashimoto, K.; Kominami, H. Hydrogen- and Noble Metal-Free Conversion of Nitro Aromatics to Amino Aromatics Having Reducible Groups over an 
Organically Modified $\mathrm{TiO}_{2}$ Photocatalyst under Visible Light Irradiation. Catal. Sci. Technol. 2019, 9 (4), 966-973.

(138) Imamura, K.; Nakanishi, K.; Hashimoto, K.; Kominami, H. Chemoselective Reduction of Nitrobenzenes Having Other Reducible Groups over Titanium(IV) Oxide Photocatalyst under Protection-, Gas-, and Metal-Free Conditions. Tetrahedron 2014, 70 (36), 61346139.

(139) Kamegawa, T.; Seto, H.; Matsuura, S.; Yamashita, H. Preparation of Hydroxynaphthalene-Modified $\mathrm{TiO}_{2}$ via Formation of Surface Complexes and Their Applications in the Photocatalytic Reduction of Nitrobenzene under Visible-Light Irradiation. ACS Appl. Mater. Interfaces 2012, 4 (12), 6635-6639.

(140) Füldner, S.; Mild, R.; Siegmund, H. I.; Schroeder, J. A.; Gruber, M.; König, B. Green-Light Photocatalytic Reduction Using DyeSensitized $\mathrm{TiO}_{2}$ and Transition Metal Nanoparticles. Green Chem. 2010, 12 (3), 400-406.

(141) Füldner, S.; Mitkina, T.; Trottmann, T.; Frimberger, A.; Gruber, M.; König, B. Urea Derivatives Enhance the Photocatalytic Activity of Dye-Modified Titanium Dioxide. Photochem. Photobiol. Sci. 2011, 10 (4), 623.

(142) Bhar, S.; Ananthakrishnan, R. Utilization of Ru(ii)-Complex Immobilized $\mathrm{ZnO}$ Hybrid in Presence of $\mathrm{Pt}(\mathrm{ii})$ Co-Catalyst for Photocatalytic Reduction of 4-Nitrophenol under Visible Light. RSC Adv. 2015, 5 (27), 20704-20711.

(143) Fukui, M.; Omori, Y.; Kitagawa, S.; Tanaka, A.; Hashimoto, K.; Kominami, H. Visible Light-Induced Diastereoselective Semihydrogenation of Alkynes to Cis-Alkenes over an Organically Modified Titanium(IV) Oxide Photocatalyst Having a Metal Co-Catalyst. J. Catal. 2019, 374, 36-42.

(144) Xie, S.; Shen, Z.; Deng, J.; Guo, P.; Zhang, Q.; Zhang, H.; Ma, C.; Jiang, Z.; Cheng, J.; Deng, D.; Wang, Y. Visible Light-Driven C-H Activation and C-C Coupling of Methanol into Ethylene Glycol. Nat. Commun. 2018, 9 (1), 1181.

(145) Wang, Y.; Liu, A.; Ma, D.; Li, S.; Lu, C.; Li, T.; Chen, C. TiO Photocatalyzed C-H Bond Transformation for C-C Coupling Reactions. Catalysts 2018, 8 (9), 355.

(146) Vila, C.; Rueping, M. Visible-Light Mediated Heterogeneous C$\mathrm{H}$ Functionalization: Oxidative Multi-Component Reactions Using a Recyclable Titanium Dioxide $\left(\mathrm{TiO}_{2}\right)$ Catalyst. Green Chem. 2013, 15 (8), 2056-2059.

(147) Rueping, M.; Zoller, J.; Fabry, D. C.; Poscharny, K.; Koenigs, R. M.; Weirich, T. E.; Mayer, J. Light-Mediated Heterogeneous Cross Dehydrogenative Coupling Reactions: Metal Oxides as Efficient, Recyclable, Photoredox Catalysts in C-C Bond-Forming Reactions. Chem. - Eur. J. 2012, 18 (12), 3478-3481.

(148) Zhang, X.; Chen, Y.; Shang, Q.; Guo, Y. Copper Doping and Organic Sensitization Enhance Photocatalytic Activity of Titanium Dioxide: Efficient Degradation of Phenol and Tetrabromobisphenol A. Sci. Total Environ. 2020, 716, 137144.

(149) Nauth, A. M.; Schechtel, E.; Dören, R.; Tremel, W.; Opatz, T. $\mathrm{TiO}_{2}$ Nanoparticles Functionalized with Non-Innocent Ligands Allow Oxidative Photocyanation of Amines with Visible/Near-Infrared Photons. J. Am. Chem. Soc. 2018, 140 (43), 14169-14177.

(150) Koohgard, M.; Hosseinpour, Z.; Sarvestani, A. M.; HosseiniSarvari, M. ARS-TiO ${ }_{2}$ Photocatalyzed Direct Functionalization of $\mathrm{Sp}^{2}$ $\mathrm{C}-\mathrm{H}$ Bonds toward Thiocyanation and Cyclization Reactions under Visible Light. Catal. Sci. Technol. 2020, 10 (5), 1401-1407.

(151) Ren, L.; Cong, H. Visible-Light-Driven Decarboxylative Alkylation of C-H Bond Catalyzed by Dye-Sensitized Semiconductor. Org. Lett. 2018, 20 (11), 3225-3228.

(152) Yamamoto, A.; Ohara, T.; Yoshida, H. Visible-Light-Induced Photocatalytic Benzene/Cyclohexane Cross-Coupling Utilizing a Ligand-to-Metal Charge Transfer Benzene Complex Adsorbed on Titanium Oxides. Catal. Sci. Technol. 2018, 8 (8), 2046-2050.

(153) Teders, M.; Henkel, C.; Anhäuser, L.; Strieth-Kalthoff, F.; Gómez-Suárez, A.; Kleinmans, R.; Kahnt, A.; Rentmeister, A.; Guldi, D.; Glorius, F. The Energy-Transfer-Enabled Biocompatible Disulfide-Ene Reaction. Nat. Chem. 2018, 10 (9), 981-988.
(154) Dénès, F.; Pichowicz, M.; Povie, G.; Renaud, P. Thiyl Radicals in Organic Synthesis. Chem. Rev. 2014, 114 (5), 2587-2693.

(155) Bhat, V. T.; Duspara, P. A.; Seo, S.; Abu Bakar, N. S. B.; Greaney, M. F. Visible Light Promoted Thiol-Ene Reactions Using Titanium Dioxide. Chem. Commun. 2015, 51 (21), 4383-4385.

(156) Fujisawa, J.; Kaneko, N.; Hanaya, M. Interfacial Charge-Transfer Transitions in $\mathrm{ZnO}$ Induced Exclusively by Adsorption of Aromatic Thiols. Chem. Commun. 2020, 56 (29), 4090-4093.

(157) Pitre, S. P.; Yoon, T. P.; Scaiano, J. C. Titanium Dioxide Visible Light Photocatalysis: Surface Association Enables Photocatalysis with Visible Light Irradiation. Chem. Commun. 2017, 53 (31), 4335-4338.

(158) Gieseler, A.; Steckhan, E.; Wiest, O.; Knoch, F. Photochemically Induced Radical-Cation Diels-Alder Reaction of Indole and ElectronRich Dienes. J. Org. Chem. 1991, 56 (4), 1405-1411.

(159) Fujisawa, J. Interfacial Charge-Transfer Transitions between $\mathrm{TiO}_{2}$ and Indole. Chem. Phys. Lett. 2020, 739, 136974.

(160) Pitre, S. P.; Scaiano, J. C.; Yoon, T. P. Photocatalytic Indole Diels-Alder Cycloadditions Mediated by Heterogeneous PlatinumModified Titanium Dioxide. ACS Catal. 2017, 7 (10), 6440-6444.

(161) Zoller, J.; Fabry, D. C.; Rueping, M. Unexpected Dual Role of Titanium Dioxide in the Visible Light Heterogeneous Catalyzed C-H Arylation of Heteroarenes. ACS Catal. 2015, 5 (6), 3900-3904.

(162) Liu, W.; Wang, C.; Wang, L. Photocatalyzed Facile Synthesis of $\alpha$-Chloro Aryl Ketones with Polyaniline-g- $\mathrm{C}_{3} \mathrm{~N}_{4}-\mathrm{TiO}_{2}$ Composite under Visible Light. Ind. Eng. Chem. Res. 2017, 56 (21), 6114-6123.

(163) Wang, L.; Shen, J.; Yang, S.; Liu, W.; Chen, Q.; He, M. C-H Arylation Reactions through Aniline Activation Catalysed by a PANI-g$\mathrm{C}_{3} \mathrm{~N}_{4}-\mathrm{TiO}_{2}$ Composite under Visible Light in Aqueous Medium. Green Chem. 2018, 20 (6), 1290-1296.

(164) Wang, L.; Wang, H.; Wang, Y.; Shen, M.; Li, S. Photocatalyzed Synthesis of Unsymmetrical Ureas via the Oxidative Decarboxylation of Oxamic Acids with PANI-g- $\mathrm{C}_{3} \mathrm{~N}_{4}-\mathrm{TiO}_{2}$ Composite under Visible Light. Tetrahedron Lett. 2020, 61 (23), 151962.

(165) Shichijo, K.; Fujitsuka, M.; Hisaeda, Y.; Shimakoshi, H. Visible Light-Driven Photocatalytic Duet Reaction Catalyzed by the $B_{12}$ Rhodium-Titanium Oxide Hybrid Catalyst. J. Organomet. Chem. 2020, 907, 121058.

(166) Yoon, H.-S.; Ho, X.-H.; Jang, J.; Lee, H.-J.; Kim, S.-J.; Jang, H.-Y. N719 Dye-Sensitized Organophotocatalysis: Enantioselective Tandem Michael Addition/Oxyamination of Aldehydes. Org. Lett. 2012, 14 (13), $3272-3275$

(167) Nicewicz, D. A.; MacMillan, D. W. C. Merging Photoredox Catalysis with Organocatalysis: The Direct Asymmetric Alkylation of Aldehydes. Science (Washington, DC, U. S.) 2008, 322 (5898), 77-80.

(168) Bahamonde, A.; Melchiorre, P. Mechanism of the Stereoselective $\alpha$-Alkylation of Aldehydes Driven by the Photochemical Activity of Enamines. J. Am. Chem. Soc. 2016, 138 (25), 8019-8030.

(169) Dana, S.; Dey, P.; Patil, S. A.; Baidya, M. Enhancing Ru(II)Catalysis with Visible-Light-Mediated Dye-Sensitized $\mathrm{TiO}_{2}$ Photocatalysis for Oxidative $\mathrm{C}-\mathrm{H}$ Olefination of Arene Carboxylic Acids at Room Temperature. Chem. - Asian J. 2020, 15 (5), 564-567.

(170) Reischauer, S.; Strauss, V.; Pieber, B. A Modular, SelfAssembling Metallaphotocatalyst for Cross Couplings Using the Full Visible-Light Spectrum. ChemRxiv Preprints 2020, DOI: 10.26434/ chemrxiv.12444908.v1.

(171) Liu, Y.; Song, L.; Du, L.; Gao, P.; Liang, N.; Wu, S.; Minami, T.; Zang, L.; Yu, C.; Xu, X. Preparation of Polyaniline/Emulsion Microsphere Composite for Efficient Adsorption of Organic Dyes. Polymers (Basel, Switz.) 2020, 12 (1), 167.

(172) Scaiano, J. C.; Lanterna, A. E. A Green Road Map for Heterogeneous Photocatalysis. Pure Appl. Chem. 2020, 92 (1), 63-73.

(173) Thomson, C. G.; Lee, A.-L.; Vilela, F. Heterogeneous Photocatalysis in Flow Chemical Reactors. Beilstein J. Org. Chem. 2020, 16, 1495-1549.

(174) Blanchard, V.; Asbai, Z.; Cottet, K.; Boissonnat, G.; Port, M.; Amara, Z. Continuous Flow Photo-Oxidations Using Supported Photocatalysts on Silica. Org. Process Res. Dev. 2020, 24 (5), 822-826. 